University of Arkansas, Fayetteville

ScholarWorks@UARK

Graduate Theses and Dissertations

8-2012

\title{
Wheel Path Wandering Based On Field Data
}

Wenting Luo

University of Arkansas, Fayetteville

Follow this and additional works at: https://scholarworks.uark.edu/etd

Part of the Civil Engineering Commons, and the Transportation Engineering Commons

\section{Citation}

Luo, W. (2012). Wheel Path Wandering Based On Field Data. Graduate Theses and Dissertations Retrieved from https://scholarworks.uark.edu/etd/521

This Thesis is brought to you for free and open access by ScholarWorks@UARK. It has been accepted for inclusion in Graduate Theses and Dissertations by an authorized administrator of ScholarWorks@UARK. For more information, please contact scholar@uark.edu. 
WHEEL PATH WANDERING BASED ON FIELD DATA 


\title{
WHEEL PATH WANDERING BASED ON FIELD DATA
}

A thesis submitted in partial fulfillment of the requirements for the degree of

Master of Science in Civil Engineering

\section{By}

\author{
Wenting Luo \\ Beijing University of Civil Engineering and \\ Architecture \\ Bachelor of Engineering, 2006 \\ Beijing Jiaotong University \\ Master of Science in Safety Engineering, 2008
}

August 2012

University of Arkansas 


\section{ABSTRACT}

The position and width of wheel path on a pavement lane is an important consideration in conducting pavement distress survey, especially for distinguishing longitudinal cracking from fatigue cracking. Currently, the widely used wheel path definition is derived from the LTPP distress manual with fixed width and position, in which the influence of traffic wander on wheel path was overlooked. This thesis attempts to develop a new wheel path definition based on the lateral placement investigation of heavy vehicles' wandering in the field. Generally, the factors influencing vehicle lateral placement can be divided into seven categories, but only four factors are considered to be the most important in this research: weather, visibility, horizontal curve, and traffic condition. To achieve this goal, a high resolution digital camera mounted on overpass is utilized to acquire lateral placement data under low and heavy traffic condition, during daytime and nighttime, in sunny, rainy, and windy weather, and at five different locations on an interstate highway. Based on the collected data, statistical methods are utilized to investigate the influence of the four factors on the lateral displacement distribution of truck wheels. Herein, the ANalysis Of VAriance (ANOVA) test was applied to rank the effects of four factors on wheel shift, and the Phillips-Perron test (pp.test) was employed to check the stability of data. Subsequently, an approach is proposed to analyze the lateral position data with different parameters. A new analysis model called Multi-Factor Traffic Lateral Position (M-FTLP) is developed in the research to compute the frequency distribution of wheel-path wandering at different deviation levels. The M-FTLP model exploits local information (index weight) to determine lateral distribution of truck positions at a particular location. Based on the frequency distributions of the wandering deviation levels from M-FTLP model, the wheel paths at the five sample road segments are identified. 
Key words: Lateral placement/position, Wheel Path, Statistical Analysis, LTPP, Heavy Vehicle, ANOVA Test 
This thesis is approved for recommendation to the Graduate Council.

Thesis Director:

Dr. Kevin D. Hall

Thesis Committee:

Dr. Kelvin C.P. Wang

Dr. Andrew F. Braham 


\section{THESIS DUPLICATION RELESE}

I hereby authorize the University of Arkansas Libraries to duplicate this thesis when needed for research and/or scholarship.

Agreed

Wenting Luo

Refused

Wenting Luo 


\section{ACKNOWLEDGMENTS}

Special thank are due to the staff of the University of Arkansas Graduate School for all of their help with my thesis. It would be impossible to make it through the semester without their help.

Also, special thanks go out to the faculty and staff at the University of Arkansas for their commitment to the University and to the students. 


\section{TABLE OF CONTENTS}

$\begin{array}{ll}\text { Abstract } & 3\end{array}$

$\begin{array}{ll}\text { Table of Contents } & 0\end{array}$

$\begin{array}{ll}\text { List of Figures } & 0\end{array}$

$\begin{array}{ll}\text { List of Tables } & 3\end{array}$

I. INTRODUCTION 1

A. Background 1

B. Problem Statement $\quad 2$

C. Research Objectives 3

D. Definition 4

II. LITERATURE REVIEW 5

A. Factors Influencing Traffic Lateral Position 5

B. Lateral Position Measurement Methods 9

1. Manual Observer 9

2. Precision Camera 9

3. Sensor based Devices 12

C. Statistical Analysis for Lateral position Research 13

D. Overview of Wheel Path Definition 14

III. FACTORS INFLUENCING LATERAL POSITION 17

A. Analysis of Influencing Factors 17

1. Weather Condition 19

2. Vehicles Types 19

3. Drivers' Habits 21

4. Road Characteristics 23 
5. Traffic 24

6. Visibility 25

$\begin{array}{ll}\text { 7. Environment } 25 & 25\end{array}$

B. Summary of Test and Un-Test Factors 25

$\begin{array}{ll}\text { IV. LATERAL POSITION MEASUREMENT } & 27\end{array}$

A. General Approach 27

B. Test Site Selection 32

C. Summary of the Collected Data 37

V. STATISTICAL ANALYSIS OF FACTORS INFLUENCING LATERAL POSITION $\begin{array}{ll}\text { DISTRIBUTION } & 39\end{array}$

A. Descriptive Statistics of Lateral Position Data 39

1. Definition of Reference Situations 39

2. Statistics of Lateral Position Data 40

3. Plotting of Lateral Position Distribution 47

B. ANOVA Test 54

1. Traditional ANOVA Test 54

2. Equal Quantity ANOVA Test 56

3. R Project Software 58

C. Analysis of Single Factor based on One-way ANOVA Test 59

1. Test Results for Road Curve $\quad 59$

2. Test Results for Traffic Condition 60

3. Test Results for Visibility Condition 62

4. Test Results for Weather Condition 64

D. Analysis of Multi-Factors based on Four-way ANOVA Test 65

1. Data Description 65 
2. Hypotheses Statement 65

3. Four-way ANOVA Test 66

VI. Multi-Factor based Traffic Lateral Position Modeling 67

A. M-FTLP Model Introduction $\quad 67$

1. PFLP-DL Parameter 67

$\begin{array}{ll}\text { 2. Index Weight Analysis } & 70\end{array}$

3. M-FTLP Modeling 76

B. M-FTLP Model Application $\quad 81$

1. Model Selection $\quad 82$

2. Index Weight Calculation $\quad 82$

3. GLP Calculation 92

$\begin{array}{ll}\text { VII. WHELL PATH DEFINITION } & 94\end{array}$

A. Lateral Position and Dimension of Trucks 94

B. Wheel Path Description 95

$\begin{array}{lll}\text { VIII. } & \text { CONCLUSION } & 98\end{array}$

$\begin{array}{ll}\text { REFERENCE } & 101\end{array}$ 


\section{LIST OF FIGURES}

FigURE 1 FACTORS ON LATERAL PLACEMENT (BLAB AND LITZKA 1995) 8

FIGURE 2 CAMERA MOUNTED ON A VEHICLE TRAILER (LENNIE AND BUNKER 2003) 10

FiguRE 3 PAINTED REFERENCE LINES (STEMPIHAR AND WILLIAMS, 2005) 10

Figure 4 TIRE PASSING EXAMPLE (STEMPIHAR AND WILLIAMS, 2005) 11

FIGURE 5 CAMERA MOUNTED ON THE OVERPASS (BUNKER, 2005) 11

FIGURE 6 VEHICLE CROSSING THE REFERENCE LINE (BUNKER, 2006) 12

FIGURE 7 SENSING MEASUREMENTS WITH A MAT (BLAB AND LIZKA 1995) 12

FIGURE 8 SENSOR SLOTS (TIMM AND PRIEST, 2005) 13

FIGURE 9 WhEEL PATH DEFINITIONS FROM LTPP (LTPP 2003) 15

FiguRE 10 GEOMETRICAL DEFINITION OF WHEEL PATH (FU AND HARVEY, 2011) 16

FigURE 11 VEHICLES FROM FHWA ClASS 4 TO 13 (ARA INC., 2004) 19

FIGURE 12 TRUCK DiMENSION OF FHWA CLASS 9 (AASHTO, 2004) 21

FIGURE 13 TRUCK DRIVER WORKFORCES BY DEMOGRAPHIC GROUPS (GLOBAL INSIGHT, INC. 2005)

FIGURE 14 TRUCK DRIVER WORKFORCES BY AGE GROUPS (GLOBAL INSIGHT, INC. 2005) 22

Figure 15 FlOW DiAgRAM OF TEST AND UN-TEST FACTORS 26

$\begin{array}{ll}\text { FIGURE } 16 \text { INSTALLATION FOR VIDEO CAMERA } & 27\end{array}$

FIGURE 17 SCHEMATIC OF MARKING REFERENCE LINES 28

FIGURE 18 MARK OF REFERENCE LINES IN THE FIELD 29

FIGURE 19 TRUCK IN MOTION WITHOUT DEVIATION 29

FIGURE 20 TRUCK IN MOTION WITH 0.5FT DEVIATION TO THE RIGHT SIDE 30

$\begin{array}{ll}\text { FIGURE } 21 \text { FREE MOVING TRUCKS } & 31\end{array}$ 
FIGURE 22 INFLUENCED TRUCKS

FIGURE 23 SCHEMATIC REPRESENTATION OF TEST SITE SELECTION

FIGURE 24 TEST SITE 1: NEAR LEFT TURN CURVE

FIGURE 25 TEST SITE 2: NEAR RIGHT TURN CURVE

FIGURE 26 TEST SITE 3: ON RIGHT TURN CURVE

FiguRE 27 TEST SITE 4: ON LEFT TURN CURVE

FIGURE 28 TEST SITE 5: ON STRAIGHT ROAD

FIGURE 29 REFERENCE SCENARIOS AND THEIR COMPARISON SCENARIOS

FIGURE 30 PLOTTING OF LATERAL POSITION DISTRIBUTION AT FIVE TEST SITES

Figure 31 PlotTING OF LATERAL POSITION DISTRIBUTION IN TWO MODES: FREE MOVING AND INFLUENCED TRAFFIC AT (A) Site 1; (B) Site 2; (C) Site 3; (D) Site 4; (E) Site 5

Figure 32 Plotting of LATERAl POSITION Distribution IN TWO MODES: IN DAYTime AND Nighttime at (A) Site 1 (FReE MOVing); (B) Site 1 (INFluenced); (C) Site 2 (FREE MOVing); (D) Site 2 (INFluenced); (E) Site 3 (FReE MOVing); (F) Site 3 (INFluenced); (G) Site 4 (FREE MOVING); (H) SITE 4 (INFLUENCED); (I) SITE 5 (FREE MOVING); (J) Site 5 (INFLUENCED);

FIGURE 33 LATERAL POSITION DISTRIBUTION IN THREE MODES: TRAFFIC ON SUNNY, WINDY AND Rainy Weather at (a) Site 1 (Free moving); (B) Site 1 (INFluenced); (C) Site 2 (FreE MOVING); (D) Site 2 (INFLUeNCEd); (E) Site 3 (FREE MOVING); (F) Site 3 (INFLUENCED); (G) Site 4 (free moving); (h) Site 4 (Influenced); (I) Site 5 (Free moving); (J) Site 5 (INFLUENCED);

Figure 34 Absolute Values of the Differences of LATERAL Position BetweEn ReFERENCE Situation (Site 5) AND THE Other Four Test Sites 
Figure 35 Absolute Values of the Differences of the Lateral Position Data Between REFERENCE SituATION AND THE OTHER FouR TEST SiteS 61

Figure 36 The Mean of Absolute Values of the Differences of Lateral Position BETWEEN DAYTIME AND NightTIME FOR FREE Moving TRUCKS 62

Figure 37 the Mean of Absolute Values of the Differences of Lateral Position BETWEEN DAYTIME AND NightTIME FOR INFLUENCED TRUCKS 63

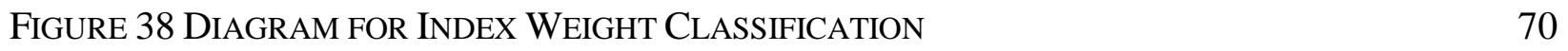

FiguRE 39 SCHEMATIC FOR LEVEL ClassiFiCATION OF INDEX WEIGHTS 71

Figure 40 Traffic Volume Rank and its Corresponding Percentage Frequency for Free $\begin{array}{ll}\text { MOVING AND INFLUENCED TRUCKS } & 74\end{array}$

$\begin{array}{ll}\text { FIGURE } 41 \text { COMPONENTS FOR M-FTLP MODEL } & 77\end{array}$

$\begin{array}{ll}\text { FigURE 42 FrAMEWORK OF M-FTLP MOdEL } & 78\end{array}$

Figure 43 Schematic of ImPlementation Procedures of M-FTLP Model 81

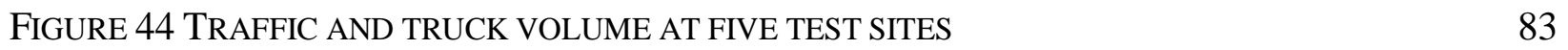

Figure 45 Weather Statistics From 2005 THROUGH 2011 IN FAyetTeVILle AR 88

FIGURE 46 SCATTER PLOT OF WINDY HOURS IN EVERY MONTH FROM 2005 TO 2011 (FAYETTEVILLE

$\begin{array}{lr}\text { AR) } & 90\end{array}$

FIGURE 47 GEOMETRICAL DEFINITION OF WHEEL PATH BASED ON TRAFFIC WANDERING 94

Figure 48 Wheel Path Geometric Definition at Test Site\#1 95

Figure 49 Wheel Path Geometric Definition at Test Sites \#2, \#3, And \#5 96

Figure 50 Wheel Path GeOMetric Definition For \#4 TESt Sites 97 


\section{LIST OF TABLES}

TABle 1 ListS ALl THE FACTORS INFLUENCING TRAFFIC TRANSVERSE DiSTRIBUTION: 18

TABle 2 Vehicle TyPeS AND THEIR DESIGN Dimension (AASHTO, 2004) 20

TABLE 3 ROAD CHARACTERISTICS AT TEST SECTIONS 24

TABLE 4 SUMMARY OF VIDEO DATA

TAble 5 Frequency of Lateral Position Data At Five Test Sites 43

TABLE 6 FREQUENCY OF LATERAL POSITION DATA UNDER TRAFFIC CONDITION AT 5 SiteS 43

Table 7 Frequency of Lateral Position Data under Visibility Condition for Free MOVING TRUCKS AT 5 SITES 44

TABle 8 Frequency OF LATERAL POSITION DATA UNDER VisibiLity Condition FOR INFLUENCED TRUCKS AT 5 SITES 44

TABle 9 Frequency of Lateral Position Data AT Five Sites Under Weather Condition FOR FREE MOVING TRUCKS 45

TABLE 10 FREQUENCY OF LATERAL POSITION DATA AT FIVE SITES UNDER WEATHER CONDITION FOR $\begin{array}{ll}\text { INFLUENCED TRUCKS } & 46\end{array}$

TABle 11 ANOVA Test Results At Five TeSt Sites $\quad 60$

TABLE 12 ANOVA Test RESUlts FOR INFLUENCED TRUCKS AT FIVE TeSt Sites 62

TAble 13 ANOVA Test Results for Lateral Position Between Daytime And NightTime FOR FREE MOVING TRUCKS AND INFLUENCED TRUCKS 63

TABle 14 ANOVA Test Results under DifFERENT WeAther CONDITION FOR FreE Moving $\begin{array}{ll}\text { TRUCKS AND INFLUENCED TRUCKS } & 64\end{array}$

TABLE 15 ANOVA TEST RESUlTS FOR FOUR TEST-FACTORS 66

TABLE 16 PFLP-DL PARAMETERS FOR NEAR LEFT TURN CURVE ROAD SECTION 68 
TABLE 17 PFLP-DL PARAMETERS FOR NEAR RIGHT TURN CURVE ROAD SECTION

TABLE 18 PFLP-DL PARAMETERS FOR IN RIGHT TURN CURVE ROAD SECTION

TABLE 19 PFLP-DL PARAMETERS FOR IN LEFT TURN CURVE ROAD SECTION

TABLE 20 PFLP-DL PARAMETERS FOR IN STRAIGHT ROAD SECTION

TABLE 21 INFLUENCED TRUCK FREQUENCIES IN DIFFERENT TRAFFIC VOLUME LEVELS

TABle 22 Influenced TRUCK Frequencies AND Truck Volume FRom 7:00 TO 24:00

(WORKDAYS)

TABle 23 Influenced Truck Frequencies AND Truck Volume From 7:00 TO 19:00 (WEEKENDS)

TABLE 24 STATISTIC OF WINDY HOURS IN EVERY MONTH FROM 2005 TO 2011(FAYETTEVILLE AR)

TABLE 25 THE PP.TEST RESULT FOR WINDY, RAINY AND SUNNY WEATHER CONDITION

TABLE 26 POSSIBILITY OF WINDY/RAINY/SUNNY WEATHER

TABLE 27 DAYTIME AND NightTIME DistribUtion IN FAYETTEVILLE AR

TABLE 28 DiSTRIBUTIONS OF WORKDAYS AND WEEKENDS IN A CALENDAR YEAR

TABLE 29 RESULTS OF LATERAL POSITION IN FIVE TEST SITES BY M-FTLP MODEL 


\section{INTRODUCTION}

\section{A. Background}

Traffic wander, or the lateral distribution of wheel loads, is a natural phenomenon observed on roadways. From a pavement design and performance evaluation perspective, traffic lateral placement is critical since it indicates how the traffic loads are distributed on the pavement lane. Typically, the more traffic loading occurs at one position, the more pavement damage it can cause at that position.

The lateral position of vehicles on the road has been of interest to investigators over a long period of time. The traffic lateral position investigation conducted by Pauls (1925) represents the early study of this type. More recently, lateral position of vehicles has been shown to provide a sensitive indication of the effect of different road geometrical schemes, such as lane width, shoulder width, and number of lanes (Smith 1976, Triggs 1983, Miller 1982). Another topic of lateral position study is about the normality of the position distribution. In Soliday's 1975 study, it has been reported that drivers tend to control their vehicles so that the lateral position of their vehicles as they travel along the highway is normally distributed with small dispersion. However, this study by Soliday used briefed subjects in an experimental vehicle. A similar low dispersion might not necessarily be found in everyday traffic when drivers are unaware that they were being observed (Triggs and Wisdom, 1978).

Various methods can be used to measure traffic lateral placement, ranging from manual observation to sensor based device. Early studies chose manual observation to collect lateral placement data (Puals, 1925, and Taragin, 1945 to 1958). However, the collected data has low accuracy with this method because of human errors. With the development of automatic 
technology, there are two methods developed to conduct lateral placement measurement: video camera based method and sensor based method.

Video camera is the commonly used device in past research in that it is easy to operate. Based on the locations of video camera in the lateral position test (mounted on the overpass, shoulder, and experimental vehicle), different lateral position data was obtained (Shankar and Lee 1985, Stempihar and Williams 2005, etc.). For instance, the video data from the camera mounted on the experimental vehicle recorded the track of vehicle wandering (longitudinal track of vehicles), and the video data from the camera mounted on the overpass or shoulder recorded the vehicle lateral placement. The lateral position data can also be obtained by using sensor based device, which is more accurate than using other methods (Buiter 1989, Timm and Priest's 2005). However, due to the high cost of this measuring system, this method was not as common as video camera.

Pavement engineers and researchers always use wheel path geometrical definition to describe the traffic lateral position. In recent years, the wheel path definition from Long-Term Pavement Performance Program (LTPP) is the only standard applied in both practice and research. In the LTPP definition, wheel path width and the distance between inner and outer wheel paths are $2.5 \mathrm{ft}$ and $4.5 \mathrm{feet}$ respectively, and the two wheel paths are parallel and have the equal distance from the lane centerline (LTPP, 2003).

\section{B. Problem Statement}

In the past, the lateral position research mainly focused on its influence on pavement design and structural damage. Moreover, the lateral position research is very helpful for identifying fatigue cracks from longitudinal cracks by defining wheel path (Nishizawat, Kajikawa, and Fukuda, 1993). In reality, it is difficult to identify certain fatigue cracking with low severity from 
longitudinal cracking based on the appearance of cracks since they have very similar shape. For example, cracks in the longitudinal direction within wheel path were defined as fatigue cracking, and cracks in the longitudinal direction outside the wheel path were defined as longitudinal cracking (ARA Inc., ERES Division, 2004), since the fatigue cracks are caused by accumulative loading of heavy vehicles.

The wheel path definition from LTPP is widely used in pavement design and pavement distress survey in many states. However, there is not much research literature to support that the wheel path definition from LTPP is based on the actual lateral position of vehicles under various situations. In reality, vehicle wandering is influenced by various factors such as vehicle types, driving habits, wind speed, mechanical alignment of trailers, pavement condition itself, and other factors associated with the randomness of wheel tracking (Buiter, 1989). In this research, four factors including road geometric, weather, visibility, and traffic condition are considered as testfactors to measure traffic lateral position. Of these, road geometric characteristic is an important factor on vehicle lateral position, thus this study provides five wheel path models at five pavement locations with different roadway geometry in that it is impossible to directly use different road geometric factors to analyze wheel path wandering. Furthermore, the study on the weight of the influencing factors was overlooked in past research, but these weights not only affect the distribution of the frequency of traffic lateral position, but also influence the lateral distribution of wheel load.

\section{Research Objectives}

Based on the literature review, there was limited research linking lateral position with wheel path definition. In real world, the wheel path should be defined based on the survey of trucks' lateral position in the field. The lateral position data from the author's and past studies shows that the 
majority of the heavy vehicles' lateral position was not located on the center of the lane, but somewhat deviated to the pavement edge. However, according to the wheel path definition from LTPP, the two wheel paths are located on the center of the lane.

If the wheel path used for data analysis does not represent the heavy vehicles' track on pavement, the collected cracking data may cause inaccuracies in pavement design and management tasks. Therefore, in order to improve the accuracy of the pavement cracking survey and other data analysis on pavement, this thesis attempts to propose a new wheel path definition based on the study on trucks' lateral positions in the field. The primary research objectives of the thesis are as follows:

- Acquiring video data of trucks showing their lateral position on pavement lane

- Plotting the distribution of lateral placement under different test factors at each test site

- Statistically analyzing the effects of test factors on lateral position of heavy vehicles

- $\quad$ Establishing an analysis model: Multi-Factor Traffic Lateral Position Model

- Describing the pavement lateral position of heavy vehicles with the model

- Defining geometrical wheel path

\section{Definition}

Lateral placement/position: In this research, the lateral placement/position of a vehicle is defined as the distance between the carriageway centerline and the centerline of the vehicle.

Wheel path: The portion of the pavement surface where the majority of vehicle wheel passages are concentrated. (FHS, 2008) 


\section{LITERATURE REVIEW}

\section{A. Factors Influencing Traffic Lateral Position}

Past research indicated that several factors influence the randomness of wheel tracking. The early study on establishing the transverse distribution of traffic on pavement was done by Pauls in 1925. Although most roads in the United States had traffic lanes less than $12 \mathrm{ft}$ wide and the vehicle size before World War II is very different from that of current vehicles, the findings with respect to the effect of road width, curves, grades, crown of surface and other physical factors on the distribution of traffic laterally are still significant to the current research. Based on Pauls' study, the factors influencing on lateral position can be divided into six categories:

- Curve - The traffic shifts toward the inside edge of the pavement in rounding horizontal curve.

- Vehicle types - The trucks are found to shift their course toward the inside of the curve less than the passenger vehicles; and truck drivers are found to adhere more closely to the edges of pavement than the operators of passenger vehicles.

- Grade - Traffic moves toward center on light down grades. Herein, the light downgrades do not suggest reduction of speed, but make the traffic away from the edge of the pavement.

- Crown - The greater crown of the wider road has so concentrated the traffic at the center as to reduce the clearance to a negative distance of 1.2 feet as compared to a negative 0.2 foot on the narrower road.

- Traffic condition - The vehicle, passed of a more mobile vehicle, apparently shuttle back and forth from the center to the side of the road. 
- Darkness - The white concrete shoulders, being more visible at night than the black center section would have the effect of holding the traffic to the edges of the pavement.

One study conducted by Taragin in 1945 is to investigate the influence of vehicle operation on vehicles' lateral positions based on 95,589 vehicles recorded at 47 test sites from 27 States. In order to truly evaluate the effect of various surface widths and shoulder types on vehicle lateral placement under different densities and compositions of traffic, the collected data were segregated into four groups, free moving vehicles, meeting vehicles, passing vehicles, and all other vehicles. In this study, road width, shoulder width, traffic volume, and darkness are considered as the significant factors to influence traffic transverse position.

- Traffic volume - With an increase in volume from 200 to 1,200 vehicles per hour, free moving vehicles moved to the right four-tenths foot, while meeting vehicles changed their transverse position only slightly as the volume increased.

- Shoulder width - The shoulder width in excess of $4 \mathrm{ft}$ does not affect transverse position of vehicle.

- Pavement width - The pavements with three different widths were tested, which are $18 \mathrm{ft}$, $20 \mathrm{ft}$, and $24 \mathrm{ft}$. The free moving vehicles, regardless of the width of the pavement, travel closer to the center line than to the edge. The commercial vehicles meeting other commercial vehicles travel closer to the center of the lane on 18 -foot than on 20 -foot pavements, but on 24-foot pavements they travel in the center of the lane.

- Darkness - The passenger cars and commercial vehicles have different response for the driving in darkness. When passenger cars meet other passenger cars at night, their transverse position are practically the same as during the day. However, drivers of 
commercial vehicles apparently prefer greater edge clearance at night than during the day for most of the several traffic conditions.

After World War II, the 12-ft wide traffic lane was universally accepted in United States as standard pavement width, which is therefore not considered as an influencing factor. In addition, another study conducted by Taragin in 1957 indicated that speed and vehicle type should be added as new factors contributing to vehicle shift. One year later, the effect of the number of traffic lanes on traffic transverse placement was also considered in Taragin's study.

- Speed - the average position of the slower moving vehicles, whether passenger cars or trucks, was close to the shoulder of the highway than that of the faster moving vehicle;

- Vehicle type - Commercial vehicles encroached on shoulders to a greater extent than passenger cars.

The study on lateral position before 1960 was focus on analyzing the effects of the road geometrical characteristics and traffic volume on lateral distribution due to the purpose of geometric design. Gradually, the relation between the lateral placement and pavement damage became a new objective for transverse position research. Buiter et al (1989) used the lateral position data for pavement layer design. He proposed some new factors influencing lateral placement and listed a systematic classification to the influencing factors. In his research, the influencing factors can be divided into six categories: 1) weather condition (e.g. wind and precipitation); 2) time (e.g. hour, day, month); 3) Heavy-goods vehicle used (e.g. type, load, and width); 4) traffic conditions (e.g. speed, intensity, proportion of heavy goods vehicles, oncoming traffic, traffic restrictions, and visibility); 5) Road characteristics (e.g. type of road surface, number of lanes, road roughness, traffic-lane width, width of the hard shoulder, superelevation, 
alignment, and road markings); 6) Environment (e.g. open, area, woodlands, built-up area, flyovers, tunnels, traffic barriers, and obstacles).

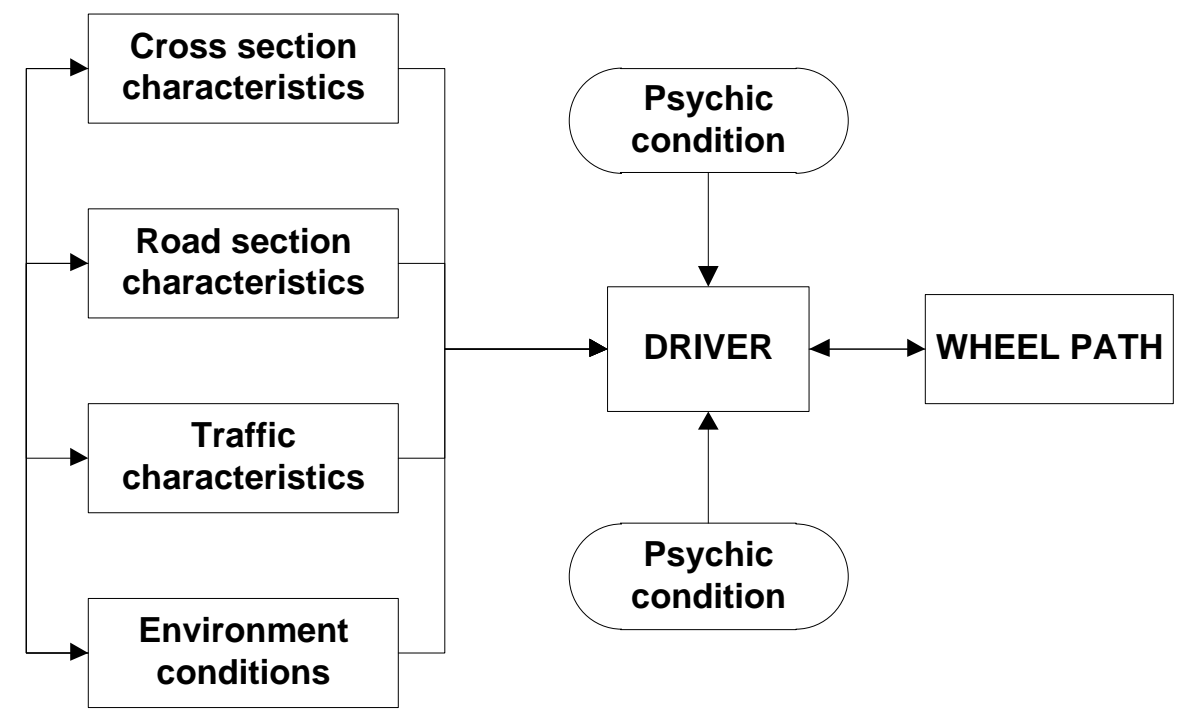

Figure 1 Factors on lateral placement (Blab and Litzka 1995)

Followed by Buiter's study, a bunch of factor classification influencing lateral position was proposed. Figure 1 shows the classification and relations of influencing factors in Blab and Litzka's 1995 study, and the influencing factors can be grouped into four categories: 1) cross section characteristics; 2) road section characteristics; 3) traffic characteristics; and 4) environmental characteristics. Among the four categories, four factors are considered to be most significant, namely lane width, vehicle width, vehicle velocity, and rutting depth in the cross section.

Research also indicated that overtaking vehicles, lane widths, shoulder widths, shoulder types, effect of line markings, and class of vehicle can be regarded as the most critical factors on lateral placement of traffic (Lennie and Bunker, 2003). 


\section{B. Lateral Position Measurement Methods}

In the past decades, several techniques were employed to measure lateral position of traffic loading on pavement lane. Most of these measurements can be categorized into three components: manual observation, precision camera, and sensor based device.

\section{Manual Observer}

Manual observation is the oldest method for lateral position measurement. In early studies, Pauls and Taragin used this method to collect transverse placement data, in which a reference line was used to help record lateral position: the paved width was marked with paint into 1 -foot sections, afterwards the right rear wheel passages in each direction were noted by different observers with tally registers (Pauls 1925, Taragin, 1945). However, this method is not accurate enough, since sometimes the observers could not record the exact position of vehicles at good speed.

\section{Precision Camera}

Precision camera is the most commonly used equipment for lateral position measurement. In terms of the locations of measuring equipment, the camera can be mounted on vehicles, shoulder, or overpass to acquire the video lateral position data.

The camera mounted unobtrusively on an experimental vehicle can record a continuous video of wheel placement for individual trucks as they traveled along the roadway, and the realview image of trucks on two selected multilane highways was obtained (Shankar and Lee 1985, Triggs 1997, Lennie and Bunker 2003). In Lennie and Bunker's 2003 study, tracking boards in Figure 2 were mounted on the rear of each trailer to measure lateral displacement during travel. However, only a few vehicles' tracks could be recorded by the camera mounted on an experimental vehicle. 


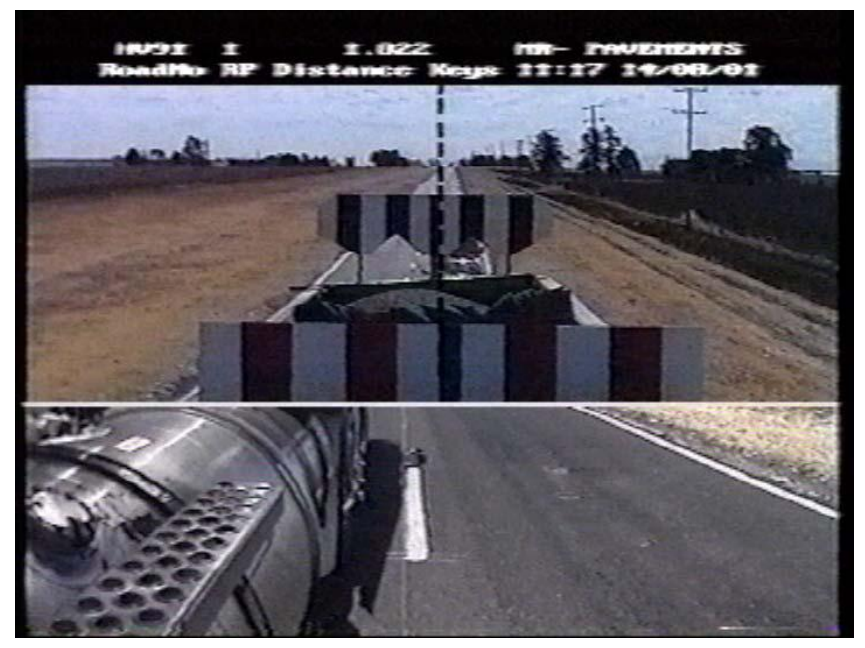

Figure 2 Camera mounted on a vehicle trailer (Lennie and Bunker 2003)

One study conducted by Stempihar and William in 2005 utilized the camera mounted on the shoulder to measure the lateral placement. In this study, reference lines were painted on the pavement before the test as shown in Figure 3. When the vehicles travel on this painted area, the lateral placement of vehicles can be identified by referring to the marking lines, as the Figure 4 shows. However, the camera mounted on the shoulder is prone to be perceived by truck drivers due to the short distance between the camera and vehicles.

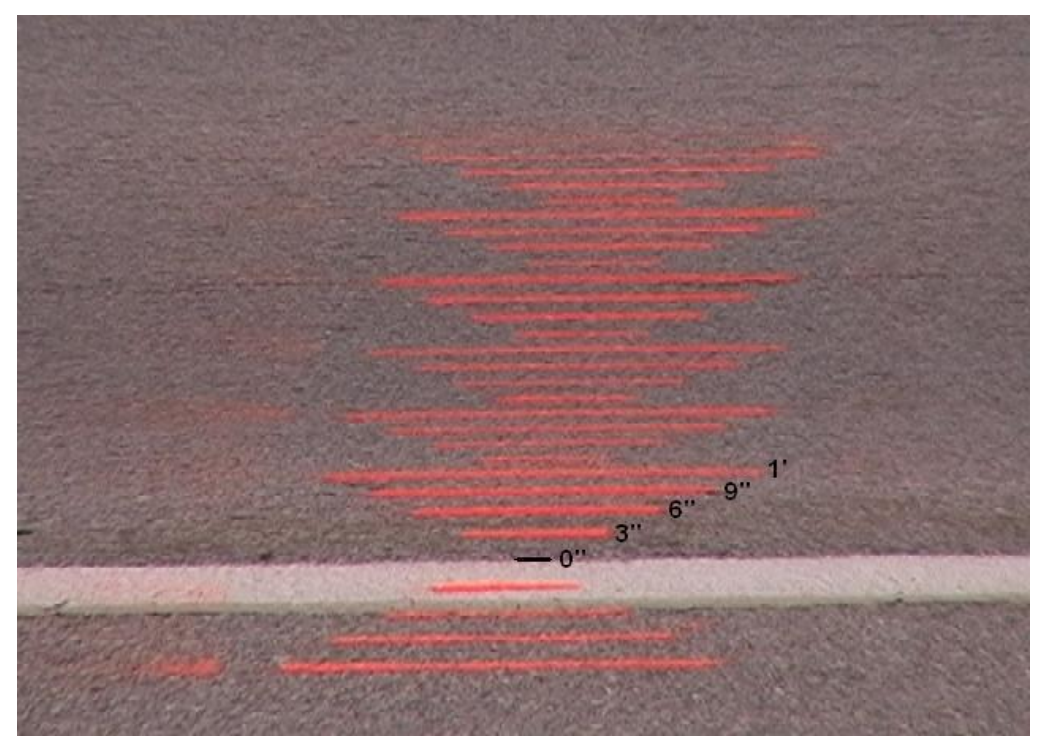

Figure 3 Painted reference lines (Stempihar and Williams, 2005) 


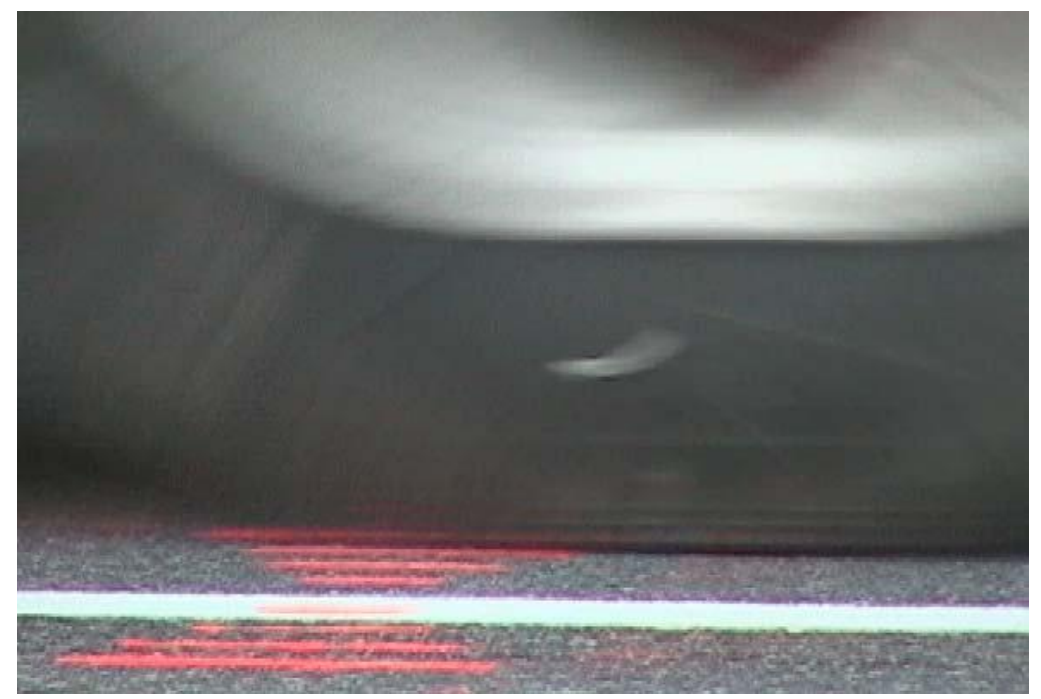

Figure 4 Tire passing example (Stempihar and Williams, 2005)

Benekohal and Bunker placed their video camera on the pedestrian walkway of an overpass over the subject motorway segment as illustrated in Figure 5 (Benekohal 1990, Bunker 2005 and 2006). Video footage was recorded and analyzed digitally with the application of a program that allows frame-by-frame analysis. Traffic data was measured by drawing a horizontal scale on an overhead transparency sheet and overlaying it on the computer screen while the video was playing (Figure 6).

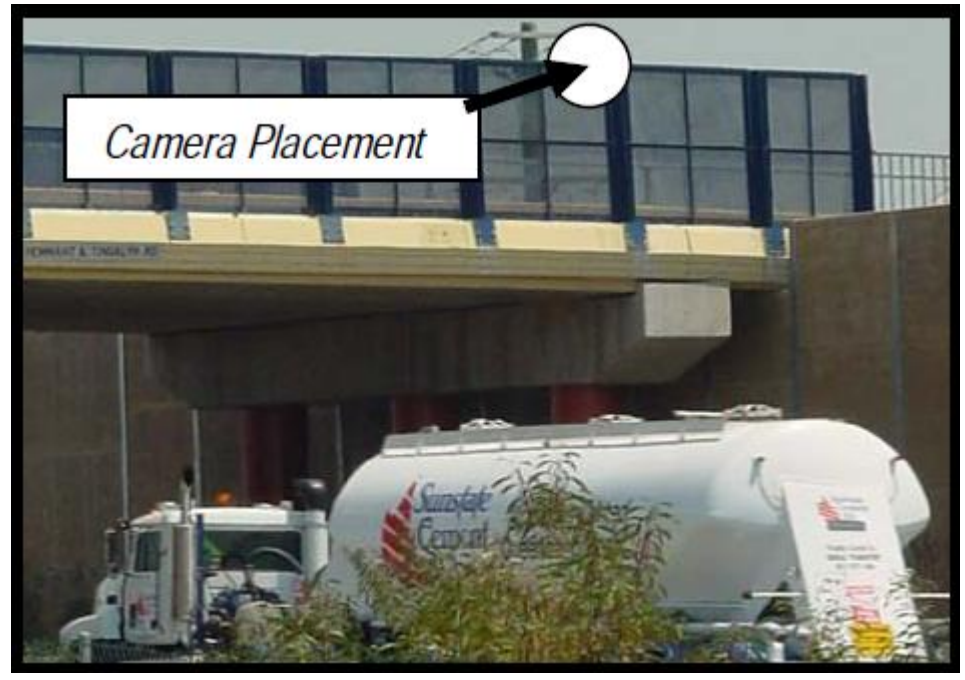

Figure 5 Camera mounted on the overpass (Bunker, 2005) 

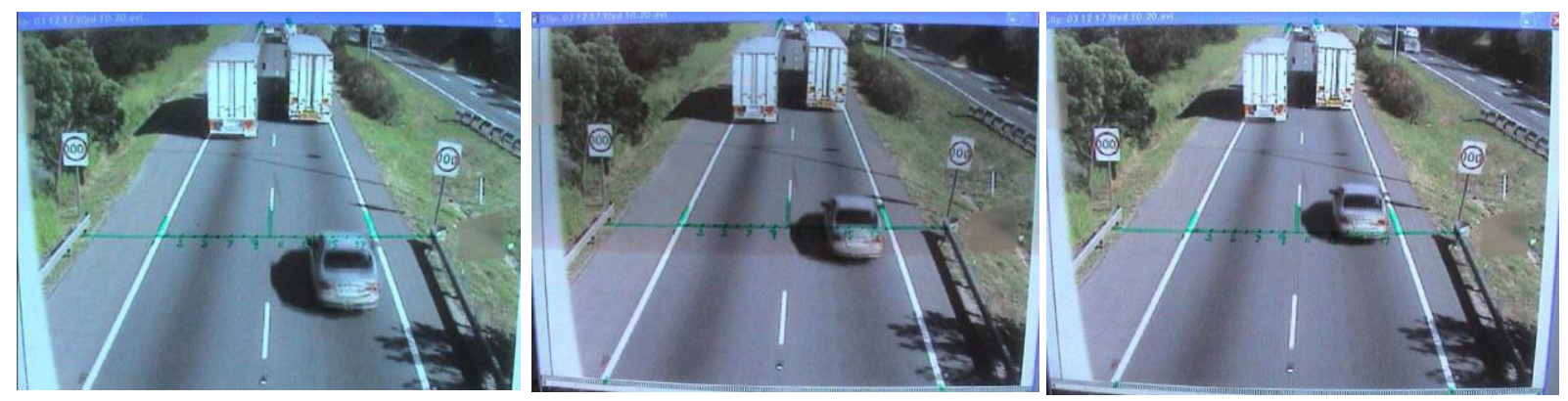

Figure 6 Vehicle crossing the reference line (Bunker, 2006)

\section{Sensor based Devices}

Around 1990, a measurement device, switch sensor, was developed to register the position speed as well. There are two ways to install the sensors: one is to place them in a mat; the other is to insert them into the pavement cut slots.

The measurement system with a mat consists of a very thin and flexible rubber mat, which can be readily attached to the road surface using double-sided adhesive tape, a registration unit and a control unit (data processing PC). In Figure 7 as a vehicle travels on the mat, some switch sensors are pressed by the tires, so the footprints of the tires separately for each axle and the speed as well are recorded. (Buiter 1989, Nishizawa 1993, Blab and Lizka 1995)

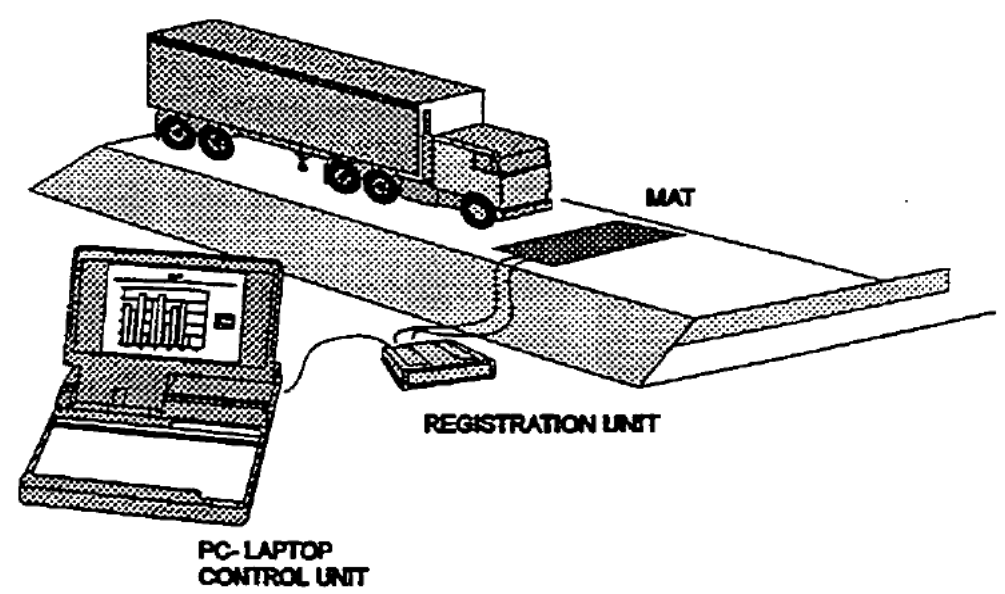

Figure 7 Sensing measurements with a mat (Blab and Lizka 1995) 
Different from using mat to measure the position and speed, the other sensor based method is to insert the sensor into the cut slots in pavement to measure transverse placement, as Figure 8 shows. (Timm and Priest's in 2005).
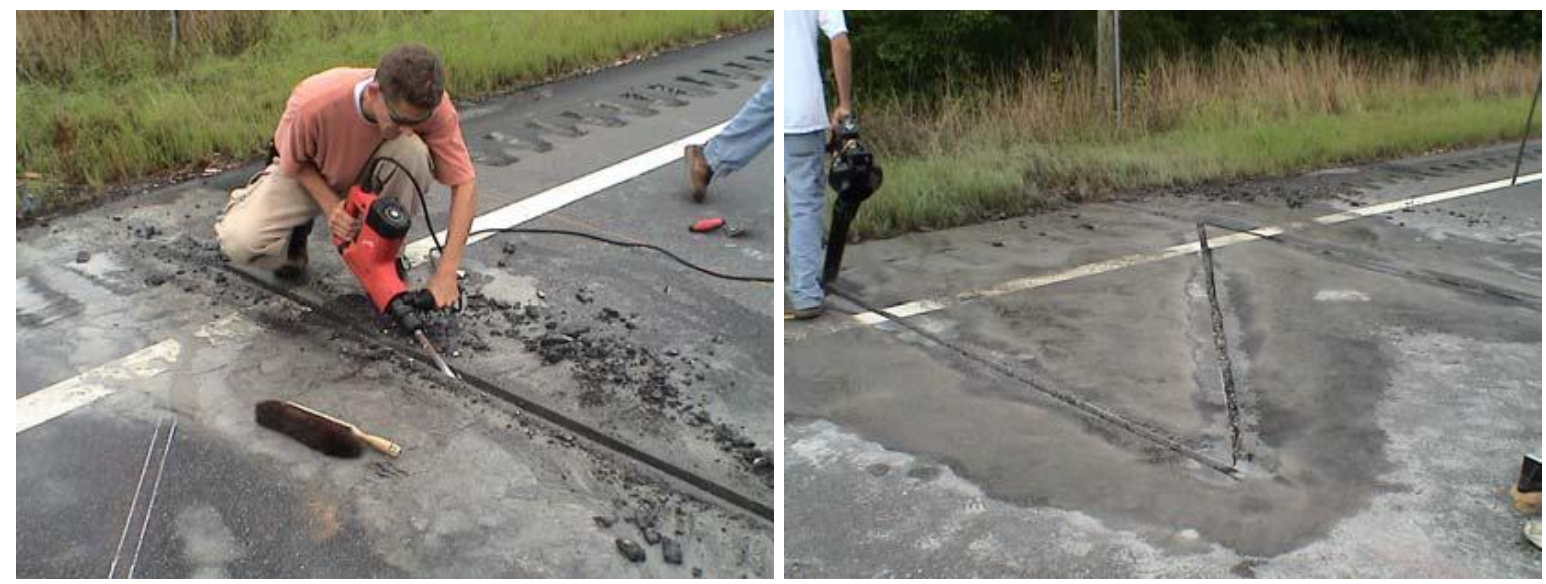

Figure 8 Sensor slots (Timm and Priest, 2005)

After the sensing measurement system was installed, it is straightforward to obtain the lateral placement data without being subjected to the effect of darkness or bad weather. In addition, automated data processing in the measuring system is more efficient than manual data processing. However, the sensor measuring system is more expensive, and especially, inserting the sensor into slots needs traffic control and damages the pavement surface.

\section{Statistical Analysis for Lateral position Research}

In order to know the distribution of the lateral placement data and identify the effect of factors on transverse position of heavy vehicles, statistical analysis on field data needs to be performed. ANalysis Of VAriance (ANOVA), a t-test or a non-parametric method are the common methods to compare means. Scores and proportions often use a chi-squared test, while dose-response relationships use regression analysis. 
In Benekohal's 1990 study, chi-square $\left(\mathrm{x}^{2}\right)$ test, F-statistic test, and Layard's test were used for lateral distribution data analysis. First of all, chi-square $\left(\mathrm{x}^{2}\right)$ tests were performed on the data sets to examine the normality of the test section distribution. Although the test section distributions already have been shown to be non-normal, an analysis of variance was still used to compare their means since their variances are homogeneous. Secondly, F-statistic test was utilized to identify the significant differences among the means of the test sections, and Layard's test was employed to validate whether the variances of two directional lateral distributions were homogeneous or not.

Different from the Benekohal's study, the lateral distribution has been shown to be normal from the lateral position test conducted by Gunay (1999). This statistical result was accepted by many researchers, such as Lennie and Bunker's 2005 study. Based on the normality of lateral distribution, the assumption that the lateral position adopted by vehicles in the left and right lane is different can be confirmed by using analysis of variance (ANOVA) statistical test (Lennie and Bunker's 2005 study).

Statistic analysis was also used in Stempihar and Williams' 2005 study to compare the position distribution for different truck classes and rutting severity. Kruskal-Wallis H-Test, one type of non-parametric statistical analysis, was chosen for comparing position distribution for different truck classes, and the test result indicated that wheel position probability distributions are independent of the truck types. Mean comparisons and $\log$ (standard deviation) analysis are used for identifying the difference of lateral position with different rut levels.

\section{Overview of Wheel Path Definition}

Pavement engineers and researchers always use geometrical wheel path definition to describe the truck track on pavement. For the pavement management, the location of the wheel path is critical 
to distinguish fatigue cracking from longitudinal cracking in flexible pavement. In recent years, the geometrical wheel path definition from LTPP is the only standard used in various types of research. Based on the wheel path definition from LTPP in Figure 9, the width of lane is assumed as $3.66 \mathrm{~m}(12 \mathrm{ft})$, and the width of inner and outer wheel path are defined as $0.76 \mathrm{~m}(2.5 \mathrm{ft})$ with their center lines $0.76 \mathrm{~m}(2.5 \mathrm{ft})$ away from the lane edge.

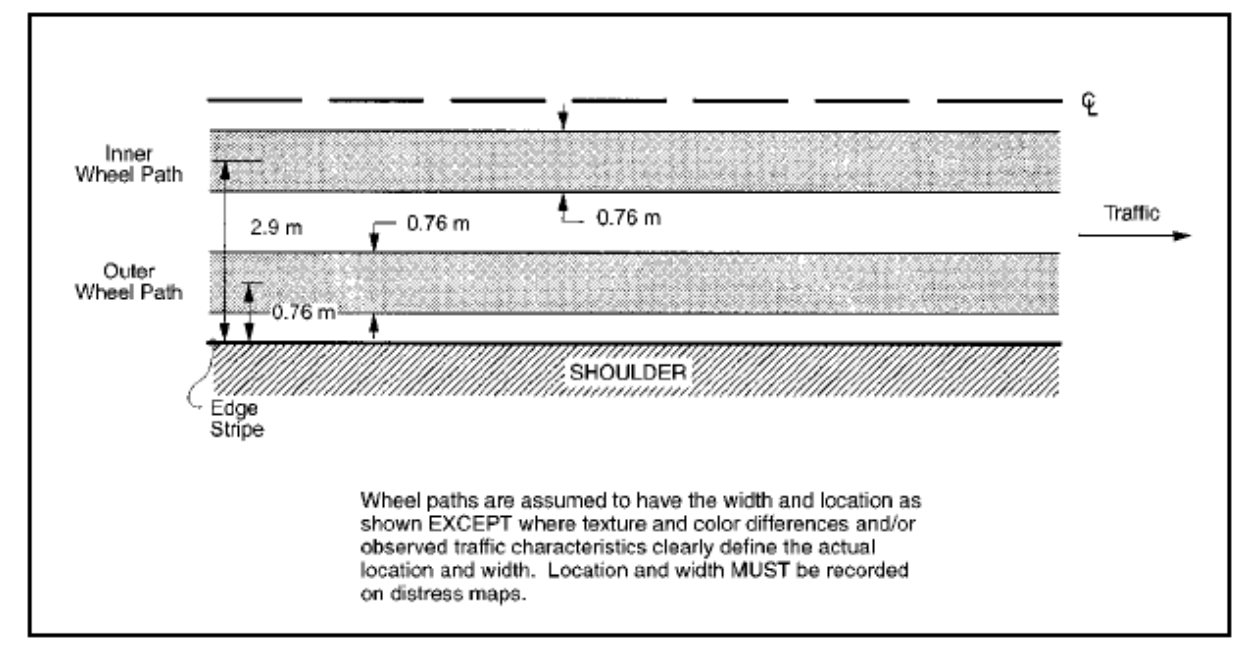

Figure 9 Wheel Path Definitions from LTPP (LTPP 2003)

Other researches also proposed their own geometrical definition of wheel path as shown in

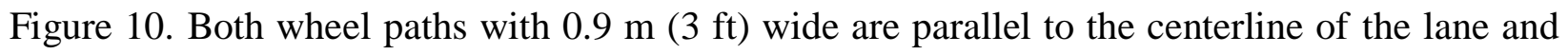
their inner edges are $0.45 \mathrm{~m}(1.5 \mathrm{ft})$ from the lane centerline. For a typical $3.6 \mathrm{~m}(12 \mathrm{ft})$ wide lane, the distances between the outer edges of the wheel paths and the lane limit lines are more than

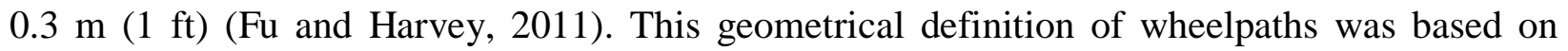
experience and consensus review by the Caltrans expert task group without field data. 


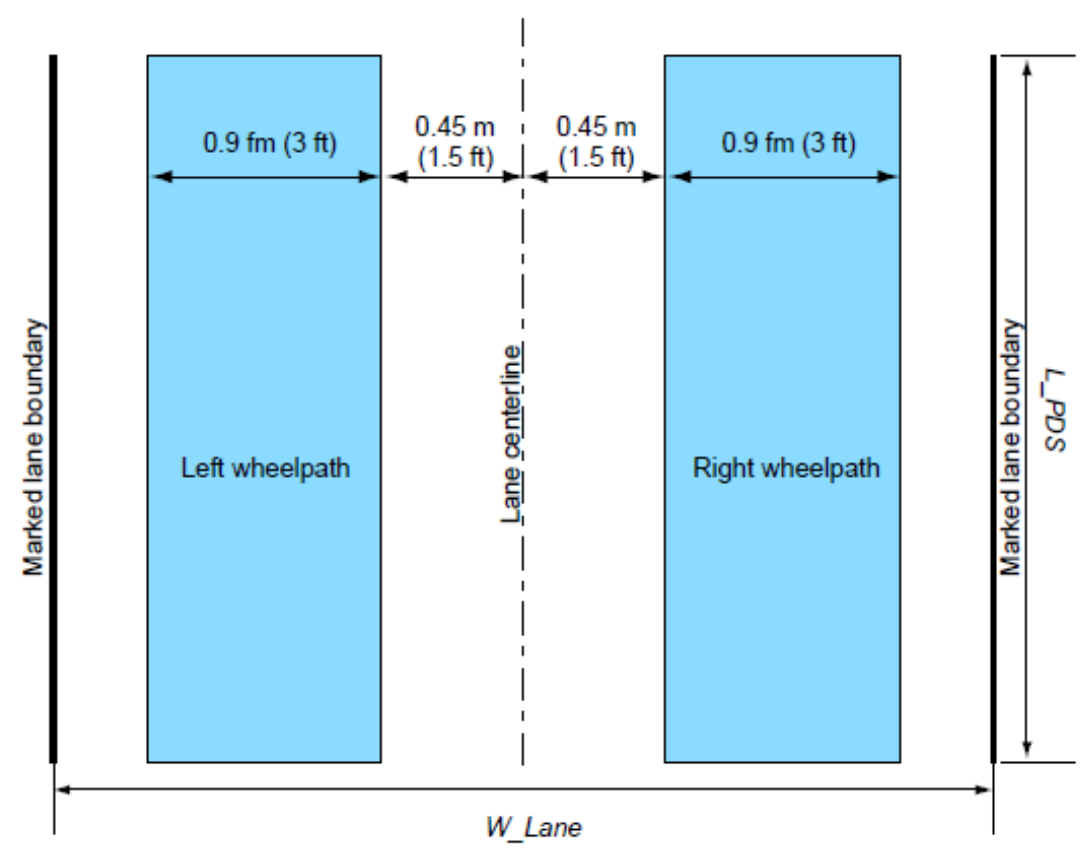

Figure 10 Geometrical definition of wheel path (Fu and Harvey, 2011) 


\section{FACTORS INFLUENCING LATERAL POSITION}

Based on the literature review regarding the influence of factors on lateral position, this thesis attempts to establish a set of factors influencing transverse distribution of truck traffic in Table 1 into seven categories: weather, divers' habit, traffic condition, visibility, road characteristics, environment, and vehicle characteristics.

\section{A. Analysis of Influencing Factors}

It is burdensome to quantify the influence of all the factors on the wheel path definition. Therefore, some factors which do not carry significant effect on lateral position, or are not common in the field are not applied in this research. 
Table 1 Lists all the Factors Influencing Traffic Transverse Distribution:

\begin{tabular}{|c|c|c|c|c|}
\hline Category & Factors & Comments & Test & Explanation \\
\hline \multirow{3}{*}{ Weather } & Wind & & \multirow{3}{*}{$\mathbf{x}$} & \multirow{3}{*}{$\begin{array}{c}\text { There was rare research on effect of weather on } \\
\text { lateral position, but it has a great impact on } \\
\text { lateral position; three kinds weather are very } \\
\text { normal phenomenon. }\end{array}$} \\
\hline & precipitation & & & \\
\hline & Sun & & & \\
\hline \multirow{7}{*}{$\begin{array}{c}\text { Drivers' } \\
\text { Habits }\end{array}$} & \multirow{3}{*}{ Age } & $20-35$ & & \multirow{7}{*}{$\begin{array}{l}\text { The gender, age, and professional level are the } \\
\text { causes of different driver habits. However, the } \\
\text { truck drivers are focus on the special area:"male, } \\
\text { age from } 35 \text { to } 65 \text {, professional". }\end{array}$} \\
\hline & & $35-65$ & & \\
\hline & & $>65$ & & \\
\hline & \multirow{2}{*}{ Gender } & Male & & \\
\hline & & Female & & \\
\hline & \multirow{2}{*}{ Professional } & Yes & & \\
\hline & & No & & \\
\hline \multirow{4}{*}{ Traffic } & $\begin{array}{l}\text { Traffic } \\
\text { volume }\end{array}$ & & $x$ & $\begin{array}{l}\text { Traffic volume influences the traffic condition, so } \\
\text { it indirectly affects lateral position. This factor } \\
\text { was tested as index weight in M-FTLP model. }\end{array}$ \\
\hline & $\begin{array}{l}\text { Traffic } \\
\text { condition }\end{array}$ & $\begin{array}{c}\text { Free moving } \\
\text { Influenced }\end{array}$ & $x$ & $\begin{array}{l}\text { Traffic condition is significant to truck lateral } \\
\text { position. }\end{array}$ \\
\hline & \multirow{2}{*}{ Speed } & $<50 \mathrm{mph}$ & & \multirow{2}{*}{$\begin{array}{l}\text { Highway speed limit is from } 55 \mathrm{mph} \text { to } 70 \mathrm{mph} \text {. } \\
\text { The test sites were located on highway. }\end{array}$} \\
\hline & & $>50 \mathrm{mph}$ & & \\
\hline \multirow{2}{*}{ Visibility } & Brightness & & \multirow{2}{*}{$x$} & \multirow{2}{*}{$\begin{array}{l}\text { Visibility is significant to lateral position; day } \\
\text { and night are very normal phenomenon. }\end{array}$} \\
\hline & Darkness & & & \\
\hline \multirow{4}{*}{ Environment } & Open & & & \multirow{4}{*}{$\begin{array}{c}\text { Over } 90 \text { percent of the existing mileages of } \\
\text { primary highways in United States were in open } \\
\text { area. }\end{array}$} \\
\hline & Tunnels & & & \\
\hline & Flyovers & & & \\
\hline & Barriers & & & \\
\hline \multirow{3}{*}{ Test Vehicle } & Vehicle & Passenger cars & & \multirow{2}{*}{$\begin{array}{l}\text { The effect of the load from passenger cars can be } \\
\text { ignored. }\end{array}$} \\
\hline & types & Heavy vehicles & & \\
\hline & $\begin{array}{c}\text { Vehicle } \\
\text { dimensions }\end{array}$ & $\begin{array}{c}\text { FHWA class } 9 \\
\text { truck }\end{array}$ & & $\begin{array}{c}\text { The greatest percentage of trucks was FHWA } \\
\text { Class } 9 \text { truck. }\end{array}$ \\
\hline \multirow{18}{*}{$\begin{array}{l}\text { Road } \\
\text { characteristics }\end{array}$} & \multirow{4}{*}{ Road types } & Rural Highway & & \multirow{4}{*}{$\begin{array}{l}\text { Over 60\% mileages of highways are rural } \\
\text { highways. }\end{array}$} \\
\hline & & Urban Highway & & \\
\hline & & Rural Road & & \\
\hline & & Urban street & & \\
\hline & \multirow{2}{*}{$\begin{array}{c}\text { Type of } \\
\text { pavement }\end{array}$} & Flexible & & \multirow{2}{*}{$\begin{array}{l}\text { 95\% existing pavements of highways in United } \\
\text { States are flexible pavement. }\end{array}$} \\
\hline & & Rigid & & \\
\hline & \multirow{2}{*}{$\begin{array}{l}\text { Road } \\
\text { roughness }\end{array}$} & Good & & Rutting has slight effect on traffic wander. \\
\hline & & fire & & (Based on the past researches) \\
\hline & & worse & & Road marking has slight effect on traffic wander. \\
\hline & marking & & & (Based on the past researches) \\
\hline & Grade & Light grade & & Grade has slight effect on traffic wander. \\
\hline & Giadic & Heavy grade & & (Based on the past researches) \\
\hline & & In curve & & There was rare research on effect of road curve \\
\hline & Curve & Near curve & $x$ & on lateral position, but it significant, and curve is \\
\hline & & Straight & & very normal on roads geometric design. \\
\hline & $\begin{array}{l}\text { Number of } \\
\text { lane }\end{array}$ & $\begin{array}{l}\text { 1-6 lane per } \\
\text { direction }\end{array}$ & & $\begin{array}{l}94 \text { percent of the existing mileages of rural } \\
\text { highways in United States were designed having } \\
\text { four-lane divided highways. }\end{array}$ \\
\hline & Lane width & $9-12 \mathrm{ft}$ & & $12 \mathrm{ft}$ lane width was accepted in USA after 1945. \\
\hline & $\begin{array}{l}\text { shoulder } \\
\text { width }\end{array}$ & $4-12 \mathrm{ft}$ & & $\begin{array}{c}\text { Shoulder wider than } 4 \mathrm{ft} \text { has slight effect on traffic } \\
\text { wander. (Based on the past research) }\end{array}$ \\
\hline
\end{tabular}




\section{Weather Condition}

Based on the literature review, the wind and precipitation are considered as critical factors influencing traffic wander. For instance, the water vapor will reduce the visibility of the lane marking when driving during the rainy days and the wind effect will force on vehicles to change their track during the windy weather. However, rare research was done to collect the data to describe the relations between the weather condition and traffic lateral distribution. Therefore, with a purpose to compare the effects of different weather on traffic wandering, the lateral placement data in this research will be conducted under sunny, windy, and rainy weather.

\section{Vehicles Types}

Vehicles can be categorized into passenger vehicles (FHWA Class 1 to 3), buses (FHWA Class 4), and trucks (FHWA Class 5 to 13) (Figure 11) based on the Mechanistic-Empirical Pavement Design Guide (MEPDG) (ARA Inc., 2004). Research indicated that the influence of the wheel loading by passenger vehicles on pavement damage can be ignored. Only heavy vehicles (FHWA class 4 to 13) are associated with pavement damage, so the heavy vehicles are used as test vehicles in this research.

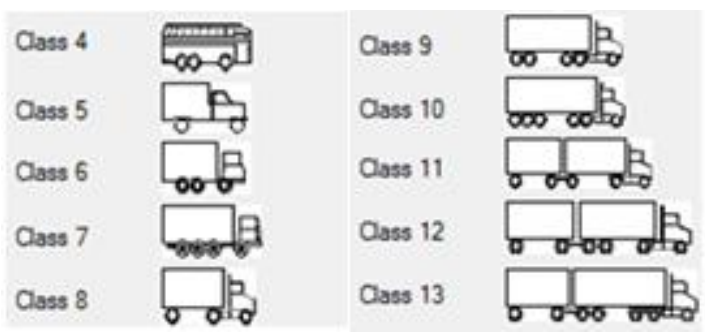

Figure 11 Vehicles from FHWA Class 4 to 13 (ARA Inc., 2004)

Vehicle dimension is a significant parameter for wheel path design, which is critical not only for the wheel path width design, but also for decision of the distance between inner and outer wheel paths. The height, length, width, axle intervals and tire widths are the basic elements of 
vehicle dimension, of these, the vehicle width and dual-tire widths are considered to be most important to the vehicle lateral position on pavement. Vehicle width limits were controlled by individual states' regulations between 1913 an 1956, with $8 \mathrm{ft}$, being the maximum in nearly all states. The first federal truck size and weight limits were contained in the Federal Aid Highway Act of 1956, which set $8 \mathrm{ft}$ as the truck width limit on all interstate highways (TRB, 1986). The 8 ft limit remained in effect until 1983, when the Surface Transportation Assistance Act of 1982 took effect increasing the limit to $8.5 \mathrm{ft}$. For the tire width, the vehicles from FWHA Class 4 to 13 all use dual-wheel and the width of single tire is $11 \mathrm{inch}$, thus the entire width of the twinwheel can be up to 2 feet when the interval between the two tires are taken into consideration.

Table 2 Vehicle Types and their Design Dimension (AASHTO, 2004)

\begin{tabular}{|c|c|c|c|}
\hline Categories & Design Vehicle Type & FWHA Symbol & Vehicle Width \\
\hline $\begin{array}{c}\text { Passenger } \\
\text { Vehicle }\end{array}$ & Passenger car & Class 2 & $7 \mathrm{ft}$ \\
\hline \multirow{4}{*}{ Buses } & Single Unite Truck & Class 3 & $8 \mathrm{ft}$ \\
\cline { 2 - 4 } & Inter-city Bus (Motor Coaches) & Class 4 & $8.5 \mathrm{ft}$ \\
\cline { 2 - 4 } & City Transit Bus & Class 4 & $8.5 \mathrm{ft}$ \\
\cline { 2 - 4 } & Conventional School Bus (65 pass) & Class 4 & $8 \mathrm{ft}$ \\
\cline { 2 - 4 } & Large School Bus (84 pass) & Class 4 & $8 \mathrm{ft}$ \\
\cline { 2 - 4 } & Articulated Bus & Class 4 & $8.5 \mathrm{ft}$ \\
\hline \multirow{4}{*}{ Trucks } & Intermediate Semitrailer & Class 5, 6 & $8 \mathrm{ft}$ \\
\cline { 2 - 4 } & Interstate Semitrailer & Class 8 & $8.5 \mathrm{ft}$ \\
\cline { 2 - 4 } & Double-Bottom-Semitrailer & Class 9 & $8.5 \mathrm{ft}$ \\
\cline { 2 - 4 } & Triple-Semitrailer & Class 7, 10 & $8.5 \mathrm{ft}$ \\
\cline { 2 - 4 } & Turnpike Double-Semitrailer & Class $11,12,13$ & $8.5 \mathrm{ft}$ \\
\hline
\end{tabular}

The vehicle width of FHWA Class 1 to 13 is shown in Table 2: vehicle widths from FHWA Class 5 to 6 is 8 feet, and FWHA Class 4 and 7 to 13 is 8.5 feet. Based on the statistic of traffic in the 2003 study by Cottrell, et al, the maximum percentage of trucks were in type of FHWA Class 9, so the truck dimension of class 9 is selected as a reference to define wheel path (Figure $12)$. 


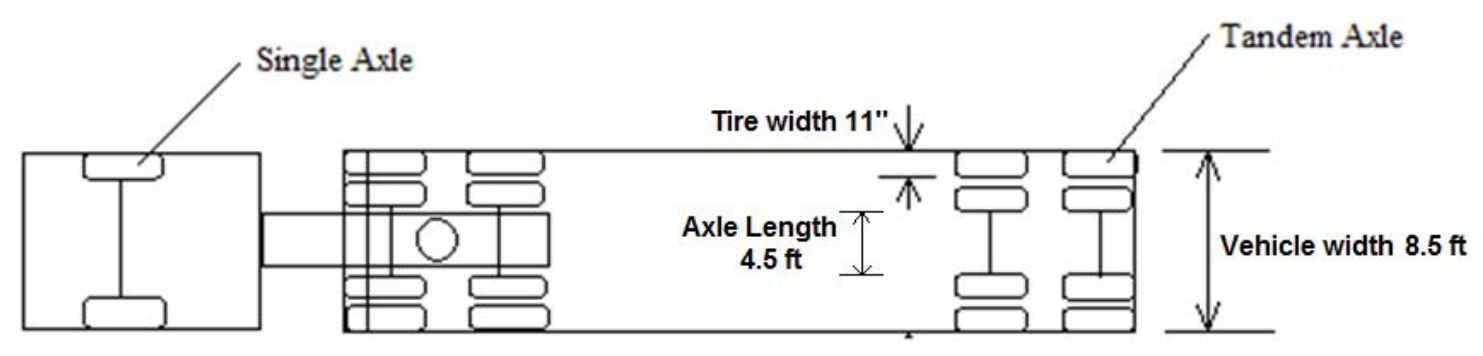

Figure 12 Truck Dimension of FHWA Class 9 (AASHTO, 2004)

\section{Drivers' Habits}

Individual drivers' habits or behavior should be affected by the drivers' age, gender, and professional level. On basis of the statistic from American Trucking Association, over 95 percent of the truck drivers are male shown in Figure 13 (Global Insight, Inc. 2005). Figure 14 shows the statistic of truck driver workforce by age. The ages of most truck drivers range from 35 to 65 (Global Insight, Inc. 2005). In addition, a truck driver is required to take a series of training before qualifying for obtaining the Commercial Driver's License (CDL). As the statistical data shows, the majority of the truck drivers are male, possess professional training, and have ages ranged from 35 to 65 . Therefore, the drivers' habits would not be regarded as test-factor proposed in this research due to the uniformity in gender, age, and training proficiency. 
Shares of the truck driver workforce

By demographic group

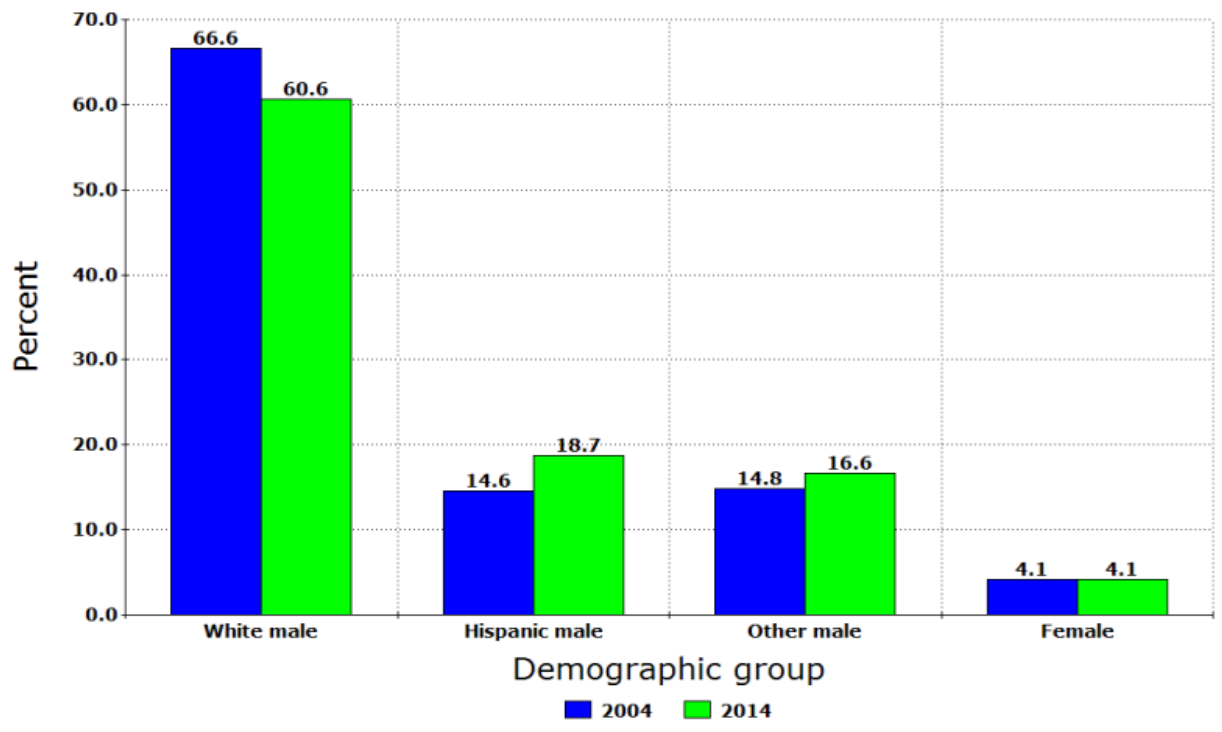

Figure 13 Truck driver workforces by demographic groups (Global Insight, Inc. 2005)

Shares of the truck driver workforce

By age

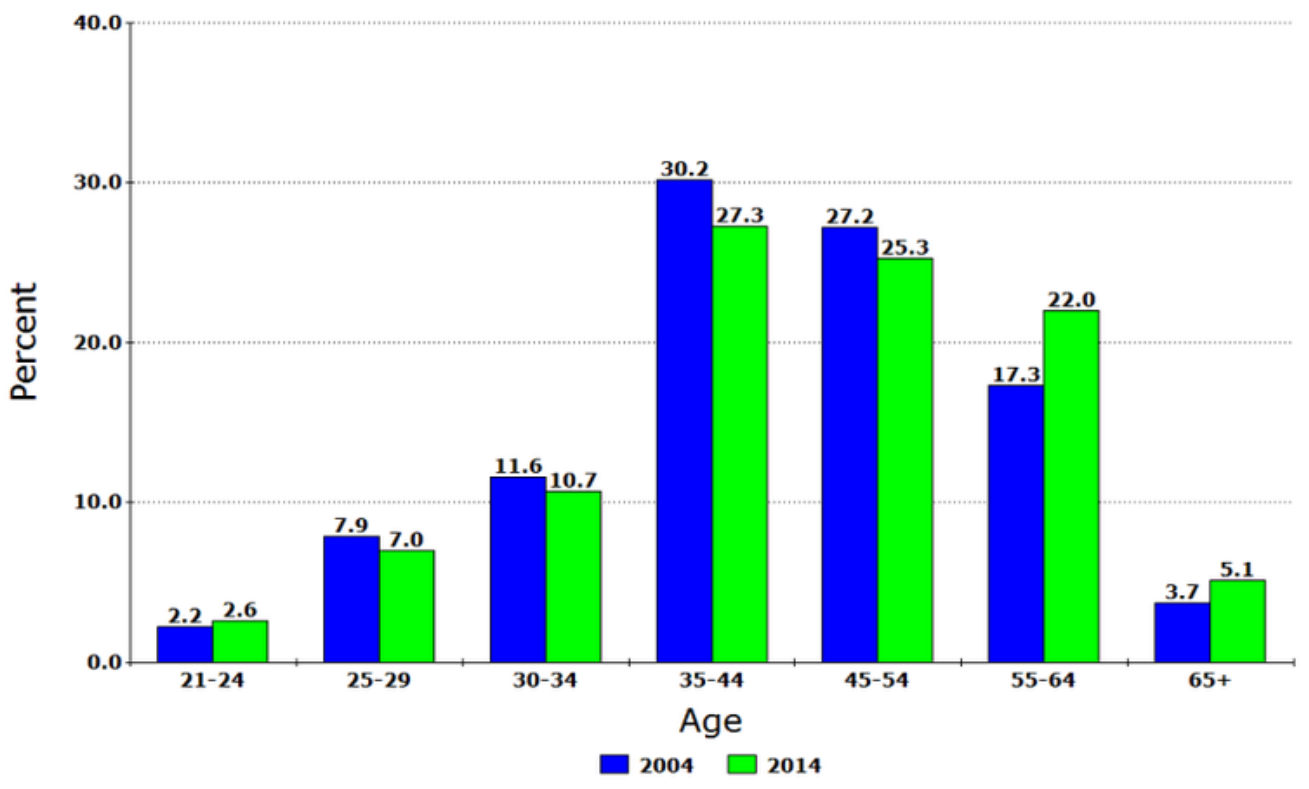

Figure 14 Truck driver workforces by age groups (Global Insight, Inc. 2005) 


\section{Road Characteristics}

The analysis of the effects of road characteristics on trucks' lateral placement is critical to pavement geometric design. Based on literature review, road types, pavement types, number of lanes, road roughness, lane marking, gradient, curvature, lane width and shoulder width all contribute to the randomness of wheel tracking. Statistics indicated that approximately 94 percent of the existing mileages of rural highways in United States were designed having fourlane divided highways (Taragin, 1957), and nearly 95 percent of the existing pavements of highways in United States were flexible pavement (Wimsatt, etc, 2009). Therefore, the test sections for this research are located on four-lane divided highway with bituminous pavement, and the outer lane, the most heavily loaded lane (nearly 74 percent of heavy vehicles were traveling on this lane) (Timm and Priest, 2005), was selected as test lane. The summary of road characteristics for the five test sections is shown in Table 3. 
Table 3 Road characteristics at test sections

\begin{tabular}{|c|c|c|c|c|c|c|c|c|}
\hline Sites & $\begin{array}{l}\text { Road } \\
\text { types }\end{array}$ & $\begin{array}{l}\text { \#of } \\
\text { lanes }\end{array}$ & $\begin{array}{c}\text { Direction } \\
\text { divided }\end{array}$ & $\begin{array}{c}\text { Pavement } \\
\text { type }\end{array}$ & $\begin{array}{l}\text { Width } \\
\text { of lane }\end{array}$ & $\begin{array}{l}\text { Width of } \\
\text { shoulder }\end{array}$ & $\begin{array}{c}\text { Road } \\
\text { roughness }\end{array}$ & Curve \\
\hline 1 & $\begin{array}{l}\text { Interstate } \\
\text { highway }\end{array}$ & 4 & Yes & Bituminous & $12 \mathrm{ft}$ & $10 \mathrm{ft}$ & Good & $\begin{array}{l}\text { close to left } \\
\text { turn curve }\end{array}$ \\
\hline 2 & $\begin{array}{l}\text { Interstate } \\
\text { highway }\end{array}$ & 4 & Yes & Bituminous & $12 \mathrm{ft}$ & $10 \mathrm{ft}$ & Good & $\begin{array}{l}\text { close to right } \\
\text { turn curve }\end{array}$ \\
\hline 3 & $\begin{array}{l}\text { Interstate } \\
\text { highway }\end{array}$ & 4 & Yes & Bituminous & $12 \mathrm{ft}$ & $10 \mathrm{ft}$ & Good & $\begin{array}{l}\text { on right turn } \\
\text { curve }\end{array}$ \\
\hline 4 & $\begin{array}{l}\text { Interstate } \\
\text { highway }\end{array}$ & 4 & Yes & Bituminous & $12 \mathrm{ft}$ & $10 \mathrm{ft}$ & Good & $\begin{array}{l}\text { on left turn } \\
\text { curve }\end{array}$ \\
\hline 5 & $\begin{array}{l}\text { Interstate } \\
\text { highway }\end{array}$ & 4 & Yes & Bituminous & $12 \mathrm{ft}$ & $10 \mathrm{ft}$ & Good & $\begin{array}{c}\text { on straight } \\
\text { road }\end{array}$ \\
\hline
\end{tabular}

\section{Traffic}

The traveling vehicles were categorized into four groups based on Taragin's research, which includes free moving vehicles, meeting vehicles, passing vehicles and all other vehicles. This classification was suitable for the lateral position research on undivided road. However, the test sites used in this research were located on 4 lane divided highway, so the test vehicles were grouped into two classifications: free moving vehicles and influenced vehicles. In terms of traffic condition, two scenarios can be set: firstly, the heavy vehicles would not be affected by oppositedirection traffic on four lane divided highway; secondly, the outside lane isn't taken as passing lane, which means the test vehicles traveling on this lane would not overtake other vehicles. Herein, the free moving vehicles represent the test vehicles uninfluenced by any other traffic, while the influenced vehicles represent the test vehicles affected by overtaking vehicles.

Other than the density of traffic, the vehicle lateral placement is also influenced by the traffic speed. One study indicated that "the average position of the slower moving vehicles, whether passenger cars or trucks, was close to the shoulder of the highway than that of the faster moving vehicle.”(Taragin, 1957) However, the truck speed always kept in special range when traveling in highways since the truck speed limits of highway in United State is from 55 to 70 
mph (Topspeed, 2006). Therefore, the speed would not be considered as a test factor in this research.

\section{Visibility}

It is difficult to see around or ahead clearly when driving at night since darkness will reduce the visibility of environment. Past researchers indicated that the white shoulders and white edge stripes were more visible at night than the black center section, and the observation provided specific support for the prevailing belief that the white shoulders have the effect of holding the traffic to the edges of the pavement (Pauls, 1925). In addition, the other study also stated the effect of darkness on the lateral placement of traffic (Taragin, 1957). Thus, the darkness was considered to be critical to vehicle shift, and the data collection would be conducted during the day and night time in this thesis.

\section{Environment}

The environmental factors of the traveling vehicle include open area, tunnels, flyovers, and traffic barriers. However, the effect of environment on lateral distribution of traffic is not significant. In addition, over 90 percent of the existing mileages of primary highways in United States were in open area. Therefore, the test sections were located on open area, and environmental factors were not considered in the test.

\section{B. Summary of Test and Un-Test Factors}

Based on the analysis of influencing factors, four factors were taken account into test in this research, namely weather condition, road curve, visibility condition, and traffic condition. However, other factors such as driver habits, vehicle speed, environment, vehicle type, road type 
and pavement type, etc. were considered as the Un-Test factors what are not used in this research as shown in Figure 15.

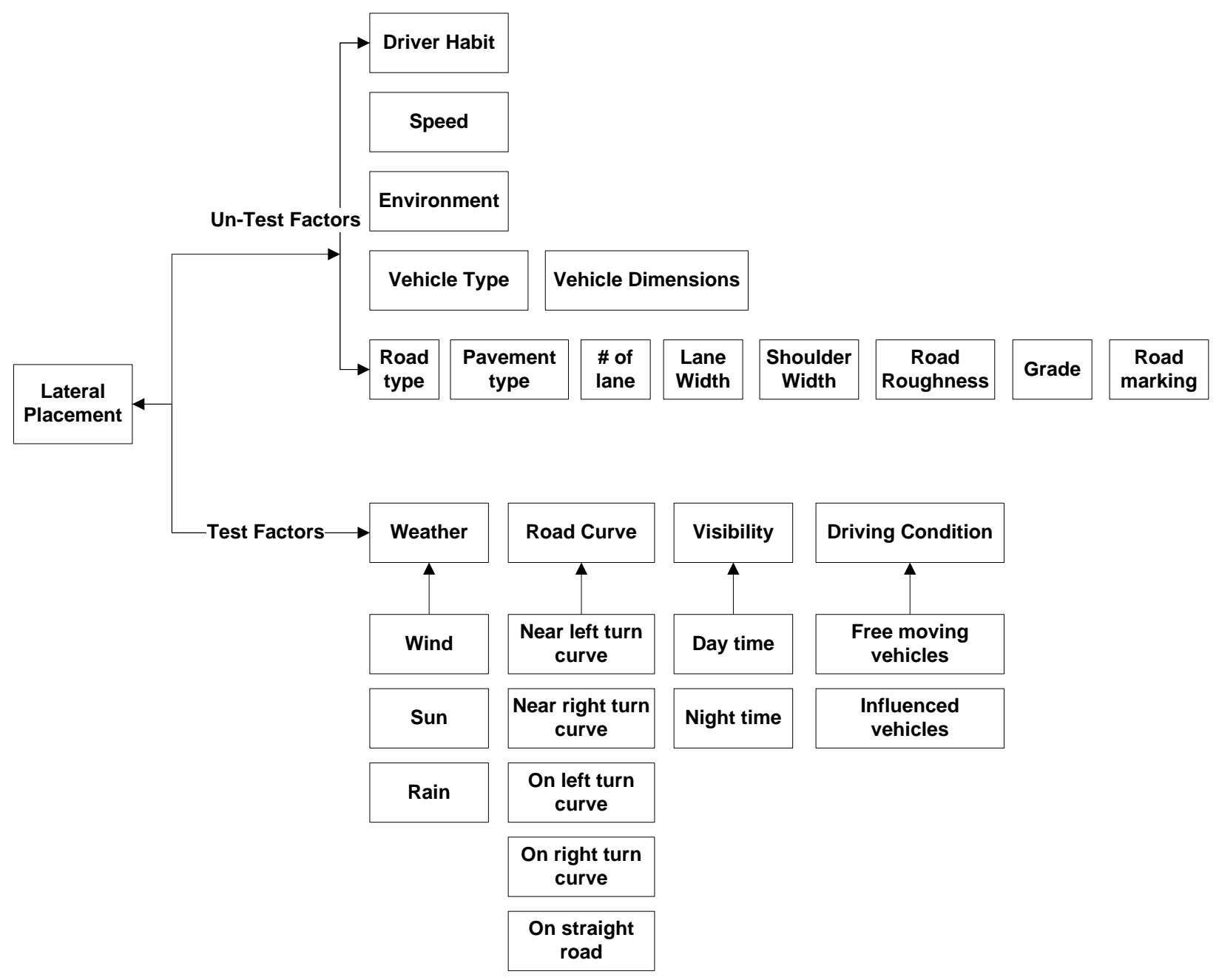

Figure 15 Flow diagram of Test and Un-Test Factors 


\section{LATERAL POSITION MEASUREMENT}

\section{A. General Approach}

According to the aforementioned lateral position measurement methods, in this research the video camera was employed to record the lateral position data based on the three following reasons:

- Availability: The video camera is easy to be obtained, e.g. purchased from the websites, or entity stores.

- Economic: The video camera is cheaper than sensor devices, e.g. hundreds of US dollars for a high quality video camera.

- Accuracy: The video camera can capture the HD images identifying truck lateral position.

The lateral placement video data were recorded by Sony Alpha NEX5K/B Digital Camera with the feature shooting 1080/60P HD movies, which was mounted on bridges over the highway. With an aim to accurately record the lateral position data, different positions, heights, and angles to set up the camera were attempted to obtain the best view of truck wheel tracking in the outside lane of test sections as shown in Figure 16.

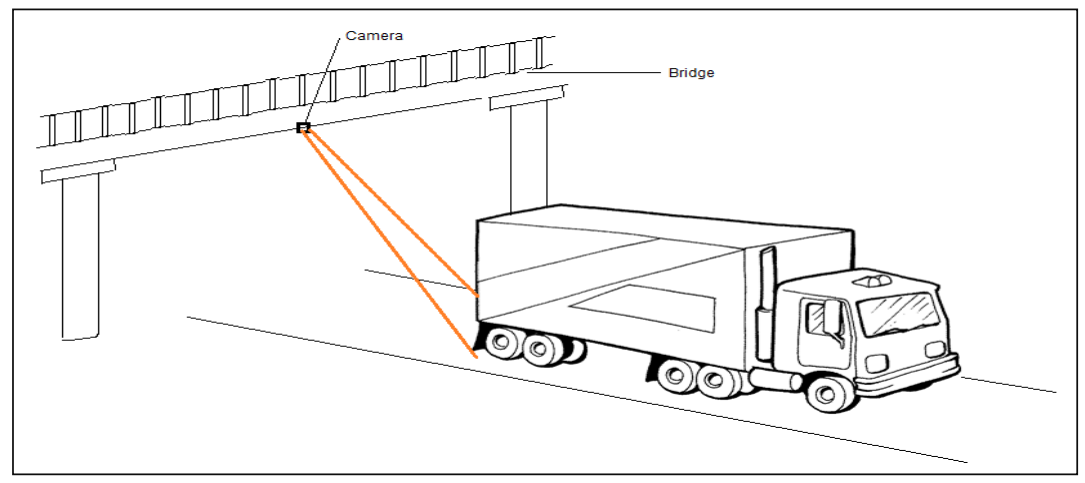

Figure 16 Installation for video camera 
The reference line or color stripes were used to mark on the lane surface to identify the lateral deviation of vehicles and the marking procedure can be implemented by the following steps. Firstly, determine the center line of the test lane and mark the dual-wheel having 2 feet wide at both sides of the centerline as shown in Figure 17. Based on the marked positions of centerline and the dual-wheels, the left and right deviation relative to the dual-wheels can be marked by color stripes. In Figure 17, the orange, purple, blue and green stripes represent 1, 0.75, 0.5 and 0.25 feet deviation away from the black lines, respectively. The practice of marking reference line in the field can be represented by Figure 18.

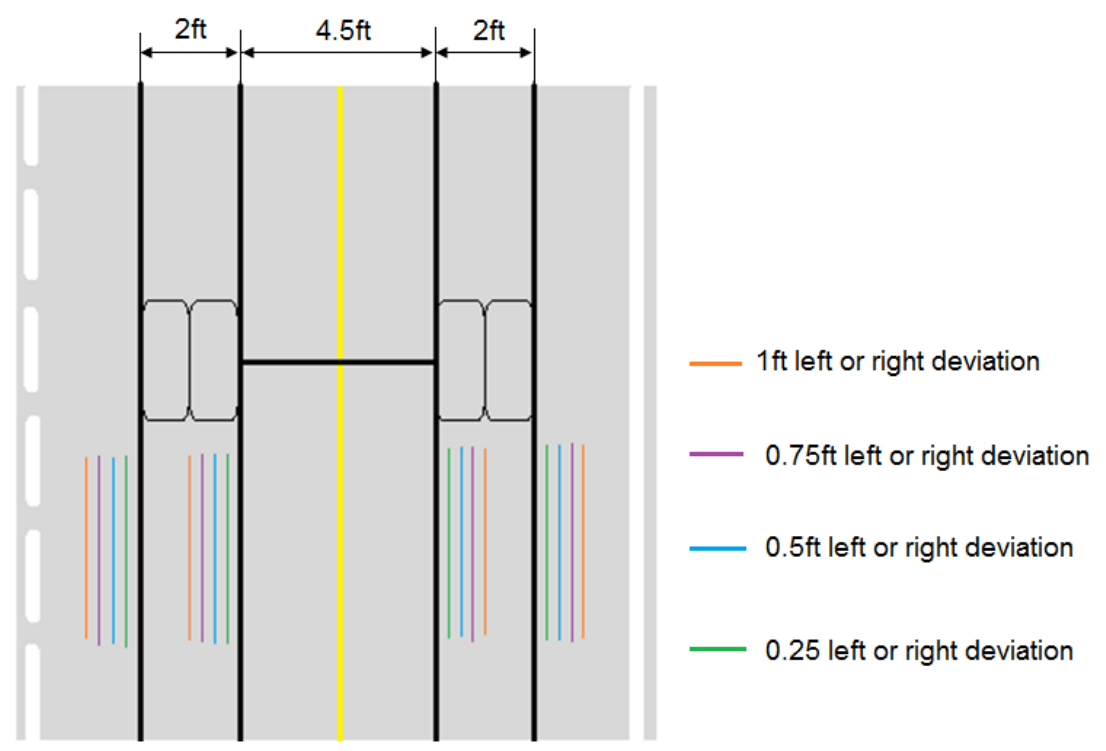

Figure 17 Schematic of marking reference lines 


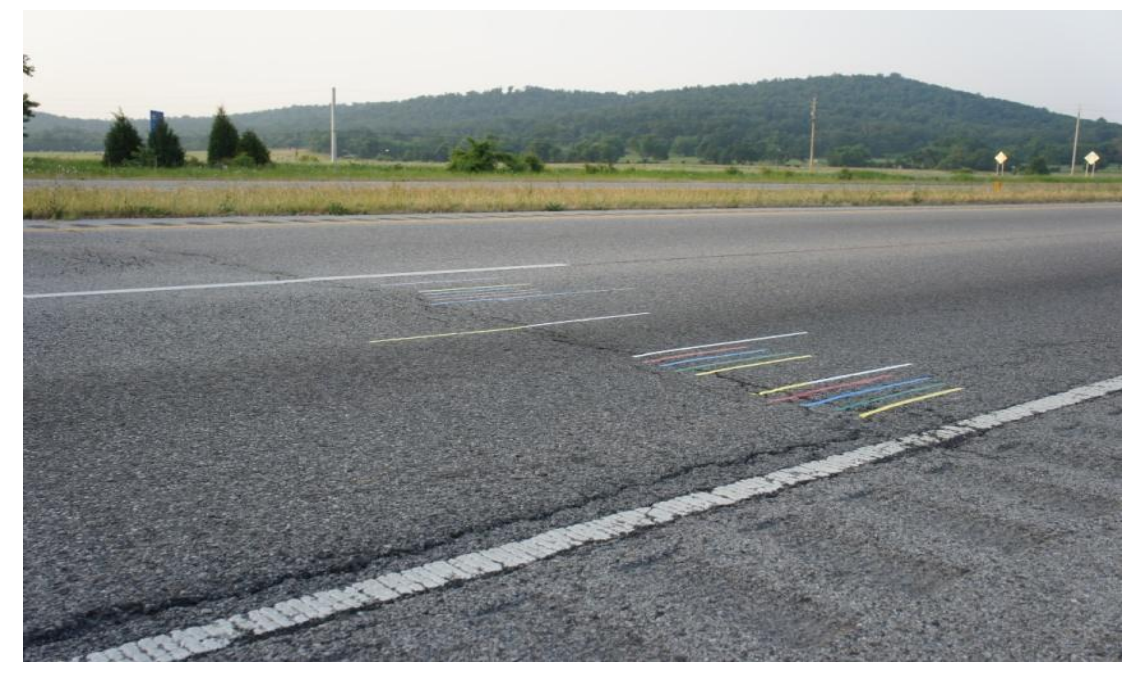

Figure 18 Mark of reference lines in the field

The specific lateral position data can be recorded when trucks traveling on the lane section marked by the reference lines. For instance, the dual-wheel marked by white stripes can be observed at both sides of the centerline, the deviation can be considered as the "Zeros" if a truck traveled within the two yellow arrows (Figure 19). Similarly, the truck with a $0.5 \mathrm{ft}$ deviation to the right side can be identified by the red arrow in Figure 20.

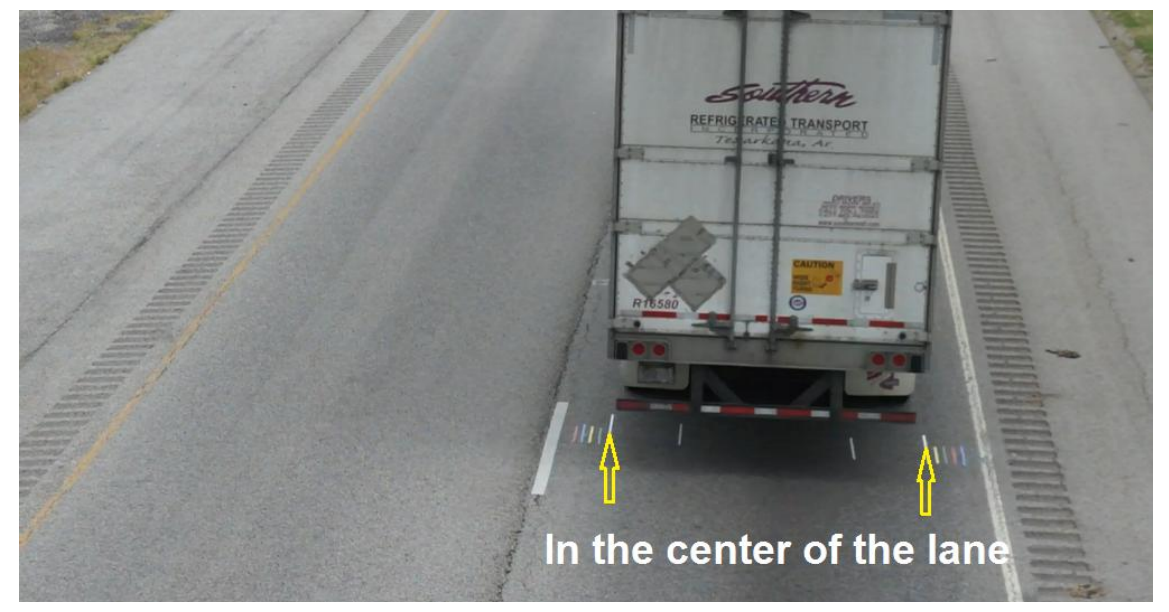

Figure 19 Truck in motion without deviation 


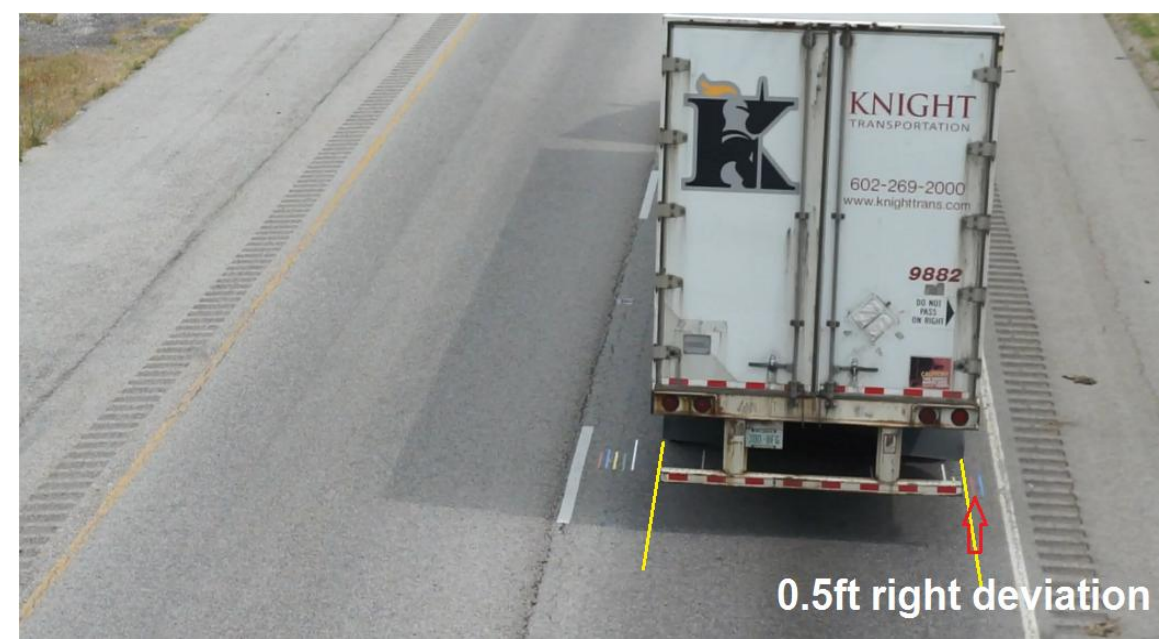

Figure 20 Truck in motion with $0.5 f t$ deviation to the right side

For the purpose of study, the test trucks on the four-lane divided highway can be classified into two groups: free moving trucks and influenced trucks.

- Free moving trucks - not influenced by the other traffic on the highway when their lateral positions were recorded as shown in Figure 21. Around 67 percentage of the trucks studied in this research can be regarded as free moving trucks.

- Influenced trucks - directly affected by other vehicles traveling in the same direction when their lateral positions were recorded as shown in Figure 22. Around 33 percent of the trucks studied in this research can be considered as the influenced trucks. 

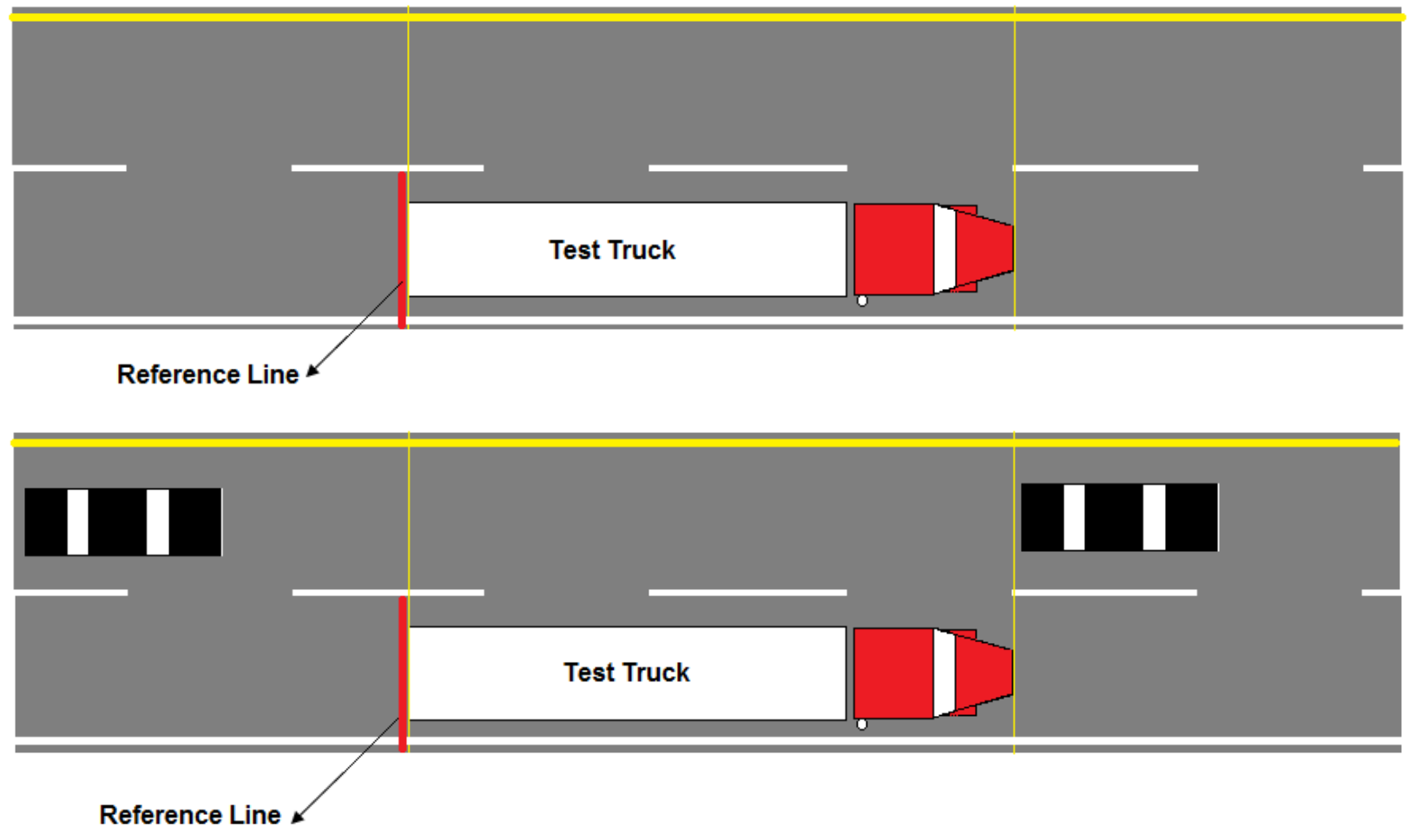

Figure 21 Free moving trucks
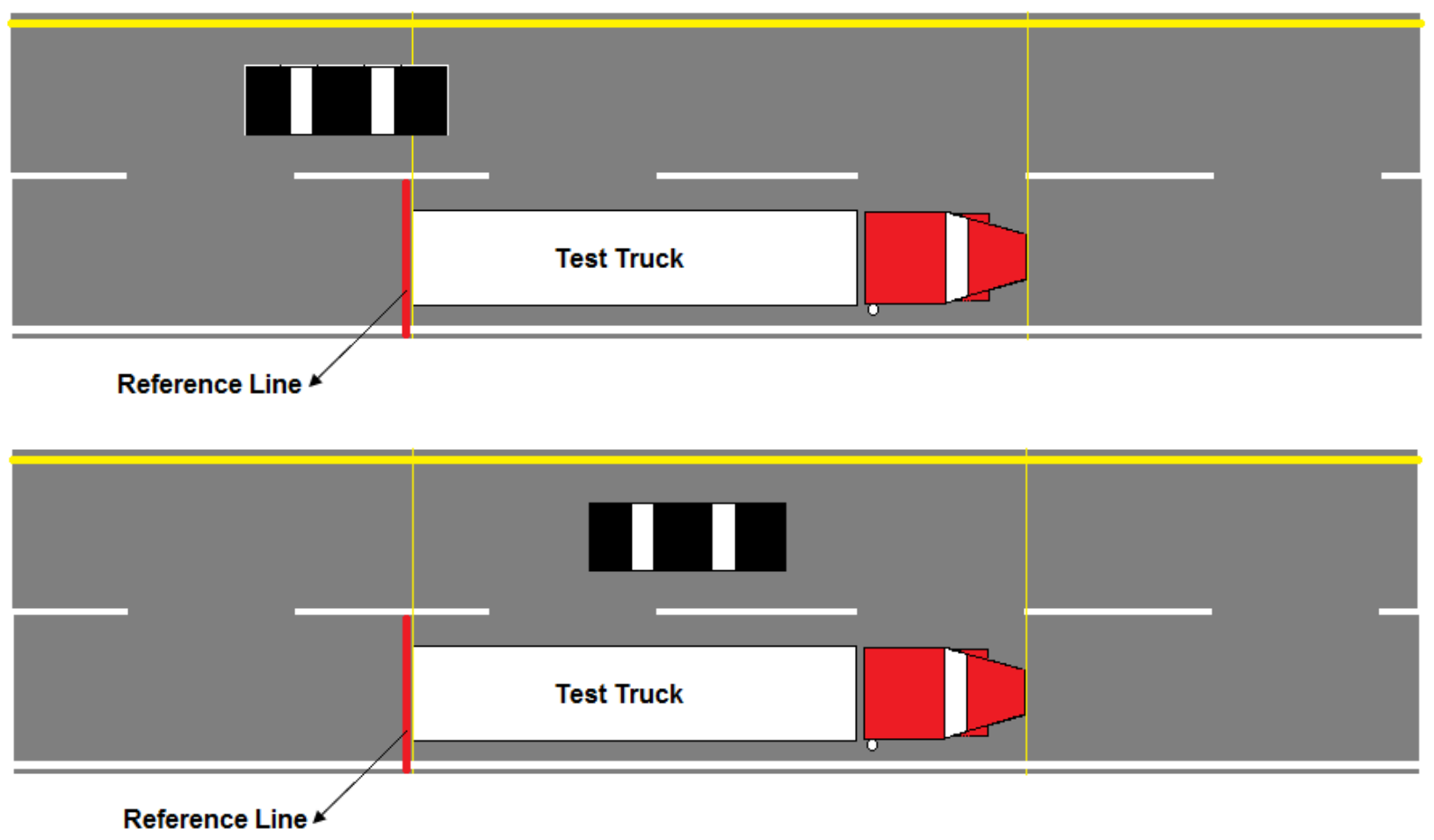

Figure 22 Influenced trucks 


\section{B. Test Site Selection}

In past studies, almost all of the test sites are located on the straight road to avoid the effect of road curve on lateral position. However, curve is commonly used in pavement geometric design. Based on the research results from "Green Book -- A policy of geometric design of highway and street" (AASHTO, 2004), the vehicles' track of road sections will be different by the distance from the curve, while there is no difference for vehicles traveling before or behind the curve. Plus, the deflection of the curve (right or left turn curve) also influenced the vehicles' track. Therefore, the road sections were defined in figure 23:

- Near left turn curve road segment: with counterclockwise traffic direction, the road sections from $\mathrm{B}$ to $\mathrm{A}, \mathrm{D}$ to $\mathrm{C}, \mathrm{F}$ to $\mathrm{E}$, and $\mathrm{H}$ to $\mathrm{G}$ which are less than 0.5 mile (AASHTO, 2004) to the near tangent of the curve are defined as near left turn curve road section.

- Near right turn curve road segment: with clockwise traffic direction, the road sections from $\mathrm{A}$ to $\mathrm{B}, \mathrm{C}$ to $\mathrm{D}, \mathrm{E}$ to $\mathrm{F}$, and $\mathrm{G}$ to $\mathrm{H}$ which are less than 0.5 mile (AASHTO, 2004) to the near tangent of the curve are defined as near left turn curve road section.

- In right turn curve road segment: with clockwise traffic direction, the road sections from $\mathrm{H}$ to $\mathrm{A}$ and $\mathrm{D}$ to $\mathrm{E}$ which are between two tangents of the curve are defined as in right turn road.

- In left turn curve road segment: with counterclockwise traffic direction, the road sections from $\mathrm{A}$ to $\mathrm{H}$ and $\mathrm{E}$ to $\mathrm{D}$ which are between two tangents of the curve are defined as in left turn road.

- In straight road segment: with clockwise or counterclockwise traffic direction, the road sections from $\mathrm{B}$ to $\mathrm{C}, \mathrm{F}$ to $\mathrm{G}, \mathrm{C}$ to $\mathrm{B}$, and $\mathrm{G}$ to $\mathrm{F}$ which are more than 0.5 mile (AASHTO, 2004) far away from the near tangent of the curve are defined as in left turn road. 


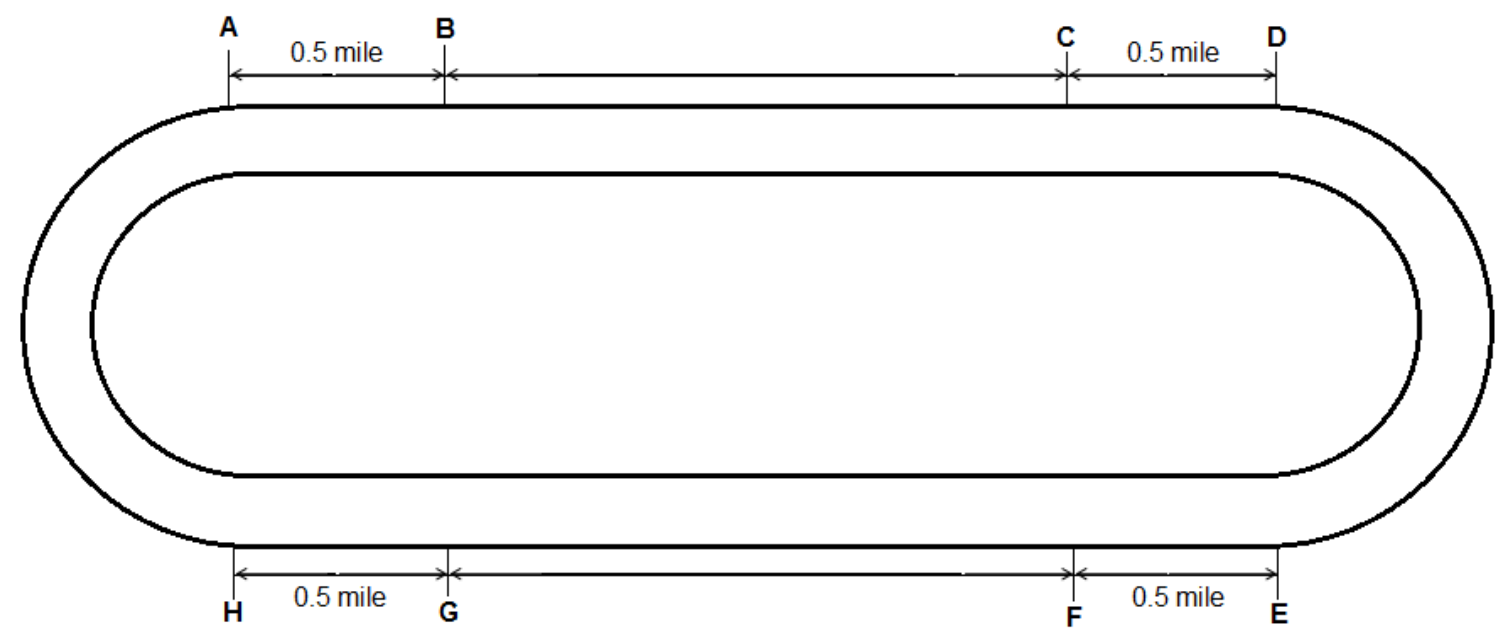

Figure 23 Schematic representation of test site selection

In this research, the test sites located on I-540 Interstate Highway in Arkansas are selected as the test bed to redefine the wheel path.

The first test site with the GPS coordinates (N36.0777, W94.2011) is located on the intersection between I-540 and W Wedington Dr (Figure 24), which is defined as "near the left turn curve", since a left turn curve appears about 0.3 miles away from the test point.

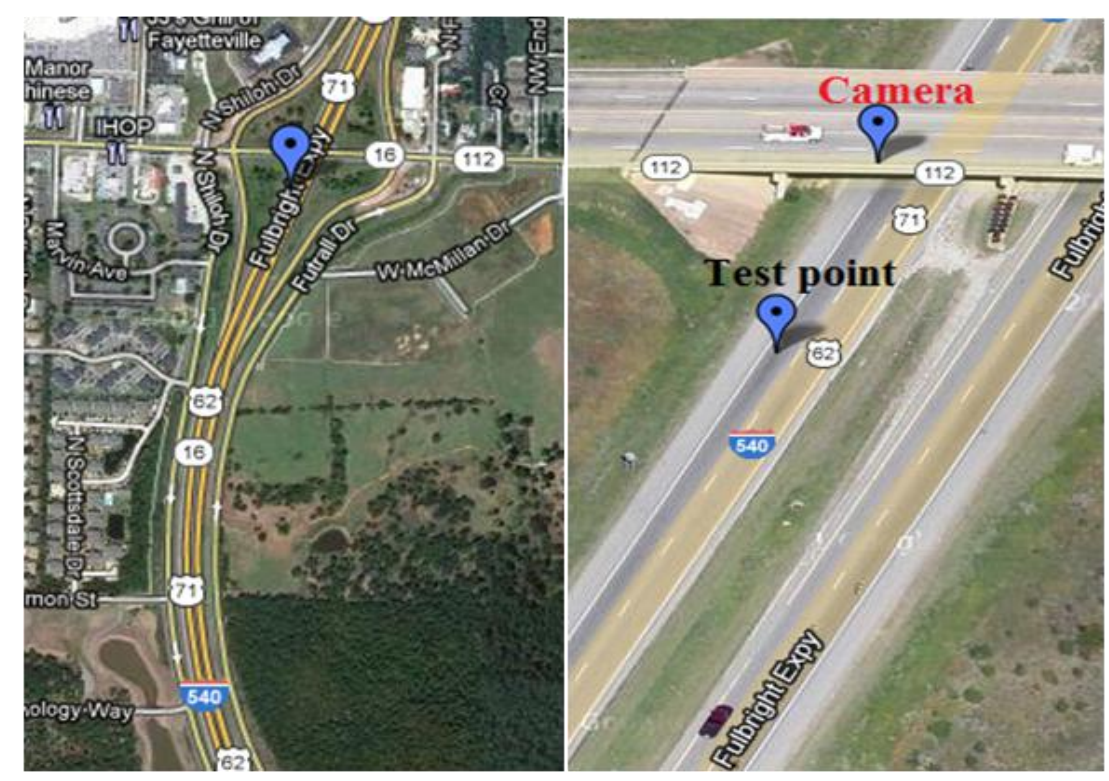

Figure 24 Test site 1: near left turn curve 
The GPS coordinates of the second test site is N 36.07876, W94.200286. This test site is located on the opposite direction of the first test site (Figure 25). Similarly, the second test site can be viewed as "near the right turn curve" since a right turn curve occurs around 0.3 miles away from this test site.

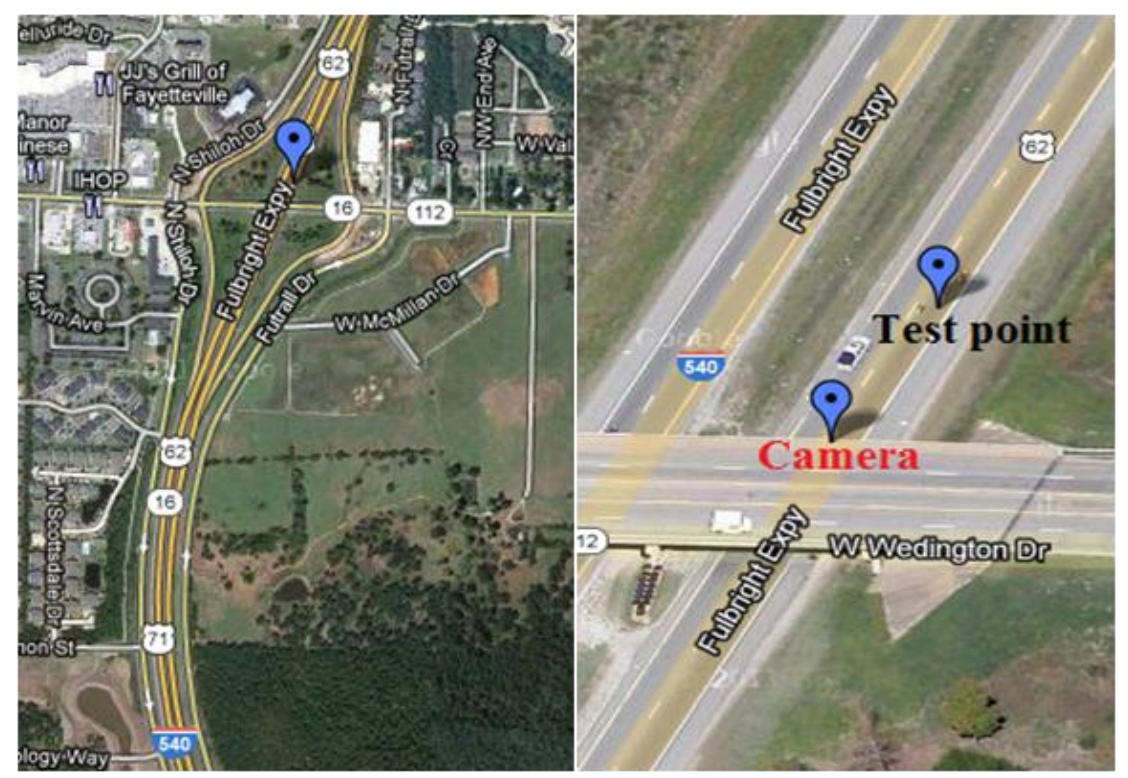

Figure 25 Test site 2: near right turn curve

The third test site with the GPS coordinates (N36.1059, W94.1793) is located on the intersection between I-540 and Hall Avenue (Figure 26). This site is defined as "on right turn curve road" since the test site locates within the two tangent points of the right turn curve. 


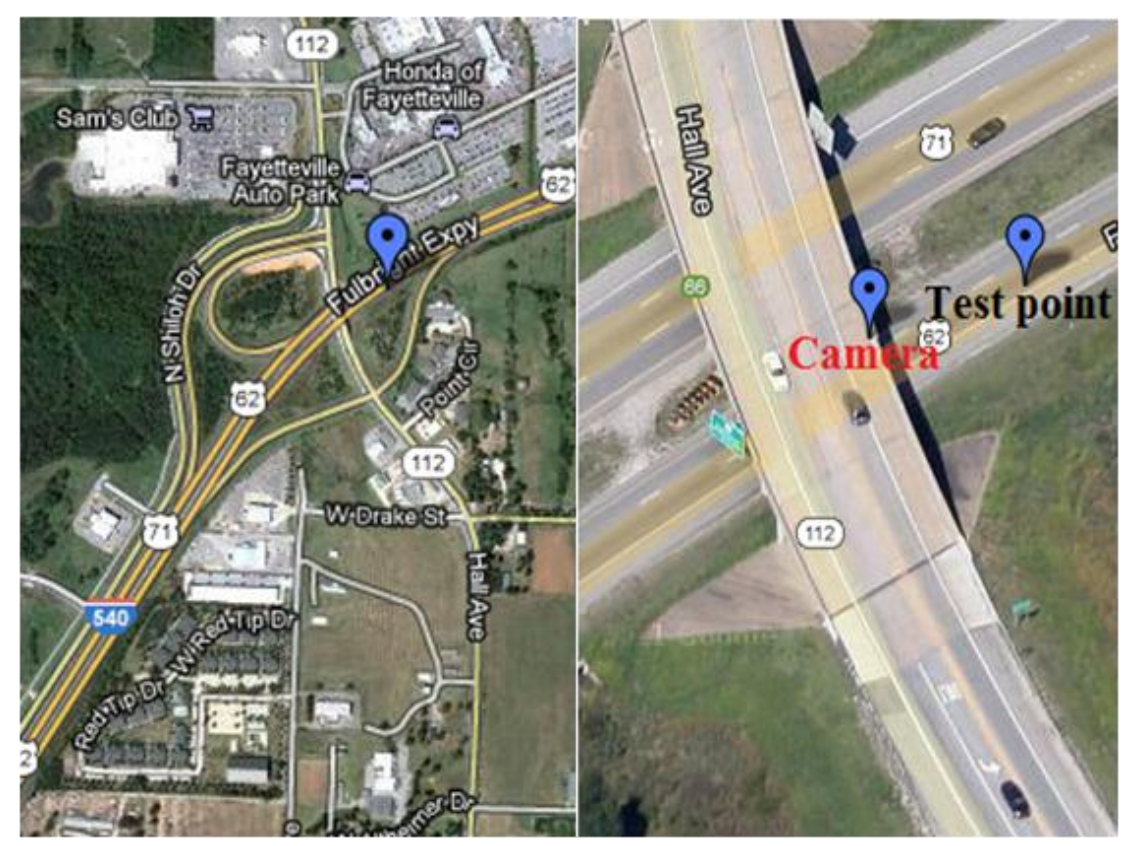

Figure 26 Test site 3: on right turn curve

The GPS coordinates of the fourth test site is N 36.105644, W94.180089. This test site is located on the opposite direction of the third test site (Figure 27). The fourth test sites can be seen as "on left turn curve" since the test site locates within the two tangent points of the left turn curve. 


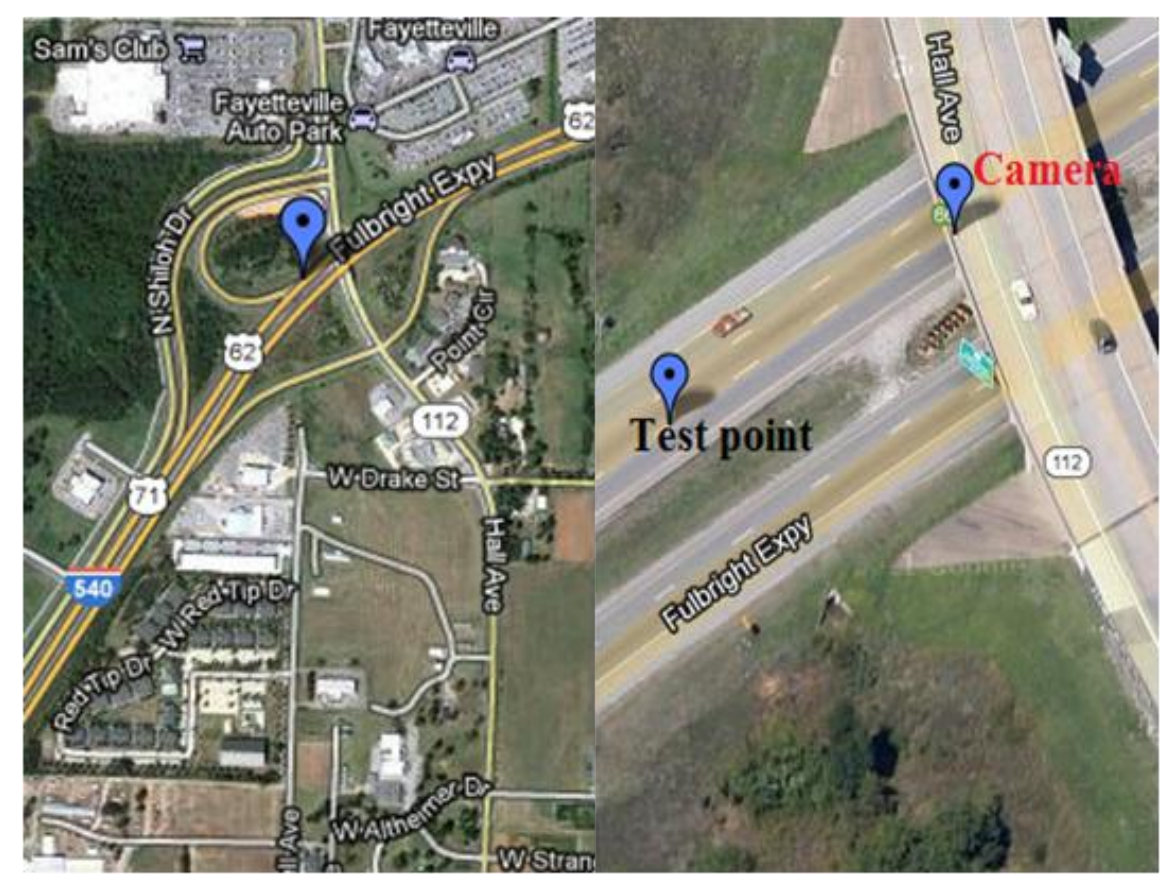

Figure 27 Test site 4: on left turn curve

The fifth test site with the GPS coordinates (N36.1611, W94.1865) is located on the intersection between I-540 and Watkins Ave (Figure 28). This test site can be treated as "in straight road" because the nearest curve away from this test site appears at more than1 mile ahead or behind. 


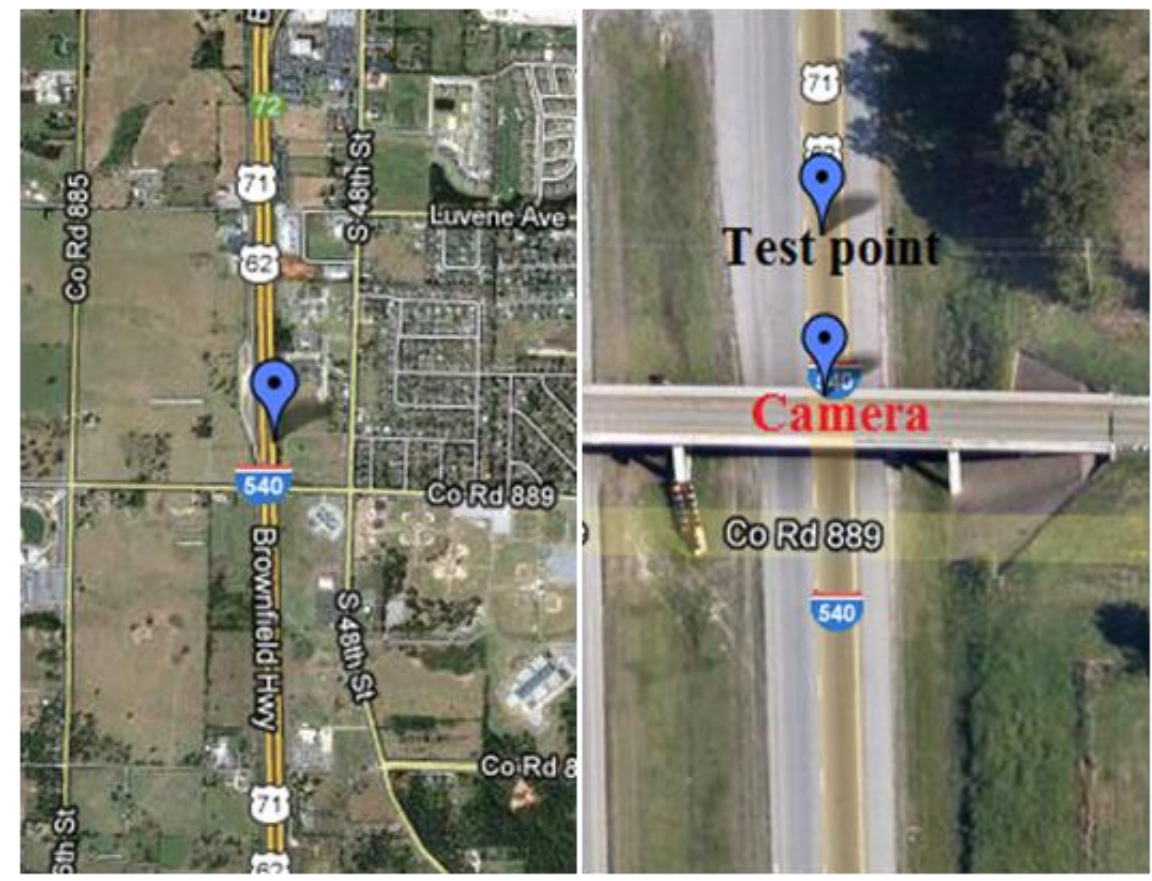

Figure 28 Test site 5: on straight road

\section{Summary of the Collected Data}

In order to measure the traffic volume distribution at test sites and the influence of weather, visibility, traffic condition and road curve on lateral position of heavy vehicles, the traffic video data were collected during the day and night time, in different days of a week, and under three types of weather. The collection and processing of traffic video data took many hours in this research.

In Table 4, there are 100 hour traffic video data in total, which were recorded at the 5 test sites. In terms of the number of vehicles, there are 155472 vehicles involved in this research, in which 9266 truck are contained. In addition, the detailed information for each test site such as the recording time, truck number, and vehicle also can also be illustrated in Table 4. 
Table 4 Summary of Video Data

\begin{tabular}{|c|c|c|c|c|c|c|c|c|}
\hline \multirow{2}{*}{$\begin{array}{l}\text { Test } \\
\text { Sites }\end{array}$} & \multirow{2}{*}{ Unit } & \multicolumn{2}{|c|}{ Workday } & \multirow{2}{*}{$\begin{array}{c}\text { Weekend } \\
\text { Day } \\
\end{array}$} & \multicolumn{3}{|c|}{ Weather } & \multirow{2}{*}{ Total } \\
\hline & & Day & Night & & Windy & Rainy & Sunny & \\
\hline \multirow{3}{*}{1} & Recording time & $15 \mathrm{hr}$ & $2 \mathrm{hr}$ & $6 \mathrm{hr}$ & $7.5 \mathrm{hr}$ & $1.5 \mathrm{hr}$ & $13.5 \mathrm{hr}$ & $24 \mathrm{hr}$ \\
\hline & Total trucks & 1663 & 89 & 492 & 701 & 201 & 1369 & 2311 \\
\hline & Total vehicles & 24080 & 1125 & 7839 & 12645 & 1808 & 18621 & 33538 \\
\hline \multirow{3}{*}{2} & Recording time & $12 \mathrm{hr}$ & $1.5 \mathrm{hr}$ & $3.5 \mathrm{hr}$ & $7.5 \mathrm{hr}$ & $2 \mathrm{hr}$ & $6 \mathrm{hr}$ & $16 \mathrm{hr}$ \\
\hline & Total trucks & 1460 & 119 & 190 & 916 & 210 & 524 & 1681 \\
\hline & Total vehicles & 17845 & 1568 & 4421 & 10087 & 3123 & 9056 & 22541 \\
\hline \multirow{3}{*}{3} & Recording time & $1 \mathrm{hr}$ & $9 \mathrm{hr}$ & $11 \mathrm{hr}$ & $1.25 \mathrm{hr}$ & $1.5 \mathrm{hr}$ & $10 \mathrm{hr}$ & $20 \mathrm{hr}$ \\
\hline & Total trucks & 66 & 580 & 586 & 62 & 125 & 590 & 1232 \\
\hline & Total vehicles & 554 & 11932 & 15420 & 2130 & 1858 & 13844 & 27906 \\
\hline \multirow{3}{*}{4} & Recording time & $14 \mathrm{hr}$ & $5 \mathrm{hr}$ & $4 \mathrm{hr}$ & $3.5 \mathrm{hr}$ & $2 \mathrm{hr}$ & $11.5 \mathrm{hr}$ & $22 \mathrm{hr}$ \\
\hline & Total trucks & 1600 & 232 & 159 & 373 & 95 & 1221 & 1921 \\
\hline & Total vehicles & 27945 & 4829 & 5912 & 5662 & 4113 & 22255 & 36859 \\
\hline \multirow{3}{*}{5} & Recording time & $12.5 \mathrm{hr}$ & $2 \mathrm{hr}$ & $1.5 \mathrm{hr}$ & $5 \mathrm{hr}$ & $2 \mathrm{hr}$ & $9 \mathrm{hr}$ & $18 \mathrm{hr}$ \\
\hline & Total trucks & 1667 & 93 & 90 & 827 & 271 & 930 & 2121 \\
\hline & Total vehicles & 26002 & 1428 & 2695 & 9220 & 4503 & 19477 & 34628 \\
\hline
\end{tabular}




\section{STATISTICAL ANALYSIS OF FACTORS INFLUENCING LATERAL POSITION DISTRIBUTION}

Factors such as road curve, traffic condition, visibility and weather condition are the significant contributors to generating wheel shift. In reality, the wheel shift can be produced by one individual factor or multiple factors. Therefore, this chapter attempted to describe the effects of one or more factors on lateral position distribution of truck wheels. Based on the results of statistical analysis, the factors influencing lateral position were ranked per their effects on lateral position.

\section{A. Descriptive Statistics of Lateral Position Data}

To investigate the effect of the test-factors on lateral position distribution, the lateral position data were extracted from traffic video and organized by their driving environment.

\section{Definition of Reference Situations}

Take the test-factor of weather as an example, it can be analyzed under three scenarios, namely windy, rainy, and sunny situations, in which sunny weather can be considered as noninfluencing situation on the lateral position of vehicles, thereby the lateral position recorded under sunny weather was taken as a reference to compare with the lateral positions read under rainy and windy weather.

Generally, the reference scenario plays the minimum effect on generating traffic wandering. In this research, four scenarios namely sunny weather, in straight road, during the day time, and with free moving can be regarded as the "reference" situations in accordance with their influences on the lateral position distribution, as shown in Figure 29. 


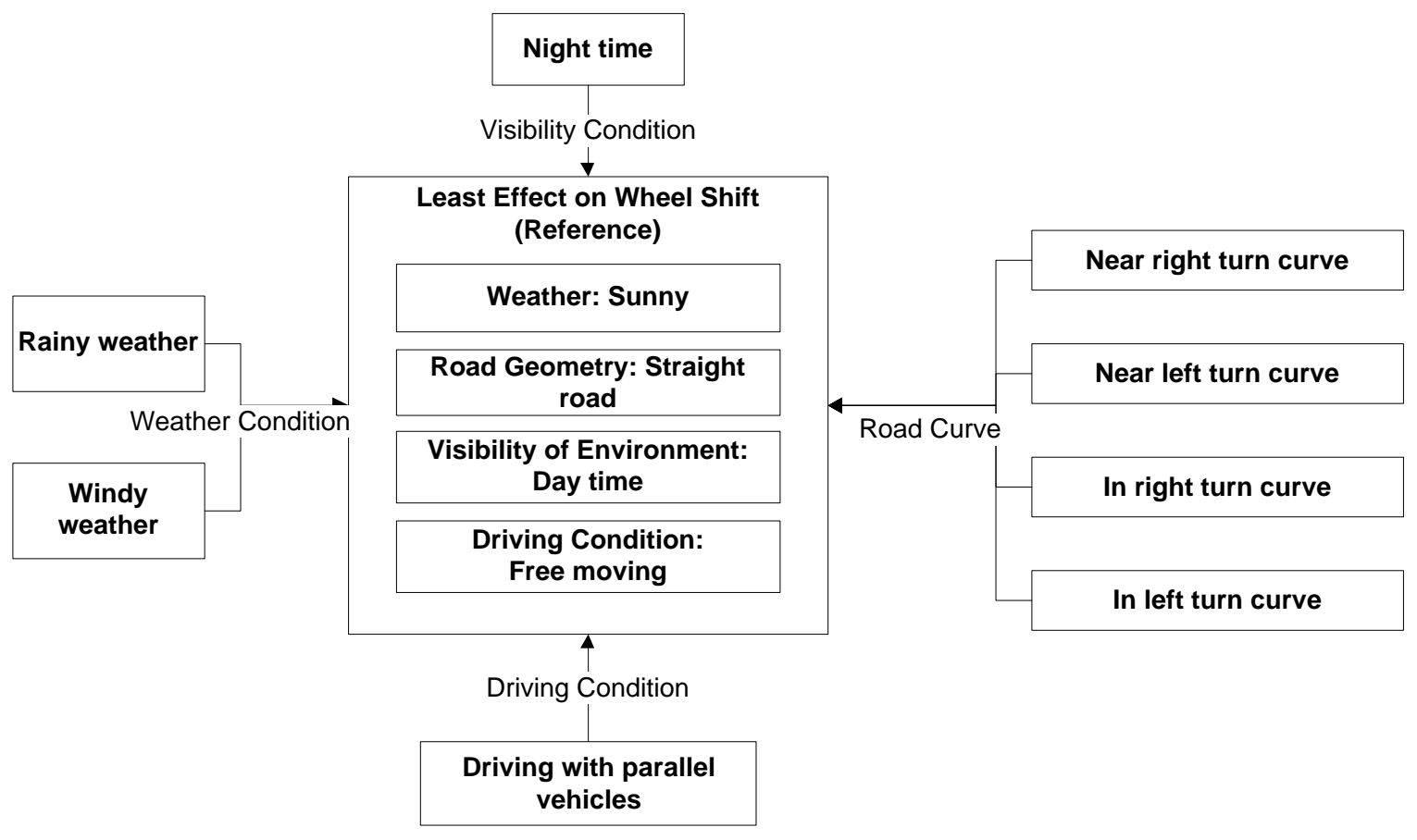

Figure 29 Reference Scenarios and Their Comparison Scenarios

\section{Statistics of Lateral Position Data}

The traffic video recorded in the field is considered as the raw data, and the number of trucks appeared at each lateral position under different situations can be obtained once the raw data are processed. However, due to the difference of the traffic video duration and the traffic volume, the sample sizes are different for each group data, as Table 4 shows. In order to analyze the lateral position distribution eliminating the influence from different sample sizes, the frequency of heavy vehicles on lateral position were transformed to corresponding percentage data. Table 5 to 10 shows the percentage of frequency at each lateral position for four test-factors. Herein, the deviation represents the distance of the center line between the vehicles and the traveling lane. The negative sign indicates the left deviation relative to center line of the traveling lane; in contrast, the positive value implied the traffic wandering to the right-side of the lane. 
In this research, the driving environment consists of weather condition, road condition, traffic condition, and visibility condition, which indicated the four factors would work together to affect the lateral position. So as to examine the effect of road curve on lateral position data and exclude the effects of other factors, the reference situation under other three test-factors was chosen as the test background for road curve test. Table 5 shows the percentage of frequency of lateral position data for trucks at five test sites with free moving trucks, under sunny weather, and in daytime.

With an aim to investigate the effect of traffic condition on lateral position distribution, the recorded trucks were broken down into two groups: free moving trucks and influenced trucks. Other than taking the road condition and traffic condition into account, the reference situations under the other two test-factors were also selected as the test bed to examine the effect of traffic condition on lateral position. Table 6 shows the lateral position data for both free moving and influenced trucks at 5 test sites under sunny weather and in daytime.

It is widely accepted that the visibility is different during the day and at night. In order to compare the lateral distribution in darkness and brightness, the test-factor, visibility condition, was added into the test. Table 7 and 8 show the lateral position data in day and night at five test sites under sunny weather for free moving trucks and influenced trucks, respectively. These lateral position data were influenced by the multiple test-factors, namely road curve, traffic condition, and visibility condition.

Weather condition may be the most complex factor to influence the lateral position since the precipitation will reduce the visibility of lane markings and result in the wheel shift, furthermore, wind will alter the vehicles' track when the external force are imposed in the recorded vehicles from the lateral side of the vehicles. Thus, three factors are incorporated into the test, namely 
road curve, traffic condition, and weather condition. Table 9 and 10 show the lateral position data at five test sites under three types of weather for free moving trucks and influenced trucks in day time, respectively. 
Table 5 Frequency of Lateral Position Data at Five Test Sites

\begin{tabular}{ccccccccccccc}
\hline $\begin{array}{c}\text { Deviation } \\
\text { (ft) }\end{array}$ & $\mathbf{- 1 . 7 5}$ & $\mathbf{- 1}$ & $\mathbf{- 0 . 7 5}$ & $\mathbf{- 0 . 5}$ & $\mathbf{- 0 . 2 5}$ & $\mathbf{0}$ & $\mathbf{0 . 2 5}$ & $\mathbf{0 . 5}$ & $\mathbf{0 . 7 5}$ & $\mathbf{1}$ & $\mathbf{1 . 7 5}$ & Sample Size \\
\hline Site 1(\%) & 0.53 & 0.64 & 0.11 & 2.14 & 2.14 & 9.40 & 6.52 & 15.92 & 12.39 & 19.34 & 30.88 & 936 \\
Site 2(\%) & 0.91 & 2.44 & 2.13 & 6.71 & 4.88 & 20.73 & 8.54 & 19.51 & 11.59 & 14.94 & 7.62 & 328 \\
Site 3(\%) & 1.11 & 2.47 & 3.46 & 9.39 & 7.29 & 17.31 & 10.75 & 20.27 & 9.64 & 11.87 & 6.18 \\
Site 4(\%) & 7.13 & 13.56 & 11.49 & 17.24 & 11.03 & 15.40 & 5.98 & 8.51 & 3.91 & 3.45 & 2.76 & 435 \\
Site 5(\%) & 0.20 & 0.40 & 1.39 & 5.96 & 2.78 & 14.12 & 9.74 & 23.86 & 14.71 & 15.51 & 11.33 & 503 \\
\hline
\end{tabular}

Table 6 Frequency of Lateral Position Data under Traffic Condition at 5 Sites

\begin{tabular}{|c|c|c|c|c|c|c|c|c|c|c|c|c|c|}
\hline Deviation (ft) & -1.75 & -1 & -0.75 & -0.5 & -0.25 & $\mathbf{0}$ & 0.25 & 0.5 & 0.75 & 1 & 1.75 & Sample size & Traffic condition \\
\hline Site 1(\%) & 0.53 & 0.64 & 0.11 & 2.14 & 2.14 & 9.40 & 6.52 & 15.92 & 12.39 & 19.34 & 30.88 & 936 & Free moving \\
\hline Site $1(\%)$ & 0 & 0.46 & 0.46 & 0 & 0.46 & 4.85 & 3.93 & 12.93 & 8.78 & 22.63 & 45.96 & 433 & Influenced \\
\hline Site $2(\%)$ & 0.91 & 2.44 & 2.13 & 6.71 & 4.88 & 20.73 & 8.54 & 19.51 & 11.59 & 14.94 & 7.62 & 328 & Free moving \\
\hline Site $2(\%)$ & 0 & 1.02 & 0.51 & 7.14 & 2.55 & 11.22 & 11.22 & 17.35 & 18.37 & 15.31 & 15.31 & 196 & Influenced \\
\hline Site 3(\%) & 1.11 & 2.47 & 3.46 & 9.39 & 7.29 & 17.31 & 10.75 & 20.27 & 9.64 & 11.87 & 6.18 & 809 & Free moving \\
\hline Site 3(\%) & 0.24 & 1.46 & 1.46 & 3.64 & 3.88 & 13.11 & 10.68 & 24.51 & 11.17 & 16.02 & 13.83 & 412 & Influenced \\
\hline Site $4(\%)$ & 7.13 & 13.6 & 11.5 & 17.24 & 11.03 & 15.4 & 5.98 & 8.51 & 3.91 & 3.45 & 2.76 & 435 & Free moving \\
\hline Site $4(\%)$ & 4.52 & 8.39 & 7.10 & 12.26 & 7.74 & 21.94 & 11.61 & 8.39 & 5.81 & 3.87 & 9.68 & 155 & Influenced \\
\hline Site $5(\%)$ & 0.20 & 0.40 & 1.39 & 5.96 & 2.78 & 14.12 & 9.74 & 23.86 & 14.71 & 15.51 & 11.33 & 503 & Free moving \\
\hline Site $5(\%)$ & 0 & 0.47 & 0.23 & 1.87 & 2.34 & 12.18 & 9.37 & 24.36 & 12.88 & 18.74 & 17.56 & 427 & Influenced \\
\hline
\end{tabular}


Table 7 Frequency of Lateral Position Data under Visibility Condition for Free Moving Trucks at 5 Sites

\begin{tabular}{ccccccccccccccc}
\hline Deviation (ft) & $\mathbf{- 1 . 7 5}$ & $\mathbf{- 1}$ & $\mathbf{- 0 . 7 5}$ & $\mathbf{- 0 . 5}$ & $\mathbf{- 0 . 2 5}$ & $\mathbf{0}$ & $\mathbf{0 . 2 5}$ & $\mathbf{0 . 5}$ & $\mathbf{0 . 7 5}$ & $\mathbf{1}$ & $\mathbf{1 . 7 5}$ & Sample size & Visibility \\
\hline Site 1(\%) & 0.53 & 0.64 & 0.11 & 2.14 & 2.14 & 9.40 & 6.52 & 15.92 & 12.39 & 19.34 & 30.88 & 936 & day \\
Site 1(\%) & 2.47 & 0 & 0 & 0 & 0 & 1.24 & 1.24 & 4.94 & 3.70 & 14.81 & 71.6 & 81 & night \\
Site 2(\%) & 0.91 & 2.44 & 2.13 & 6.71 & 4.88 & 20.73 & 8.54 & 19.51 & 11.59 & 14.94 & 7.62 & 328 & day \\
Site 2(\%) & 4.88 & 0 & 1.22 & 3.66 & 4.88 & 12.20 & 9.76 & 18.29 & 12.20 & 15.85 & 17.07 & 82 & night \\
Site 3(\%) & 1.11 & 2.47 & 3.46 & 9.39 & 7.29 & 17.31 & 10.75 & 20.27 & 9.64 & 11.87 & 6.18 & 809 & day \\
Site 3(\%) & 0.54 & 1.63 & 1.09 & 2.72 & 1.63 & 9.78 & 6.52 & 16.85 & 13.59 & 16.30 & 29.35 & 184 & night \\
Site 4(\%) & 7.13 & 13.56 & 11.49 & 17.24 & 11 & 15.40 & 5.98 & 8.51 & 3.91 & 3.45 & 2.76 & 435 & day \\
Site 4(\%) & 5.63 & 7.81 & 7.5 & 15 & 7.5 & 17.5 & 12.19 & 12.81 & 5.63 & 5.31 & 3.13 & 320 & night \\
Site 5 (\%) & 0.20 & 0.40 & 1.39 & 5.96 & 2.78 & 14.12 & 9.74 & 23.86 & 14.71 & 15.51 & 11.33 & 503 & day \\
Site 5 (\%) & 4.17 & 5.56 & 2.78 & 2.78 & 2.78 & 8.33 & 8.33 & 22.22 & 15.28 & 15.28 & 12.50 & 72 & night
\end{tabular}

Table 8 Frequency of Lateral Position Data under Visibility Condition for Influenced Trucks at 5 Sites

\begin{tabular}{ccccccccccccccc}
\hline \hline Deviation (ft) & $\mathbf{- 1 . 7 5}$ & $\mathbf{- 1}$ & $\mathbf{- 0 . 7 5}$ & $\mathbf{- 0 . 5}$ & $\mathbf{- 0 . 2 5}$ & $\mathbf{0}$ & $\mathbf{0 . 2 5}$ & $\mathbf{0 . 5}$ & $\mathbf{0 . 7 5}$ & $\mathbf{1}$ & $\mathbf{1 . 7 5}$ & Sample size & Visibility \\
\hline Site 1(\%) & 0 & 0.46 & 0.46 & 0 & 0.46 & 4.85 & 3.93 & 12.93 & 8.78 & 22.63 & 45.96 & 433 & day \\
Site 1(\%) & 0 & 0 & 0 & 0 & 0 & 12.5 & 0 & 0 & 0 & 0 & 87.50 & 8 & night \\
Site 2(\%) & 0 & 1.02 & 0.51 & 7.14 & 2.55 & 11.22 & 11.22 & 17.35 & 18.37 & 15.31 & 15.31 & 196 & day \\
Site 2(\%) & 0 & 0 & 0 & 2.70 & 0 & 8.11 & 5.41 & 13.51 & 8.11 & 32.43 & 29.73 & 37 & night \\
Site 3(\%) & 0.24 & 1.46 & 1.46 & 3.64 & 3.88 & 13.11 & 10.68 & 24.51 & 11.17 & 16.02 & 13.83 & 412 & day \\
Site 3(\%) & 0 & 0 & 0 & 0 & 0 & 4.17 & 4.17 & 14.58 & 12.5 & 33.33 & 31.25 & 48 & night \\
Site 4(\%) & 4.52 & 8.39 & 7.10 & 12.26 & 7.74 & 21.94 & 11.61 & 8.39 & 5.81 & 3.87 & 9.68 & 155 & day \\
Site 4(\%) & 0.74 & 2.96 & 3.70 & 8.89 & 8.89 & 20.74 & 14.81 & 20.74 & 6.67 & 5.93 & 5.93 & 135 & night \\
Site 5 (\%) & 0 & 0.47 & 0.23 & 1.87 & 2.34 & 12.18 & 9.37 & 24.36 & 12.88 & 18.74 & 17.56 & 427 & day \\
Site 5 (\%) & 0 & 0 & 4.76 & 0 & 0 & 19.05 & 9.52 & 28.57 & 14.29 & 9.52 & 14.29 & 72 & night \\
\hline \hline
\end{tabular}


Table 9 Frequency of Lateral Position Data at Five Sites under Weather Condition for Free Moving Trucks

\begin{tabular}{|c|c|c|c|c|c|c|c|c|c|c|c|c|c|}
\hline $\begin{array}{c}\text { Deviation } \\
\text { (ft) }\end{array}$ & -1.75 & -1 & -0.75 & -0.5 & -0.25 & 0 & 0.25 & 0.5 & 0.75 & 1 & 1.75 & $\begin{array}{c}\text { Sample } \\
\text { size }\end{array}$ & Weather \\
\hline Site $1(\%)$ & 0.53 & 0.64 & 0.11 & 2.14 & 2.14 & 9.4 & 6.52 & 15.92 & 12.39 & 19.34 & 30.88 & 936 & sunny \\
\hline Site $1(\%)$ & 0 & 1.43 & 0.71 & 5 & 0.71 & 5.71 & 10 & 29.29 & 12.86 & 12.86 & 21.43 & 140 & Rainy \\
\hline Site $1(\%)$ & 0.23 & 1.15 & 0.46 & 2.98 & 1.83 & 9.86 & 5.96 & 12.84 & 10.32 & 16.06 & 38.3 & 436 & windy \\
\hline Site $2(\%)$ & 0.91 & 2.44 & 2.13 & 6.71 & 4.88 & 20.73 & 8.54 & 19.51 & 11.59 & 14.94 & 7.62 & 328 & sunny \\
\hline Site $2(\%)$ & 0.7 & 2.1 & 0 & 4.9 & 4.9 & 24.48 & 7.69 & 18.88 & 16.78 & 13.99 & 5.59 & 143 & rainy \\
\hline Site $2(\%)$ & 0.76 & 4.09 & 3.94 & 8.64 & 6.52 & 19.09 & 11.5 & 12.88 & 9.55 & 12.73 & 10.3 & 660 & windy \\
\hline Site $3(\%)$ & 1.11 & 2.47 & 3.46 & 9.39 & 7.29 & 17.31 & 10.75 & 20.27 & 9.64 & 11.87 & 6.18 & 809 & Sunny \\
\hline Site $3(\%)$ & 0 & 0 & 1.61 & 12.9 & 1.61 & 19.35 & 11.29 & 24.19 & 12.9 & 12.9 & 3.23 & 62 & rainy \\
\hline Site $3(\%)$ & 0.76 & 2.66 & 3.42 & 7.61 & 5.7 & 22.05 & 11.41 & 21.67 & 8.37 & 9.89 & 6.46 & 263 & windy \\
\hline Site $4(\%)$ & 7.13 & 13.56 & 11.49 & 17.24 & 11 & 15.4 & 5.98 & 8.51 & 3.91 & 3.45 & 2.76 & 435 & sunny \\
\hline Site $4(\%)$ & 4.21 & 5.26 & 3.16 & 14.74 & 9.47 & 25.26 & 7.37 & 12.63 & 5.26 & 6.32 & 6.32 & 95 & rainy \\
\hline Site $4(\%)$ & 10.53 & 15.79 & 7.89 & 15.79 & 2.63 & 23.68 & 7.89 & 7.9 & 5.26 & 0 & 2.63 & 38 & windy \\
\hline Site $5(\%)$ & 0.2 & 0.4 & 1.39 & 5.96 & 2.78 & 14.12 & 9.74 & 23.86 & 14.71 & 15.51 & 11.33 & 503 & Sunny \\
\hline Site 5 (\%) & 1.29 & 1.29 & 1.29 & 7.1 & 2.58 & 19.35 & 9.03 & 25.16 & 14.19 & 12.9 & 5.81 & 155 & rainy \\
\hline Site 5 (\%) & 1.15 & 1.53 & 0.77 & 5.56 & 4.41 & 22.03 & 9.39 & 29.12 & 9.58 & 12.26 & 4.22 & 522 & windy \\
\hline
\end{tabular}


Table 10 Frequency of lateral position data at five sites under weather condition for influenced trucks

\begin{tabular}{|c|c|c|c|c|c|c|c|c|c|c|c|c|c|}
\hline $\begin{array}{c}\text { Deviation } \\
(\mathrm{ft})\end{array}$ & -1.75 & -1 & -0.75 & -0.5 & -0.25 & 0 & 0.25 & 0.5 & 0.75 & 1 & 1.75 & $\begin{array}{l}\text { Sample } \\
\text { size }\end{array}$ & Weather \\
\hline Site 1(\%) & 0 & 0.46 & 0.46 & 0 & 0.46 & 4.85 & 3.93 & 12.93 & 8.78 & 22.63 & 45.96 & 433 & sunny \\
\hline Site $1(\%)$ & 0 & 0 & 0 & 0 & 0 & 1.64 & 4.92 & 16.39 & 13.11 & 18.03 & 45.9 & 61 & Rainy \\
\hline Site $1(\%)$ & 0 & 0.38 & 0 & 0.38 & 1.51 & 6.04 & 7.92 & 15.85 & 7.55 & 18.11 & 42.26 & 265 & windy \\
\hline Site $2(\%)$ & 0 & 1.02 & 0.51 & 7.14 & 2.55 & 11.22 & 11.22 & 17.35 & 18.37 & 15.31 & 15.31 & 196 & sunny \\
\hline Site $2(\%)$ & 1.49 & 1.49 & 0 & 0 & 5.97 & 8.96 & 10.45 & 10.45 & 13.43 & 32.84 & 14.93 & 67 & rainy \\
\hline Site $2(\%)$ & 0.39 & 0.39 & 1.17 & 3.13 & 3.91 & 16.02 & 6.25 & 15.23 & 10.94 & 23.44 & 19.14 & 256 & windy \\
\hline Site $3(\%)$ & 0.24 & 1.46 & 1.46 & 3.64 & 3.88 & 13.11 & 10.68 & 24.51 & 11.17 & 16.02 & 13.83 & 412 & Sunny \\
\hline Site $3(\%)$ & 0 & 0 & 3.03 & 6.06 & 0 & 6.06 & 3.03 & 15.15 & 27.27 & 27.27 & 12.12 & 33 & rainy \\
\hline Site $3(\%)$ & 0 & 0 & 3.64 & 2.73 & 2.73 & 15.45 & 5.46 & 21.82 & 13.64 & 25.45 & 9.09 & 110 & windy \\
\hline Site $4(\%)$ & 4.52 & 8.39 & 7.1 & 12.26 & 7.74 & 21.94 & 11.6 & 8.39 & 5.81 & 3.87 & 9.68 & 155 & sunny \\
\hline Site $4(\%)$ & 0 & 3.33 & 0 & 6.67 & 6.67 & 13.33 & 20 & 23.33 & 10 & 13.33 & 3.33 & 30 & rainy \\
\hline Site $4(\%)$ & 0 & 4.17 & 16.67 & 12.5 & 12.5 & 16.67 & 4.17 & 16.67 & 8.33 & 4.17 & 4.17 & 24 & windy \\
\hline Site 5 (\%) & 0 & 0.47 & 0.23 & 1.87 & 2.34 & 12.18 & 9.37 & 24.36 & 12.88 & 18.74 & 17.56 & 427 & Sunny \\
\hline Site $5(\%)$ & 0.86 & 0.86 & 0 & 6.03 & 1.72 & 17.24 & 9.48 & 24.14 & 13.79 & 18.97 & 6.9 & 116 & rainy \\
\hline Site 5 (\%) & 0.33 & 1.31 & 0.66 & 2.62 & 3.61 & 14.1 & 10.82 & 29.18 & 14.1 & 13.11 & 10.16 & 305 & windy \\
\hline
\end{tabular}




\section{Plotting of Lateral Position Distribution}

Based on the presented data, geometric characteristics of road, visibility, traffic condition, and weather will impact trucks' track shift towards the left- or right- side of the lane. Lateral position distribution under different situations can be presented as follows:

1) Effect of Road Curve on Lateral Position Distribution

Figure 30 shows the lateral position distribution of the trucks at the five test sites. It is shown that the wheel positions at the four test sites (\#1, \#2, \#3, and \#5) shift to the right side of the lane except for test site \#4. In addition, the chart also indicates that most trucks at test site \#1 were travelling near the right-side edge of pavement.

In this case, the lateral position distribution in straight road section (test site \#5) was taken as a reference, and the effect of road curve on lateral position can be stated as follows:

- Near road curve - The trucks travelling near the road curve shift towards the rightside edge of the curve.

- In road curve - The trucks travelling in the road curve shift towards the left-side edge of the pavement lane.

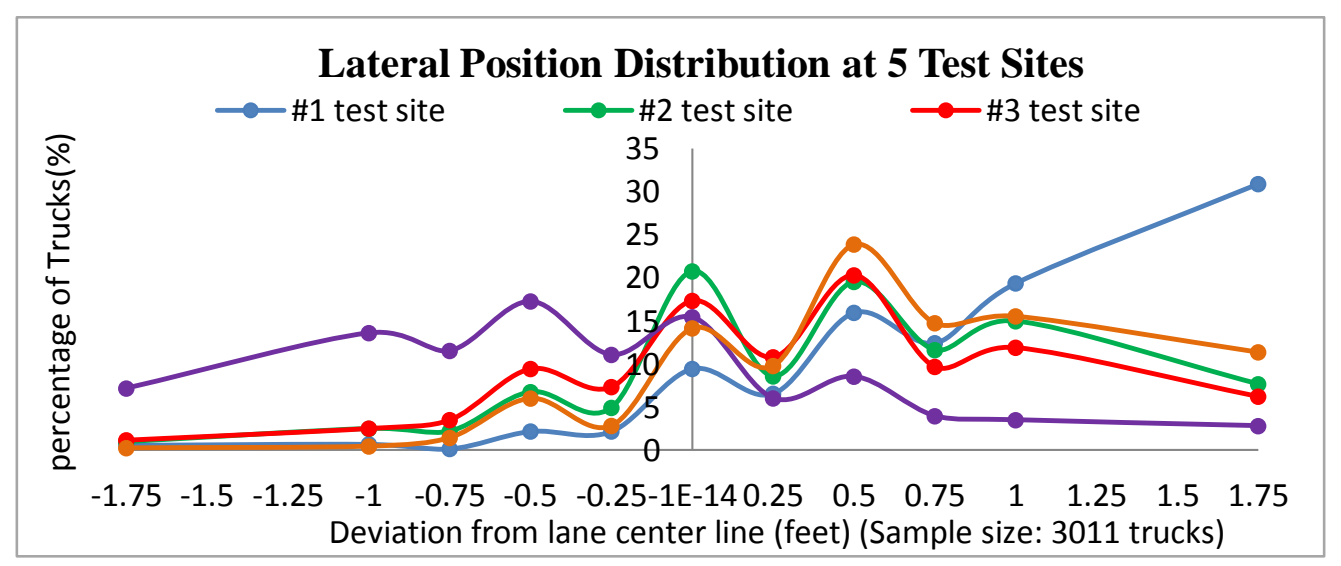

Figure 30 Plotting of lateral position distribution at five test sites 
Two types of traffic condition in four-way divided highway can be considered in this research: free moving trucks not influenced by other vehicles; and influenced trucks influenced by parallel vehicles traveling in the same direction. Figure 31 shows the relative frequency of the lateral position distribution for free moving and influenced trucks. As this figure shows, the blue curve represents the lateral position distribution for free moving trucks, and the red curve represents the lateral position distribution for influenced trucks. Based on the charts from (a) to (e), one or two intersections between free moving and influenced vehicles can be observed, and these intersections can be regarded as the thresholds to investigate the influence of traffic condition on the lateral position distribution of trucks: on the left of the intersection, the blue line is above red line, while on the right side of the intersection, the blue line is under red line. These charts indicate that the influenced trucks are more inclined to shift to the right side of the lane than free moving trucks. 

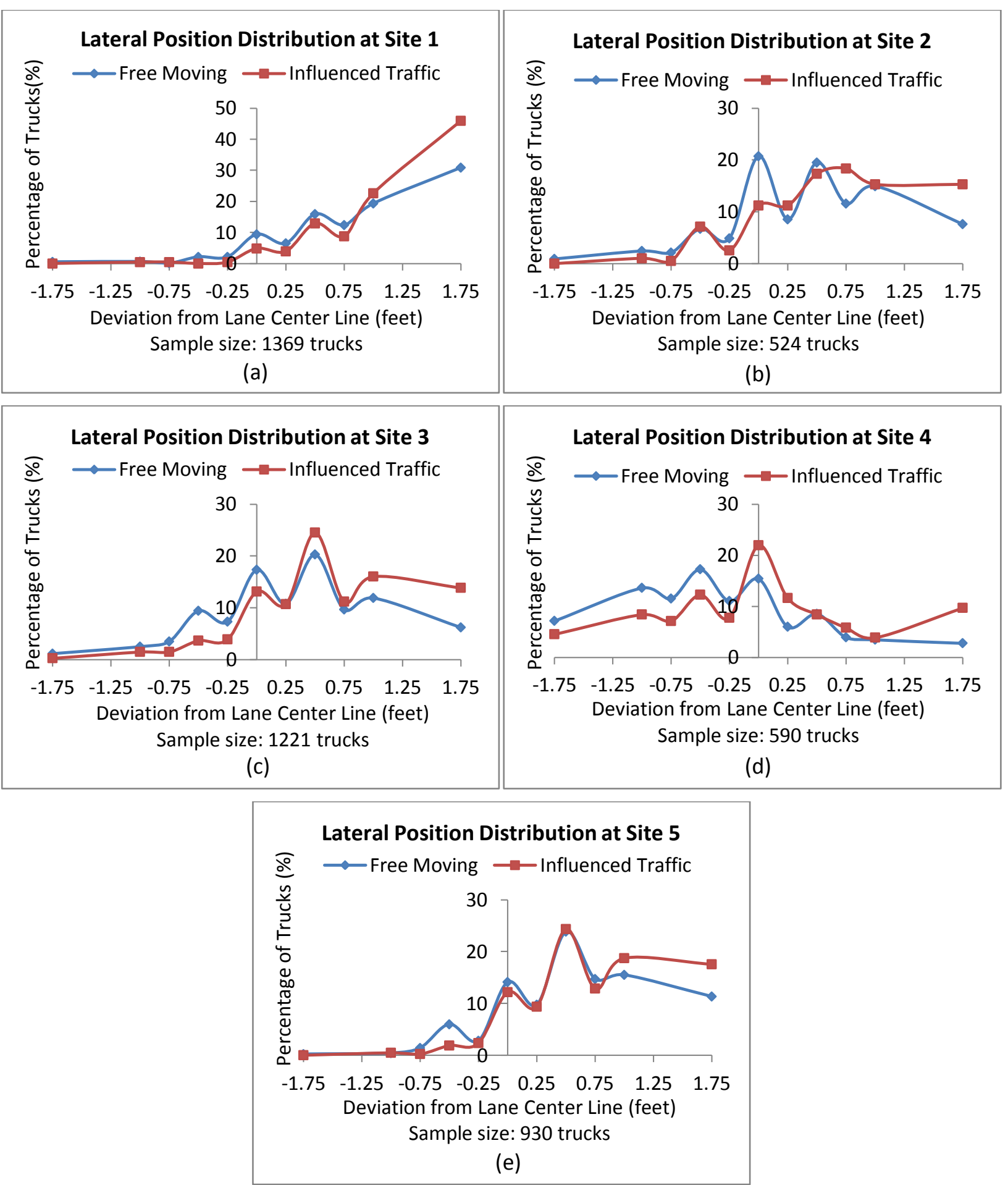

Figure 31 Plotting of lateral position distribution in two modes: free moving and influenced traffic at (a) Site 1; (b) Site 2; (c) Site 3; (d) Site 4; (e) Site 5 
The lateral position distribution at the five test sites during day and at night for free moving and influenced trucks was shown in Figure 32. The F1-day and F1-night in Figure 32 (a), (c), (e), (g), and (i) represent the lateral position distribution with free moving trucks in day-time and nighttime, respectively. Similarly, I1-day and I1-night in Figure 32 (b), (d), (f), (h), and (j) represent the lateral position distribution under influenced trucks in day-time and night-time, respectively.

The wheel position in night time is different from that in day time since the white edge marking at night were more visible than those in day time. Based on the distribution of lateral position data, the following findings can be drawn:

- The wheel positions in night time were much closer to the right side of the lane than those in day time;

- The wheel position of influenced trucks was much closer to the pavement edge than those of free moving trucks when driving in darkness. 


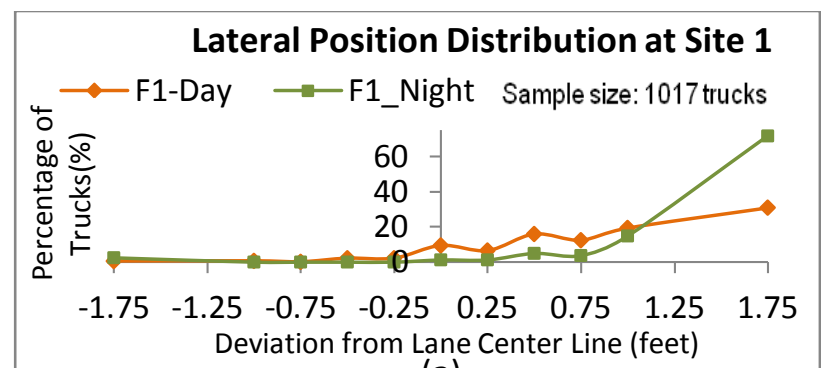

(a)
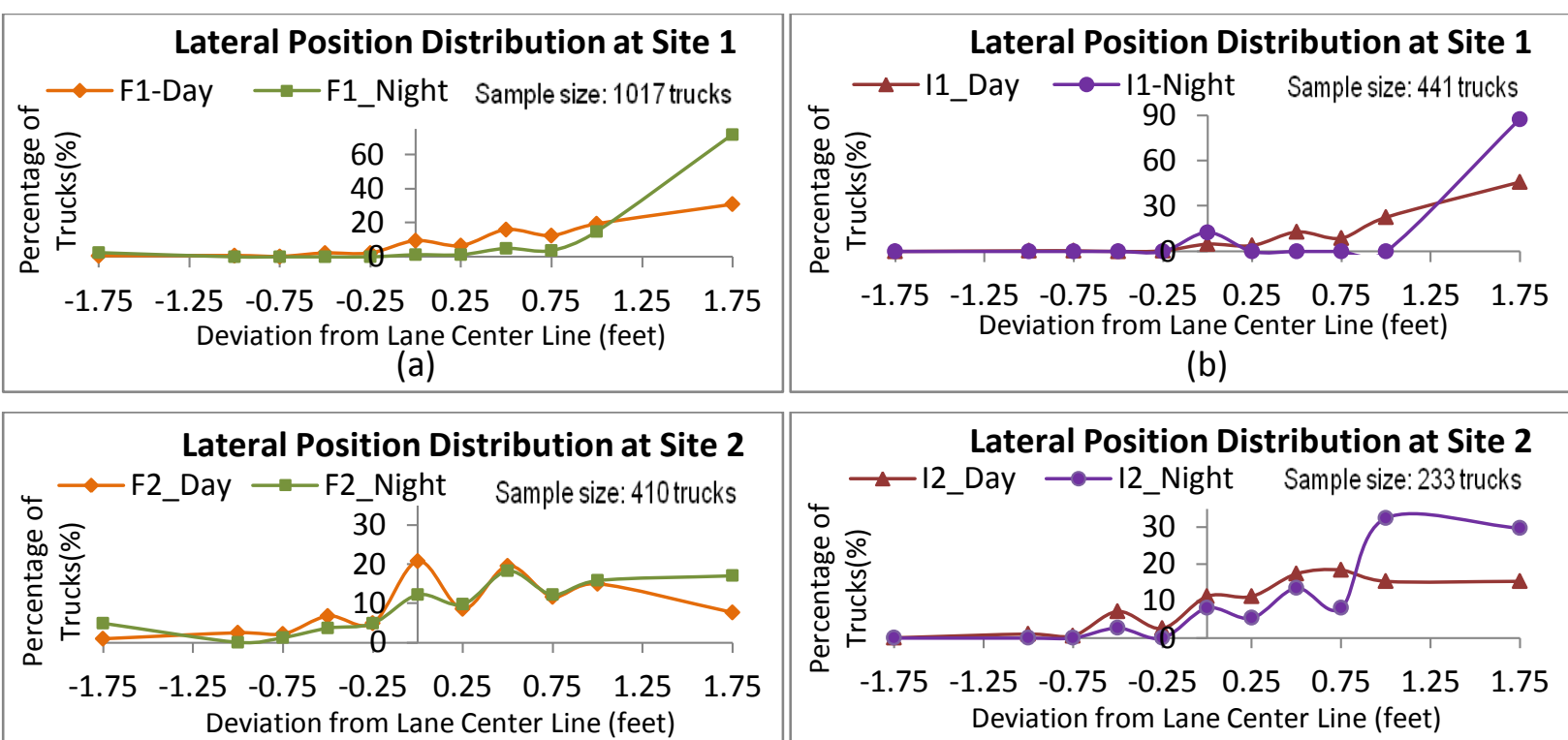

(c)

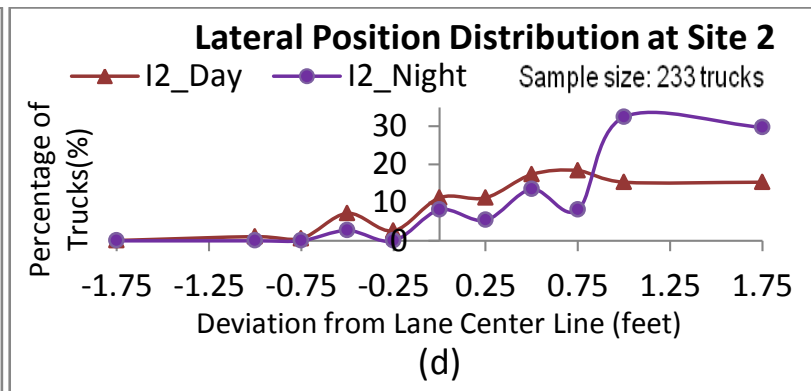

(d)

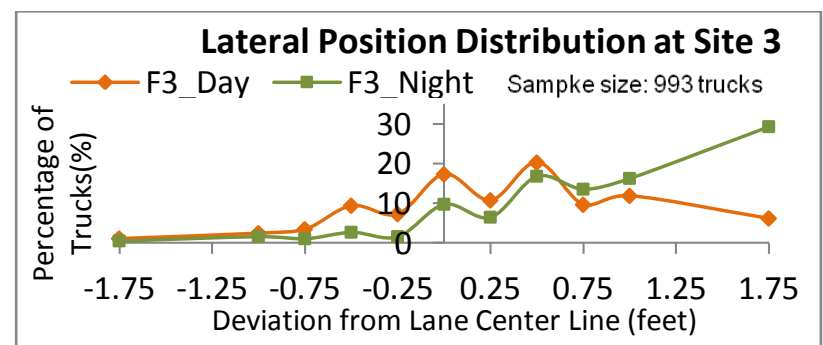

(e)

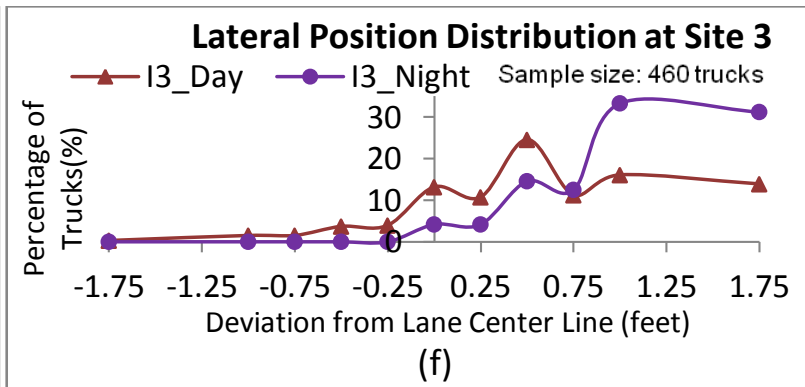

(f)

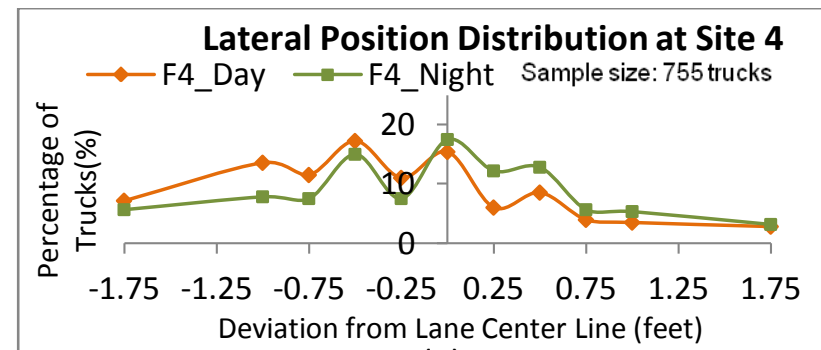

(g)

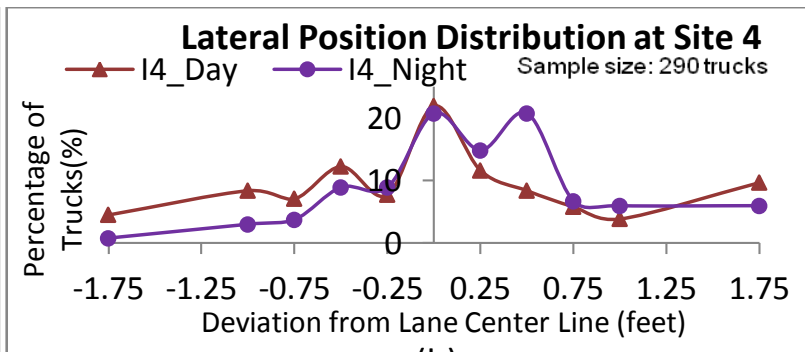

(h)

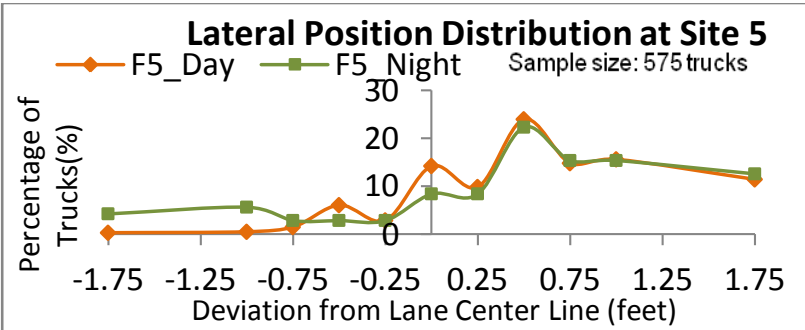

(i)

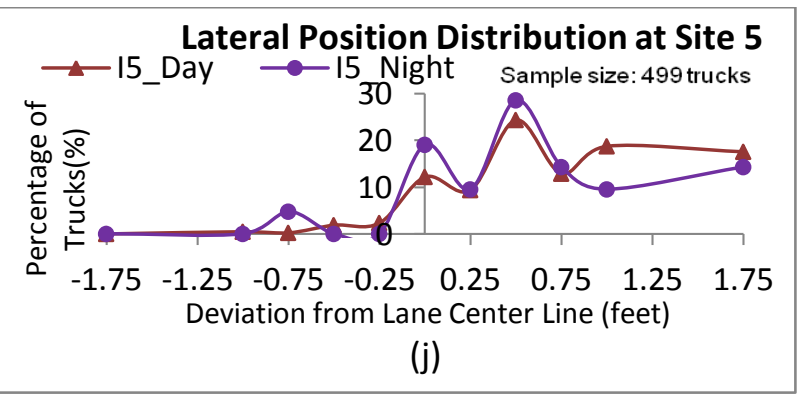

Figure 32 Plotting of lateral position distribution in two modes: in daytime and nighttime

at (a) Site 1 (free moving); (b) Site 1 (influenced); (c) Site 2 (free moving); (d) Site 2

(influenced); (e) Site 3 (free moving); (f) Site 3 (influenced); (g) Site 4 (free moving); (h) Site 4 (influenced); (i) Site 5 (free moving); (j) Site 5 (influenced); 
Figure 33 ((a), (c), (e), (g), and (i)) shows the lateral position distribution at the five test sites for free moving trucks. F1-sunny, F1- Windy, and F1- Rainy represent the lateral position distribution for free moving trucks in sunny, windy, and rainy days, respectively. Similarly, Figure 33 ((b), (d), (f), (h), and (j)) shows the lateral position distribution at the five test sites for influenced trucks, and I1-sunny, I1- Windy, and I1- Rainy represent the lateral position distribution for influenced trucks in sunny, windy, and rainy days respectively.

The effect of weather condition on lateral position can be observed after combining with the traffic condition and road geometric characteristics, and the following findings can be drawn:

- Traffic condition - The effect of weather condition on wheel shift for free moving trucks is smaller than those for influenced trucks. In particular, trucks in free moving mode tend to travelling on the lane center in the rainy and windy days; while the trucks in influenced mode tend to shift to the edge of the pavement in the rainy and windy days.

- Road geometric characteristics - The effect of weather condition on wheel shift in the straight road is smallest among these five road test sites, which indicated the road curve would aggravate the influence of weather condition on wheel shift. 


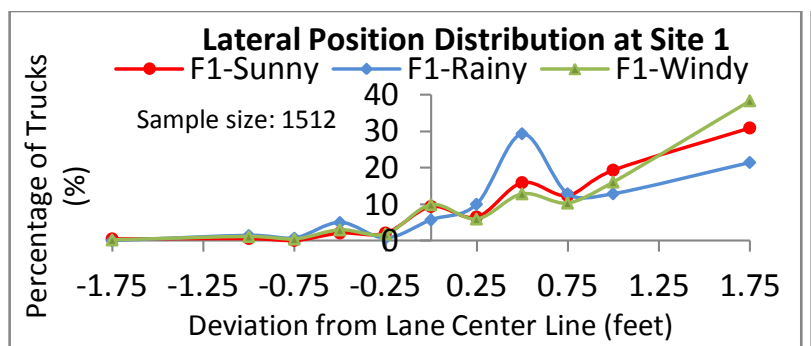

(a)

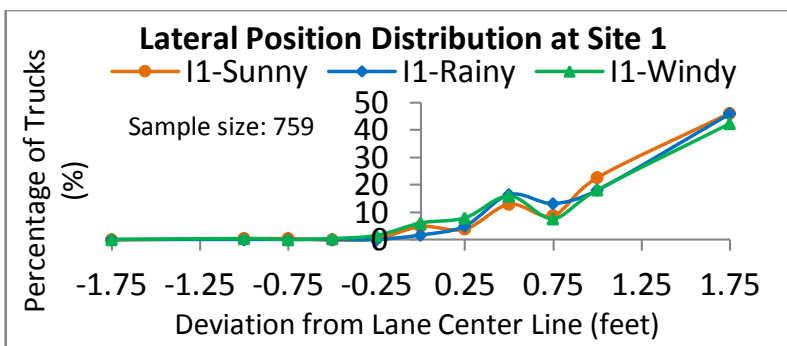

(b)

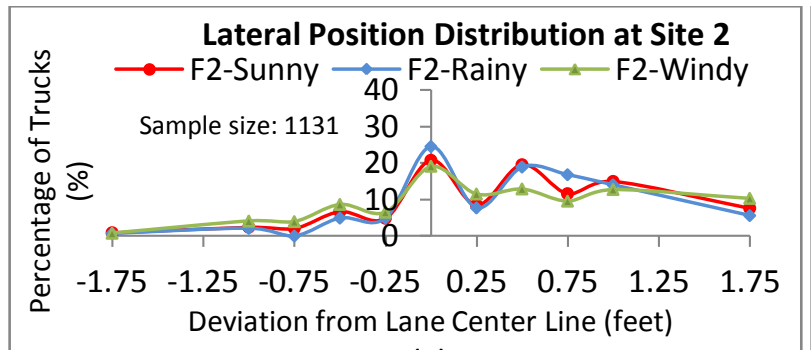

(c)

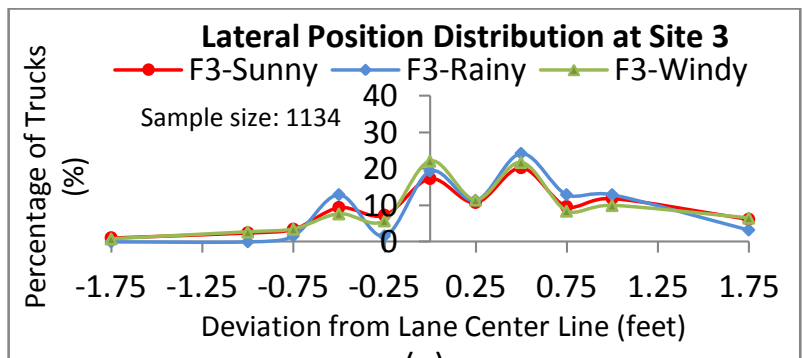

(e)

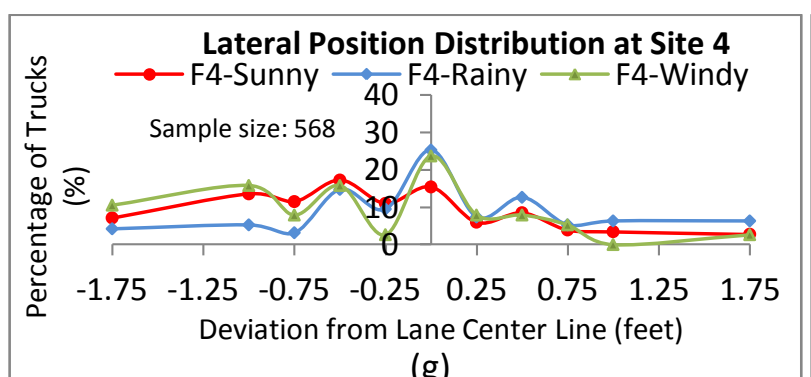

(g)

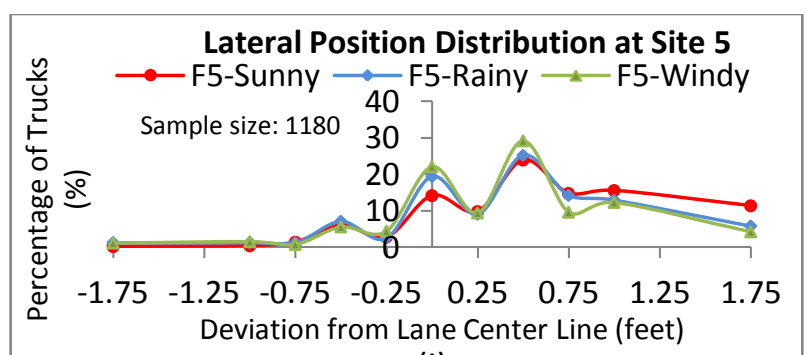

(i)

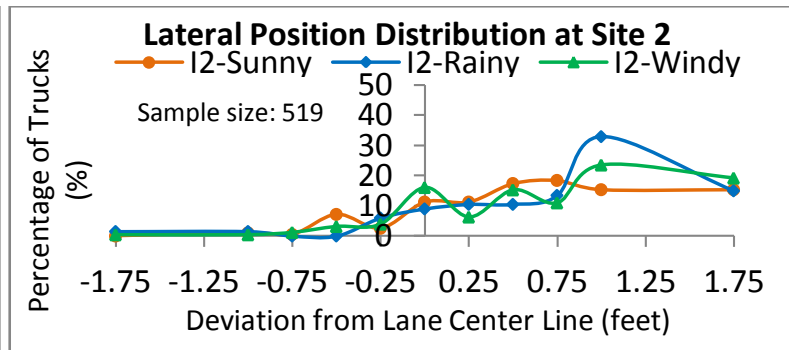

(d)

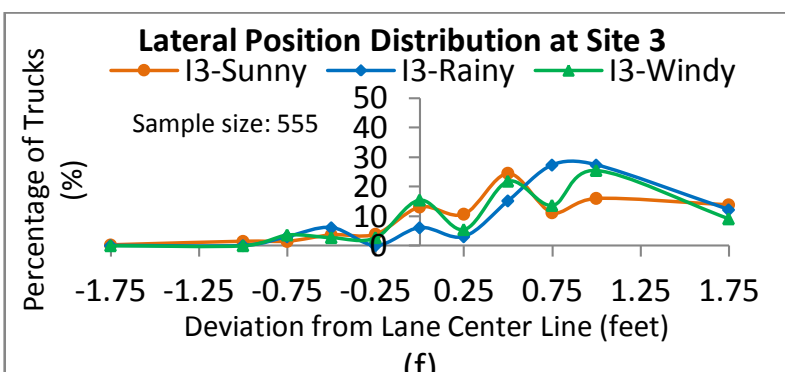

(f)
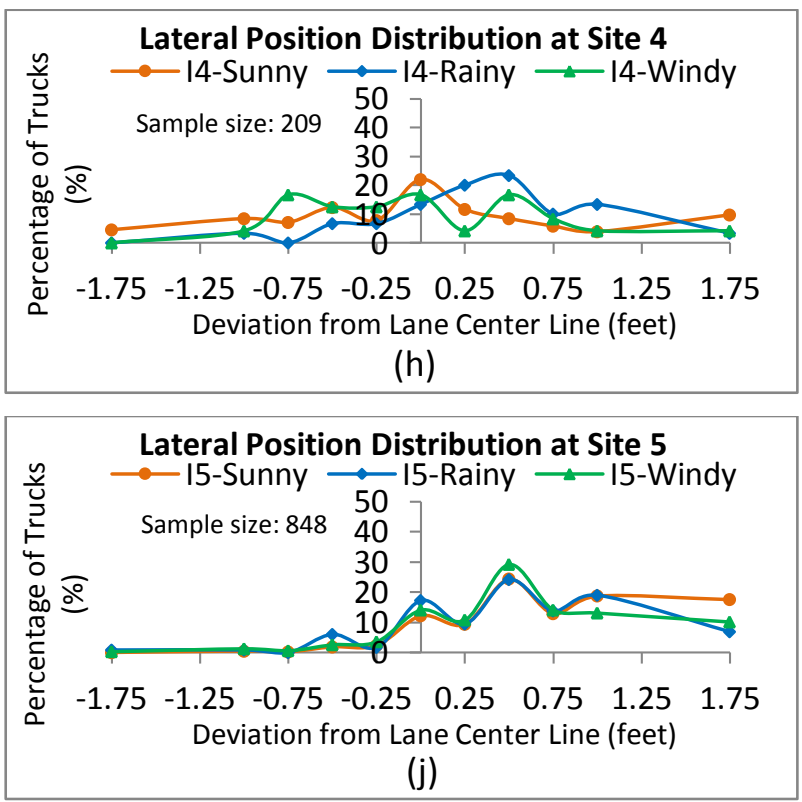

Figure 33 Lateral position distribution in three modes: traffic on sunny, windy and rainy weather at (a) Site 1 (free moving); (b) Site 1 (influenced); (c) Site 2 (free moving); (d) Site 2 (influenced); (e) Site 3 (free moving); (f) Site 3 (influenced); (g) Site 4 (free moving); (h) Site 4 (influenced); (i) Site 5 (free moving); (j) Site 5 (influenced); 


\section{B. ANOVA Test}

Analysis of the effect of influencing factors on wheel shift through visual plotting only provides preliminary indications of truck wheel wandering. However, the statistic method can quantitatively measure the effect of factors on wheel shift. Based on the test results, the factors can be ranked by their effect on wheel shift. Herein, the hypothesis test suitable for testing the difference of the data set was applied in this research. A hypothesis is a specific conjecture (statement) about a property of a population of interest. A null hypothesis is a specific baseline statement to be tested and it usually takes such forms as "no effect" or "no difference."(Cohen and Jacob, 1988) An alternative (research) hypothesis is denial of the null hypothesis. Researchers often, but not always, expect that evidence supports the alternative hypothesis.

\section{Traditional ANOVA Test}

Analysis of variance (ANOVA) is a general technique that can be used to test the hypothesis that the variations among two or more groups are equal. ANOVA is a collection of statistical methods, which separates the total variation into two disjoint source of variation. In ANOVA test, three sums of squares were calculated to measure the variations along with their degrees of freedom $(d f)$. Equations $1-11$ to calculate three sums of squares and F-Value are given as follows (Faraway, 2004):

$$
\begin{aligned}
& \text { Total variati }=\text { Variation between groups }(\text { treatements }) \\
& + \text { Variation } \text { within groups }(\text { treatments } \\
& \begin{aligned}
\text { Deviation }= & \text { Observation }- \text { Grand meean } \\
& =(\text { mean of each group }- \text { grand mean }) \\
& +(\text { observation }- \text { mean of each group })
\end{aligned}
\end{aligned}
$$




$$
\begin{gathered}
S S_{T o t}=S S_{T r t}+S S_{E r r} \\
d f_{T o t}=d f_{T r t}+d f_{\text {Err }} \\
S S_{\text {Tot }}=\sum(\text { observation }- \text { grand mean })^{2} \\
d f_{\text {Tot }}=n_{1}+n_{2}-1 \\
S S_{\text {Trt }}=\sum(\text { mean of each group }- \text { grand mean })^{2} \\
d f_{\text {Trt }}=\# \text { of groups }-1 \\
d(\text { observation }- \text { mean of each group })^{2} \\
d f_{\text {Err }}=\left(n_{1}-1\right)+\left(n_{2}-1\right) \\
F-\text { Value }=\frac{M S_{\text {Trt }}}{M S_{\text {Err }}}
\end{gathered}
$$

Where:

$S S_{T o t}-$ Total sum of squares;

$S S_{T r t}-$ Treatment sum of squares (Explains the variation between groups)

$S S_{E r r}-$ Error sum of squares (Explains the variation within groups)

$M S_{T r t}-$ Mean of Treatment sum of squares

$M S_{E r r}{ }^{--}$Mean of Error sum of squares

F-Value -- Used to verify the hypothesis

Herein, the F-Value always transform to P-Value to verify the hypothesis. There are five levels for P-Value: $0-0.001,0.01-0.01,0.01-0.05,0.05-0.1,0.1-1$. The smaller P-Value represents that the alternative hypothesis is more significant. 
The ANOVA test is always used for determining the amount of the differences between two or more group data. However, there is some limitation for traditional ANOVA Test:

- The ANOVA Test cannot test the difference of the distribution in addition to testing the difference of the quantity for each group data.

- If each group data have the same sample size or the sum is the same for each data, such as probability data, the ANOVA Test is useless.

\section{2. $\quad$ Equal Quantity ANOVA Test}

In this research, the purpose to use the statistic method is to measure the difference of the distribution for each group data. The tested data, lateral position of heavy vehicles, are probability distribution data. The traditional ANOVA Test cannot satisfy the requirement of this

study, thereby an improved method was developed and employed to conduct the ANOVA Test. According to the function of the improved ANOVA Test, it is named as equal quantity ANOVA Test in this study. Based on the traditional ANOVA Test, the data preprocessing was integrated into the equal quantity ANOVA Test. The following procedures illustrate the difference between the traditional ANOVA Test and equal quantity ANOVA Test.

- Define Data Set:

$$
\begin{gathered}
A=\left(a_{1}, a_{2}, a_{3} \ldots a_{n}\right) \\
B=\left(b_{1}, b_{2}, b_{3} \ldots b_{n}\right) \\
C=\left(c_{1}, c_{2}, c_{3} \ldots c_{n}\right) \\
\ldots \\
R=\left(r_{1}, r_{2}, r_{3} \ldots r_{n}\right)
\end{gathered}
$$


- Traditional ANOVA Test:

Test the variations of data set: “A", "B", "C"... "R".

The hypothesis:

$$
\left\{\begin{array}{l}
H_{0}: \sigma_{A}^{2}=\sigma_{B}^{2}=\sigma_{C}^{2} \ldots=\sigma_{R}^{2} \\
H_{a}: \sigma_{A}^{2} \neq \sigma_{B}^{2} \neq \sigma_{C}^{2} \ldots \neq \sigma_{R}^{2}
\end{array}\right.
$$

Where:

$$
\sigma^{2} \text { : Variation of lateral position frequency data; }
$$

- Equal quantity ANOVA Test:

$>$ In test data set, define the original or the non-influenced data as reference data:

Reference data: $R=\left(r_{1}, r_{2}, r_{3} \ldots r_{n}\right)$

Calculate the difference between the reference data and other influenced data:

$$
\begin{aligned}
& A_{D}=\left(a_{1}-r_{1}, a_{2}-r_{2}, a_{3}-r_{3}, \ldots, a_{n}-r_{n}\right) \\
& B_{D}=\left(b_{1}-r_{1}, b_{2}-r_{2}, b_{3}-r_{3}, \ldots, b_{n}-r_{n}\right) \\
& C_{D}=\left(c_{1}-r_{1}, c_{2}-r_{2}, c_{3}-r_{3}, \ldots, c_{n}-r_{n}\right)
\end{aligned}
$$

Obtain the absolute value (new data set):

$$
\begin{aligned}
& A_{D}^{\prime}=\left(\left|a_{1}-r_{1}\right|,\left|a_{2}-r_{2}\right|,\left|a_{3}-r_{3}\right|, \ldots,\left|a_{n}-r_{n}\right|\right) \\
& B_{D}^{\prime}=\left(\left|b_{1}-r_{1}\right|,\left|b_{2}-r_{2}\right|,\left|b_{3}-r_{3}\right|, \ldots,\left|b_{n}-r_{n}\right|\right) \\
& C^{\prime}{ }_{D}=\left(\left|c_{1}-r_{1}\right|,\left|c_{2}-r_{2}\right|,\left|c_{3}-r_{3}\right|, \ldots,\left|c_{n}-r_{n}\right|\right)
\end{aligned}
$$


Test the variations of new data set: “ $A_{D}^{\prime}{ }_{D}$ " " $B_{D}^{\prime}{ }^{\prime}$, " $C^{\prime}{ }_{D}$ " $\ldots$

The hypothesis:

$$
\left\{\begin{array}{l}
H_{0}: \sigma_{A^{\prime} D}^{2}=\sigma_{B^{\prime} D}^{2}=\sigma_{C^{\prime} D}^{2}=\cdots \\
H_{a}: \sigma_{A^{\prime} D}^{2} \neq \sigma_{B^{\prime} D}^{2} \neq \sigma_{C^{\prime} D}^{2} \neq \cdots
\end{array}\right.
$$

Where:

$$
\sigma^{2} \text { : Variation of lateral position frequency data; }
$$

The equal quantity ANOVA Test is suitable for these tests:

* Each group in data set has the same sample size or the test data is probability data;

* In data set, one group data can be considered as standard to test other group data;

* Each group data has equal numbers of elements;

The aim of the test is to test the distribution, not the quantity.

\section{R Project Software}

In order to obtain more accurate results from the test, statistical software, $R$ project, was selected for calculation in this thesis, which is an open source and freely available software environment, based on the $\mathrm{S}$ language originally developed at the Bell (AT\&T) Laboratories. The $\mathrm{S}$ language was designed for the purpose of data handling and analysis, marking it an attractive tool to the applied statistician and econometrician. This, together with powerful graphics utilities, marks $\mathrm{R}$ ideal for a time series analysis. Available libraries provide a range of functions especially suited to econometrics and finance, marking $\mathrm{R}$ a strong competitor to specialist financial software; $\mathrm{R}$ is also supported by a number of internationally recognized economic and finance groups and university departments (www.r-project.org). 


\section{Analysis of Single Factor based on One-way ANOVA Test}

Several situations would be covered in each test-factor. For instance, the weather condition can be explored in the sunny, rainy, and windy days. The purpose of One-way ANOVA Test used in this thesis is to compare and evaluate the effect of each individual situation under every testfactor. The F-value and P-value from ANOVA Test indicate the refusal or acceptance of the hypothesis. Typically, the greater F-value and smaller P-value indicated the difference of the variation is significant.

\section{Test Results for Road Curve}

Based on the geometric design of the pavement, the road sections can be divided into near the left turn curve, near the right turn curve, in the right turn curve, in the left turn curve, and in the straight road. For this test-factor, the situation of pavement section in the straight road was considered as a reference to analyze the effect of the other four road sections on wheel shift. Figure 34 shows the mean of absolute differences of lateral position data at each individual deviation level (distributed along with the horizontal axis, e.g.,--.05, -0.25, 0.25, and 0.5 feet) between those four test sites (\#1, \#2, \#3,and\#4) and at the reference test site (\#5). 


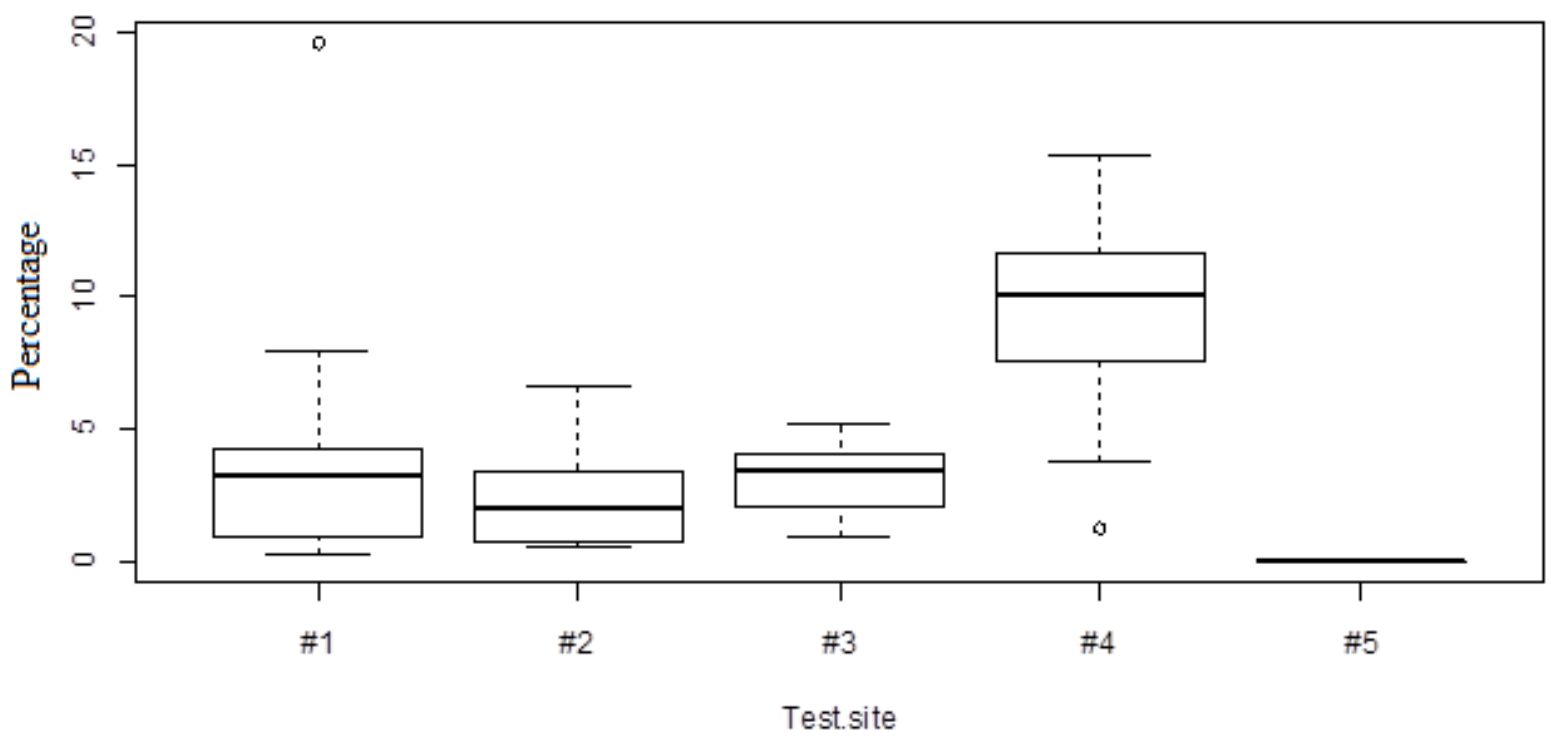

Figure 34 Absolute Values of the Differences of Lateral Position between Reference Situation (Site 5) and the other Four Test Sites

Based on the F-value or P-value calculated by one-way ANOVA test, the rank of the effects of road curve on lateral position were obtained as shown in Table 11. By comparing with the test site in the straight road, the lateral position distribution in the left turn curve with the maximum variation can be obtained, while the effect of the road section (near left turn curve) with the minimum variation can be observed as well.

Table 11 ANOVA Test Results at Five Test Sites

\begin{tabular}{cccc}
\hline Rank of Signification (Road curve) & Test site & F-value (F=MSTrt/MSErr) & P-value \\
\hline 1 & $\# 4$ & 55.745 & $3.33 \mathrm{E}-07$ \\
2 & $\# 3$ & 49.63 & $7.84 \mathrm{E}-07$ \\
3 & $\# 2$ & 16.446 & 0.00062 \\
4 & $\# 1$ & 6.8079 & 0.01679 \\
\hline
\end{tabular}

\section{Test Results for Traffic Condition}

The ideal traffic condition is free moving condition, in which no traffic interrupts or influences the tested trucks. The other traffic situation is called influenced trucks, in which the tested trucks 
will be affected by parallel vehicles travelling in the same direction. For the four-lane divided highway, the trucks always tend to shift to the right side of the lane to keep away from the traffic traveling on the left lane. The lateral position for free moving trucks is considered as a reference to examine the effect of influenced vehicles on wheel shift. Figure 35 shows the mean of absolute values of the difference of the lateral position between free moving trucks and influenced trucks at each test site.

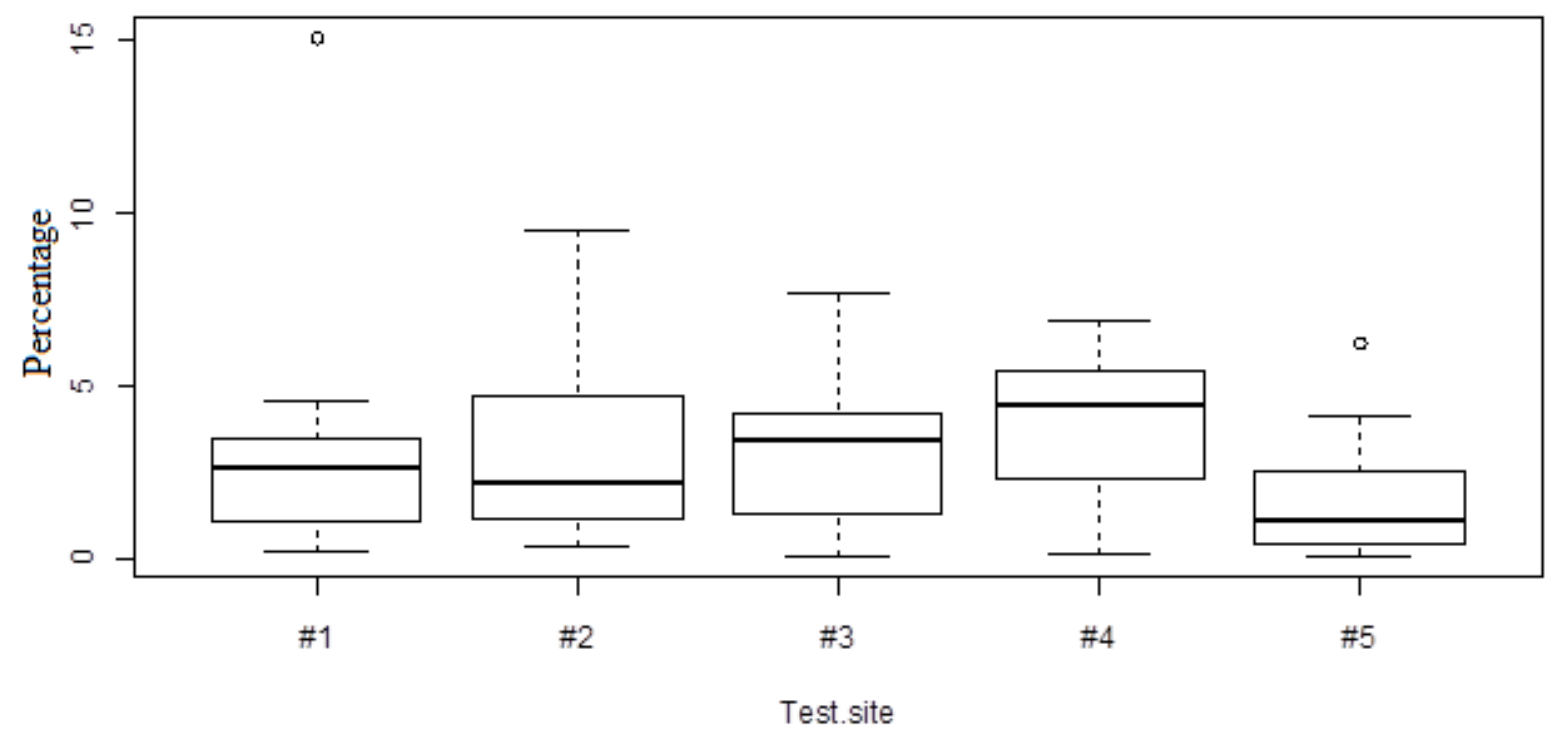

Figure 35 Absolute Values of the Differences of the Lateral Position Data between Reference Situation and the Other Four Test Sites

Similarly, based on the F-value and P-value listed in Table 12, the effect of the traffic condition at five test sites can be ranked as shown in Table 12, and the effect of parallel vehicles on test trucks' wheel shift at test site \#4 (in the left turn curve) is most distinguished among these five test sites, followed by test sites \#3, \#2, \#5, and \#1. 
Table 12 ANOVA Test Results for Influenced Trucks at Five Test Sites

\begin{tabular}{cccc}
\hline Rank of Signification (Traffic condition) & Test site & F-value(F=MSTrt/MSErr) & P-value \\
\hline 1 & $\# 4$ & 29.409 & $2.62 \mathrm{E}-05$ \\
2 & $\# 3$ & 20.644 & 0.0002 \\
3 & $\# 2$ & 11.549 & 0.00285 \\
4 & $\# 5$ & 9.508 & 0.00586 \\
5 & $\# 1$ & 7.2714 & 0.01388 \\
\hline
\end{tabular}

\section{Test Results for Visibility Condition}

It is well known that there are different visibility conditions in the day-time and night- time. In this study, the lateral position data in day time was considered as a reference to investigate the effect of darkness on wheel shift. Furthermore, the test was conducted on two group data, namely free moving and influenced trucks at five test sites since the effect of visibility on wheel shift varies with test sites and traffic condition. Figure 36 and 37 shows the mean of absolute values of the difference of the lateral position between the day-time and the night-time at each test site for free moving trucks and influenced truck, respectively.

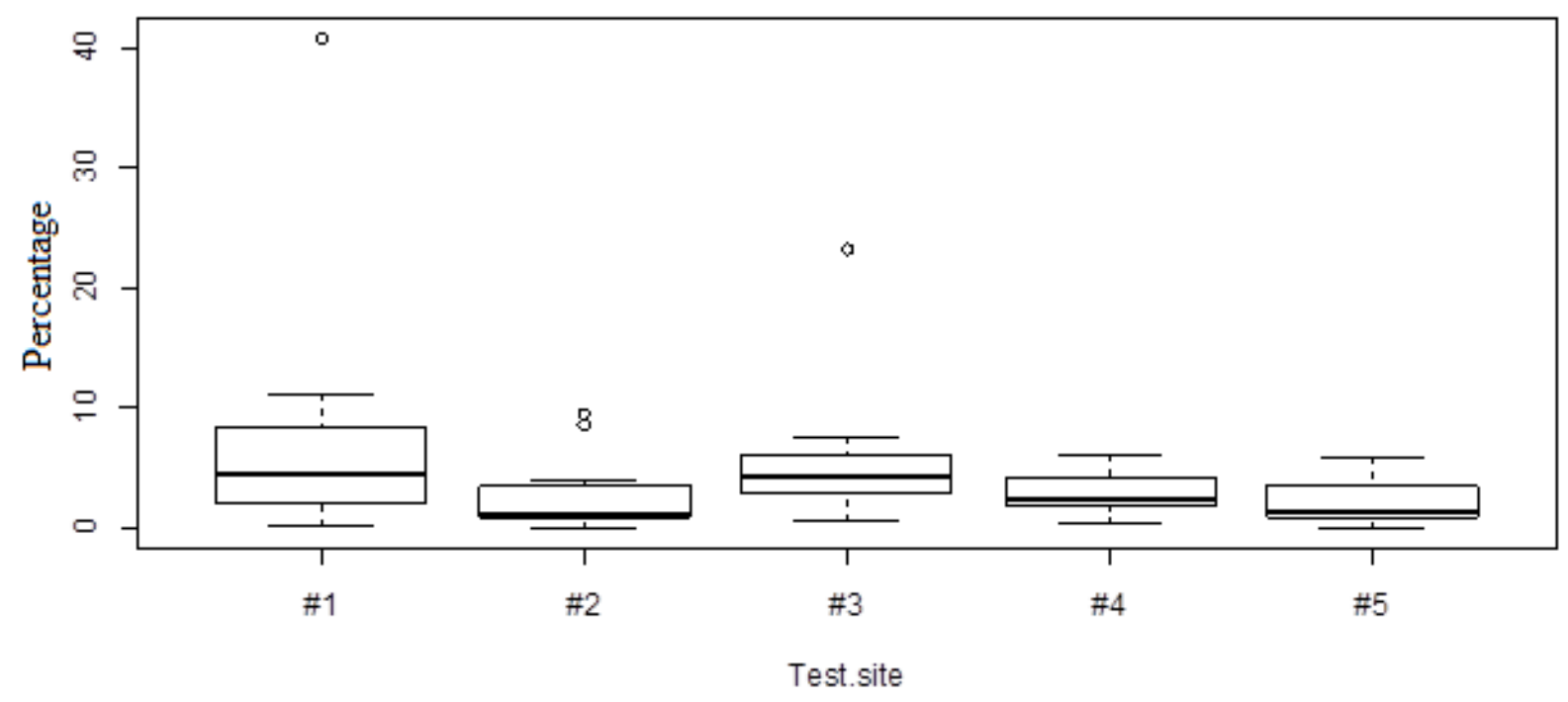

Figure 36 The Mean of Absolute Values of the Differences of Lateral Position between Daytime and Nighttime for Free Moving Trucks 


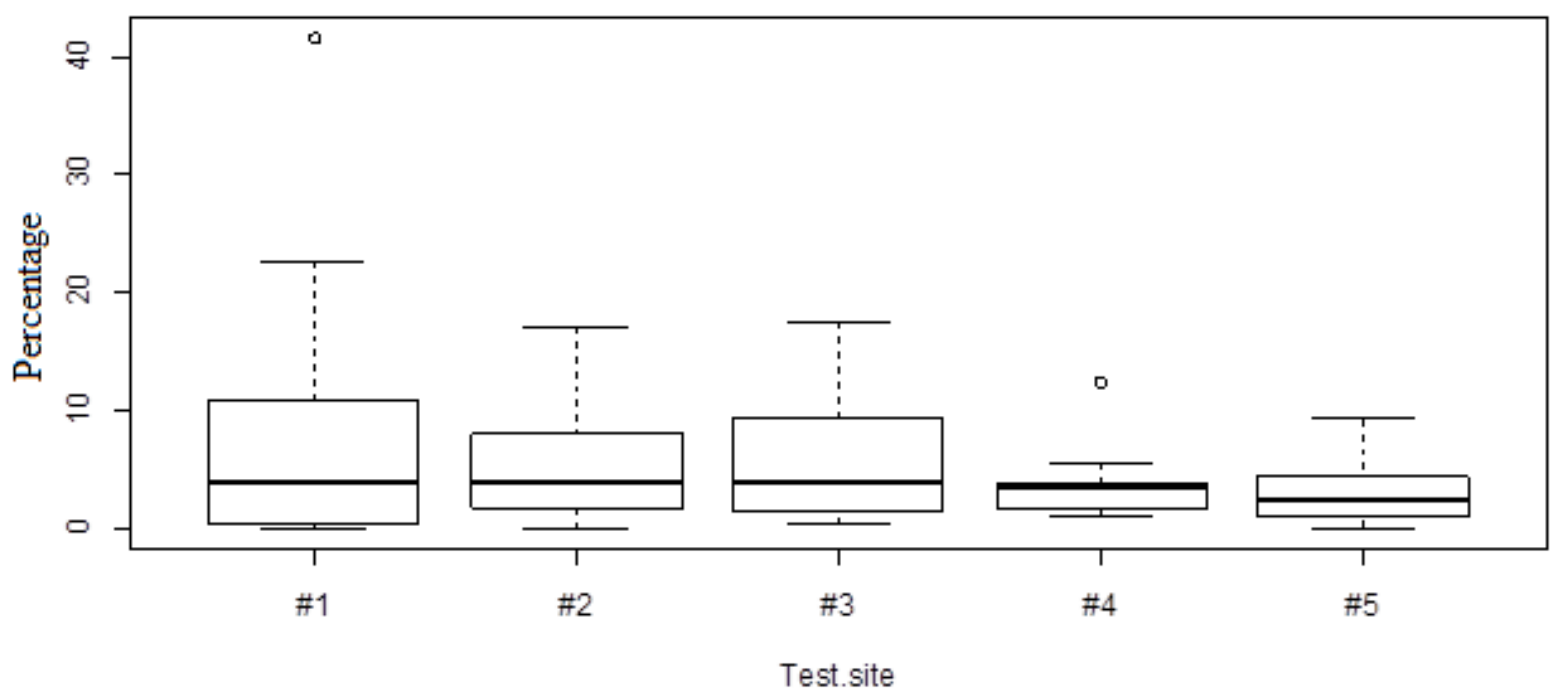

Figure 37 the Mean of Absolute Values of the Differences of Lateral Position between Daytime and Nighttime for Influenced Trucks

Two tests for free moving trucks and influenced trucks were conducted respectively in this subsection. Based on the F-value and P-value calculated from ANOVA test, the same rank can be obtained for these two group data as shown in Table 13. Among these five test sites, the effect of darkness on lateral position at test site \#4 is most significant, and followed by test sites \#5, \#3, $\# 2$, and \#1.

Table 13 ANOVA Test Results for Lateral Position between Daytime and Nighttime for Free Moving Trucks and Influenced Trucks

\begin{tabular}{cccccc}
\hline \multirow{2}{*}{$\begin{array}{c}\text { Rank of Signification } \\
\text { (Visibility) }\end{array}$} & Test site & F-value & P-value & F-value & P-value \\
\hline 1 & $\# 4$ & 29.857 & $2.39 \mathrm{E}-05$ & 14.687 & 0.00104 \\
2 & $\# 5$ & 13.733 & 0.0014 & 12.591 & 0.00202 \\
3 & $\# 3$ & 9.3841 & 0.00613 & 12.264 & 0.00225 \\
4 & $\# 2$ & 9.1976 & 0.00657 & 10.953 & 0.0035 \\
5 & $\# 1$ & 5.0123 & 0.0367 & 5.3231 & 0.03187 \\
\hline
\end{tabular}




\section{Test Results for Weather Condition}

Typically, different weather condition has different effects on wheel shift. For instance, the rain will reduce the visibility of lane marking when the rainy water dropped and flowed on the pavement surface, and the wind might place external forces on vehicles from the lateral sides of the vehicles and slightly influences the lateral position of vehicles. Nonetheless, sunny weather carries the minimum effect on wheel shift, so sunny weather was considered as a reference to investigate the effect of rainy and windy weather on lateral position. In addition, the tested trucks were categorized into two groups: free moving and influenced trucks, thereby the tests were conducted at each test site to explore the effect of three types of weather on wheel shift.

Table 14 ANOVA Test Results under Different Weather Condition for Free Moving Trucks and Influenced Trucks

\begin{tabular}{cccccccc}
\hline \multirow{2}{*}{ Test site } & $\begin{array}{c}\text { Rank of Signification } \\
\text { (Weather) }\end{array}$ & \multicolumn{3}{c}{ Free Moving } & \multicolumn{3}{c}{ Influenced } \\
\multirow{2}{*}{$\# 1$} & 1 & weather & F-value & P-value & weather & F-value & P-value \\
& 2 & Windy & 9.4975 & 0.005883 & Windy & 12.231 & 0.00227 \\
$\# 2$ & 1 & Windy & 22.716 & 0.000118 & Windy & 18.157 & 0.00038 \\
& 2 & Rainy & 11.236 & 0.003174 & Rainy & 7.3444 & 0.01348 \\
$\# 3$ & 1 & Rainy & 32.596 & $1.38 \mathrm{E}-05$ & Windy & 14.291 & 0.00118 \\
& 2 & Windy & 10.418 & 0.00422 & Rainy & 14.132 & 0.00124 \\
$\# 4$ & 1 & Rainy & 20.736 & 0.000193 & Rainy & 39.622 & $3.82 \mathrm{E}-06$ \\
& 2 & Windy & 14.098 & 0.001248 & Windy & 28.116 & $3.44 \mathrm{E}-05$ \\
$\# 5$ & 1 & Windy & 12.988 & 0.001772 & Windy & 10.571 & 0.004 \\
& 2 & Rainy & 9.279 & 0.006377 & Rainy & 4.5938 & 0.04457 \\
\hline
\end{tabular}

Reference to the F-value and P-value, the effects of three types of weather on lateral position at each test sites can be ranked as Table 14. In particular, the effect of rainy and windy days on wheel shift was different at five test sites for free moving and influenced trucks. 


\section{Analysis of Multi-Factors based on Four-way ANOVA Test}

Actually the wheel shift is not the result of only one factor, but depends on the outcome affected by a variety of factors. As described above, one situation or scenario under each test-factor can be selected as the reference, such as sunny days in weather condition. In this study, the effects of the four test-factors on lateral position were compared and ranked. In the field, each lateral position data were recorded with its four corresponding test-factors. Among the recorded traffic video data, the lateral position data collected at the straight road, under free moving trucks, during sunny days, and in day time, was considered as a reference to examine the effect of other combined factors on lateral position.

\section{Data Description}

With a purpose to quantitatively measure the effect of all four factors on lateral position, the four-way ANOVA test is chosen to analyze these lateral position data characterized with their corresponding weather condition, traffic condition, visibility condition, and road geometric condition. Based on the F-value or P-value calculated from ANOVA test, the four test-factors can be ranked.

\section{Hypotheses Statement}

By comparing with the reference, this test will help verify whether the differences of the variation of the lateral position data under four different situations exist or not. For the ANOVA test, the hypothesis can be described as follows.

$$
\left\{\begin{array}{l}
H_{0}: \sigma_{a b c d}^{2}=\sigma_{5 f d s}^{2} \\
H_{a}: \sigma_{a b c d}^{2} \neq \sigma_{5 f d s}^{2}
\end{array}\right.
$$

Where: 
$\sigma_{a b c d}^{2}:$ Variation of lateral position data;

$\sigma_{5 f d s}^{2}:$ Variation of reference lateral position data;

$a$ : At test site \# a $(a=1,2,3,4,5)$;

$b$ : At two situations for traffic condition ( $b=f$ (free moving trucks), $i$ (influenced trucks));

$c$ : Day-time and night-time $(c=d$ (day time), $n$ (night time))

$d$ : Under three types of weather condition ( $d=s$ (sunny days), $r$ (rainy days), $w$ (windy days))

\section{Four-way ANOVA Test}

One-way ANOVA test is used to measure the effect of one factor, whereas four-way ANOVA test is applied to simultaneously measure and compare the effects of four factors on lateral position relative to reference standard. Based on the F-value and P-value, the effects of the four test-factors on lateral position were ranked as Table 15.

Based on the test results shown in table 15, the following is the findings: the effect of road curve on lateral position was most distinguished compared with the other three test-factors, followed by traffic condition, visibility and weather condition. However, the effects of traffic condition, visibility condition, and weather condition on wheel shift were not significant because the F-value is less than 2 or the P-values is greater than 0.05 .

Table 15 ANOVA Test Results for Four Test-factors

\begin{tabular}{cccc}
\hline Rank of Signification & Factor & F-value & P-value \\
\hline 1 & Road Curve & 9.3509 & $2.961 \mathrm{e}-07$ \\
2 & Traffic condition & 1.5896 & 0.2081 \\
3 & Visibility & 0.0793 & 0.7784 \\
4 & Weather & 0.2407 & 0.7862 \\
\hline
\end{tabular}




\section{MULTI-FACTOR BASED TRAFFIC LATERAL POSITION MODELING}

Based on the field test, the lateral position data with different situations for each test-factor were obtained, but these individual and scattered lateral position data are still unable to be directly used for pavement design or wheel path definition. Thence, a model capable of combining these lateral position data needs to be developed to define pavement wheel path. To achieve this aim, the Multi-Factor Traffic Lateral Position Model (M-FTLPM) was proposed to incorporate the lateral position data together with the weight of the variables in this thesis.

\section{A. M-FTLP Model Introduction}

Two basic elements are involved in M-FTLP model: the Percentage Frequency of Lateral Position at each Deviation Level (PFLP-DL) and index weight. The first element is the expression of the percentage frequency of the lateral position data at each deviation level under the four test-factors. The index weight represents the weight of each variable or parameter, which is employed to emphasize the importance of the PFLP-DL variables.

\section{PFLP-DL Parameter}

Each PFLP-DL parameter was characterized with weather condition, traffic condition, visibility condition, and road curve locations. Based on the field work of lateral position measurement, eight PFLP-DL parameters were obtained for each road section, and given as follows:

- PFLP-DLfsd -- PFLP-DL recorded during daytime, in sunny weather, for free moving trucks;

- PFLP-DLfrd - PFLP-DL recorded during daytime, in rainy weather, for free moving trucks; 
- PFLP-DLfwd - PFLP-DL recorded during daytime, in windy weather, for free moving trucks;

- PFLP-DLisd - PFLP-DL recorded during daytime, in sunny weather, for influenced trucks;

- PFLP-DLird - PFLP-DL recorded during daytime, in rainy weather, for influenced trucks;

- PFLP-DLiwd - PFLP-DL recorded during daytime, in windy weather, for influenced trucks;

- PFLP-DL $f_{s n}$ - PFLP-DL recorded during nighttime, in sunny weather, for free moving trucks;

- PFLP-DLisn - PFLP-DL recorded during nighttime, in sunny weather, for influenced trucks.

PFLP-DL parameters represent the frequency distribution of lateral position level (e.g. -0.5, $-0.25,0.25$, and 0.5 , distributed along the $\mathrm{x}$ axis) collected at each test site. Table 16 to 20 shows the corresponding deviation values at lateral position level for each PFLP-DL parameter at five test sites.

Table 16 PFLP-DL Parameters for near Left Turn Curve Road Section

\begin{tabular}{lccccccccccc}
\hline Parameter & $\mathbf{- 1 . 7 5}$ & $\mathbf{- 1}$ & $\mathbf{- 0 . 7 5}$ & $\mathbf{- 0 . 5}$ & $\mathbf{- 0 . 2 5}$ & $\mathbf{0}$ & $\mathbf{0 . 2 5}$ & $\mathbf{0 . 5}$ & $\mathbf{0 . 7 5}$ & $\mathbf{1}$ & $\mathbf{1 . 7 5}$ \\
\hline PFLP-DLfsd & 0.53 & 0.64 & 0.11 & 2.14 & 2.14 & 9.40 & 6.52 & 15.92 & 12.39 & 19.34 & 30.88 \\
PFLP-DLfrd & 0 & 1.43 & 0.71 & 5 & 0.71 & 5.71 & 10 & 29.29 & 12.86 & 12.86 & 21.43 \\
PFLP-DLfwd & 0.23 & 1.15 & 0.46 & 2.98 & 1.84 & 9.86 & 5.96 & 12.84 & 10.32 & 16.06 & 38.30 \\
PFLP-DLisd & 0 & 0.46 & 0.46 & 0 & 0.46 & 4.85 & 3.93 & 12.93 & 8.78 & 22.63 & 45.96 \\
PFLP-DLird & 0 & 0 & 0 & 0 & 0 & 1.64 & 4.92 & 16.39 & 13.11 & 18.03 & 45.90 \\
PFLP-DLiwd & 0 & 0.38 & 0 & 0.38 & 1.51 & 6.04 & 7.93 & 15.85 & 7.55 & 18.11 & 42.26 \\
PFLP-DLisn & 0 & 0 & 0 & 0 & 0 & 12.50 & 0 & 0 & 0 & 0 & 87.50 \\
PFLP-DLfsn & 2.47 & 0 & 0 & 0 & 0 & 1.24 & 1.24 & 4.94 & 3.70 & 14.81 & 71.61 \\
\hline
\end{tabular}


Table 17 PFLP-DL Parameters for near Right Turn Curve Road Section

\begin{tabular}{lccccccccccc}
\hline Parameter & $\mathbf{- 1 . 7 5}$ & $\mathbf{- 1}$ & $\mathbf{- 0 . 7 5}$ & $\mathbf{- 0 . 5}$ & $\mathbf{- 0 . 2 5}$ & $\mathbf{0}$ & $\mathbf{0 . 2 5}$ & $\mathbf{0 . 5}$ & $\mathbf{0 . 7 5}$ & $\mathbf{1}$ & $\mathbf{1 . 7 5}$ \\
\hline PFLP-DLfsd & 0.92 & 2.44 & 2.13 & 6.71 & 4.88 & 20.73 & 8.54 & 19.51 & 11.59 & 14.94 & 7.622 \\
PFLP-DLfrd & 0.70 & 2.10 & 0 & 4.90 & 4.90 & 24.48 & 7.69 & 18.88 & 16.78 & 13.99 & 5.594 \\
PFLP-DLfwd & 0.756 & 4.09 & 3.94 & 8.64 & 6.52 & 19.09 & 11.52 & 12.88 & 9.55 & 12.73 & 10.30 \\
PFLP-DLisd & 0 & 1.02 & 0.51 & 7.14 & 2.55 & 11.22 & 11.22 & 17.35 & 18.37 & 15.31 & 15.31 \\
PFLP-DLird & 1.49 & 1.49 & 0 & 0 & 5.97 & 8.96 & 10.45 & 10.45 & 13.43 & 32.84 & 14.93 \\
PFLP-DLiwd & 0.39 & 0.39 & 1.17 & 3.13 & 3.91 & 16.02 & 6.25 & 15.23 & 10.94 & 23.44 & 19.14 \\
PFLP-DLfsn & 4.88 & 0 & 1.22 & 3.66 & 4.88 & 12.20 & 9.76 & 18.29 & 12.2 & 15.85 & 17.07 \\
PFLP-DLisn & 0 & 0 & 0 & 2.70 & 0 & 8.11 & 5.41 & 13.51 & 8.108 & 32.43 & 29.73 \\
\hline
\end{tabular}

Table 18 PFLP-DL Parameters for in Right Turn Curve Road Section

\begin{tabular}{lccccccccccc}
\hline Parameter & $\mathbf{- 1 . 7 5}$ & $\mathbf{- 1}$ & $\mathbf{- 0 . 7 5}$ & $\mathbf{- 0 . 5}$ & $\mathbf{- 0 . 2 5}$ & $\mathbf{0}$ & $\mathbf{0 . 2 5}$ & $\mathbf{0 . 5}$ & $\mathbf{0 . 7 5}$ & $\mathbf{1}$ & $\mathbf{1 . 7 5}$ \\
\hline PFLP-DLfsd & 1.11 & 2.47 & 3.46 & 9.39 & 7.29 & 17.31 & 10.75 & 20.27 & 9.64 & 11.87 & 6.18 \\
PFLP-DLfrd & 0 & 0 & 1.61 & 12.90 & 1.61 & 19.35 & 11.29 & 24.19 & 12.90 & 12.90 & 3.23 \\
PFLP-DLfwd & 0.76 & 2.66 & 3.42 & 7.61 & 5.70 & 22.05 & 11.41 & 21.67 & 8.37 & 9.89 & 6.46 \\
PFLP-DLisd & 0.24 & 1.46 & 1.46 & 3.64 & 3.88 & 13.11 & 10.68 & 24.51 & 11.17 & 16.02 & 13.83 \\
PFLP-DLird & 0 & 0 & 3.03 & 6.06 & 0 & 6.06 & 3.03 & 15.15 & 27.27 & 27.27 & 12.12 \\
PFLP-DLiwd & 0 & 0 & 3.64 & 2.73 & 2.73 & 15.45 & 5.46 & 21.82 & 13.64 & 25.45 & 9.09 \\
PFLP-DLfsn & 0.54 & 1.63 & 1.09 & 2.72 & 1.63 & 9.78 & 6.52 & 16.85 & 13.59 & 16.30 & 29.35 \\
PFLP-DLisn & 0 & 0 & 0 & 0 & 0 & 4.17 & 4.17 & 14.58 & 12.50 & 33.33 & 31.25 \\
\hline
\end{tabular}

Table 19 PFLP-DL Parameters for in Left Turn Curve Road Section

\begin{tabular}{lccccccccccc}
\hline Parameter & $\mathbf{- 1 . 7 5}$ & $\mathbf{- 1}$ & $\mathbf{- 0 . 7 5}$ & $\mathbf{- 0 . 5}$ & $\mathbf{- 0 . 2 5}$ & $\mathbf{0}$ & $\mathbf{0 . 2 5}$ & $\mathbf{0 . 5}$ & $\mathbf{0 . 7 5}$ & $\mathbf{1}$ & $\mathbf{1 . 7 5}$ \\
\hline PFLP-DLfsd & 7.13 & 13.56 & 11.49 & 17.24 & 11.03 & 15.40 & 5.98 & 8.51 & 3.91 & 3.45 & 2.76 \\
PFLP-DLfrd & 4.21 & 5.26 & 3.16 & 14.74 & 9.47 & 25.26 & 7.37 & 12.63 & 5.26 & 6.32 & 6.32 \\
PFLP-DLfwd & 10.53 & 15.79 & 7.90 & 15.79 & 2.63 & 23.68 & 7.90 & 7.90 & 5.26 & 0 & 2.63 \\
PFLP-DLisd & 4.52 & 8.39 & 7.10 & 12.26 & 7.74 & 21.94 & 11.61 & 8.39 & 5.81 & 3.87 & 9.68 \\
PFLP-DLird & 0 & 3.33 & 0 & 6.67 & 6.67 & 13.33 & 20 & 23.33 & 10 & 13.33 & 3.33 \\
PFLP-DLiwd & 0 & 4.17 & 16.67 & 12.50 & 12.50 & 16.67 & 4.17 & 16.67 & 8.33 & 4.17 & 4.17 \\
PFLP-DLfsn & 5.63 & 7.81 & 7.5 & 15 & 7.50 & 17.50 & 12.19 & 12.81 & 5.63 & 5.31 & 3.13 \\
PFLP-DLisn & 0.74 & 2.96 & 3.70 & 8.89 & 8.89 & 20.74 & 14.81 & 20.74 & 6.67 & 5.93 & 5.93 \\
\hline
\end{tabular}


Table 20 PFLP-DL Parameters for in Straight Road Section

\begin{tabular}{lccccccccccc}
\hline Parameter & $\mathbf{- 1 . 7 5}$ & $\mathbf{- 1}$ & $\mathbf{- 0 . 7 5}$ & $\mathbf{- 0 . 5}$ & $\mathbf{- 0 . 2 5}$ & $\mathbf{0}$ & $\mathbf{0 . 2 5}$ & $\mathbf{0 . 5}$ & $\mathbf{0 . 7 5}$ & $\mathbf{1}$ & $\mathbf{1 . 7 5}$ \\
\hline PFLP-DLfsd & 0.20 & 0.40 & 1.39 & 5.96 & 2.78 & 14.12 & 9.74 & 23.86 & 14.71 & 15.51 & 11.33 \\
PFLP-DLfrd & 1.29 & 1.29 & 1.29 & 7.10 & 2.58 & 19.35 & 9.03 & 25.16 & 14.19 & 12.90 & 5.81 \\
PFLP-DLfwd & 1.15 & 1.53 & 0.77 & 5.56 & 4.41 & 22.03 & 9.39 & 29.12 & 9.58 & 12.26 & 4.22 \\
PFLP-DLisd & 0 & 0.47 & 0.23 & 1.87 & 2.34 & 12.18 & 9.37 & 24.36 & 12.88 & 18.74 & 17.56 \\
PFLP-DLird & 0.86 & 0.86 & 0 & 6.03 & 1.72 & 17.24 & 9.48 & 24.14 & 13.79 & 18.97 & 6.90 \\
PFLP-DLiwd & 0.33 & 1.31 & 0.66 & 2.62 & 3.61 & 14.10 & 10.82 & 29.18 & 14.10 & 13.11 & 10.16 \\
PFLP-DLfsn & 4.17 & 5.56 & 2.78 & 2.78 & 2.78 & 8.33 & 8.33 & 22.22 & 15.28 & 15.28 & 12.50 \\
PFLP-DLisn & 0 & 0 & 4.76 & 0 & 0 & 19.05 & 9.52 & 28.57 & 14.29 & 9.524 & 14.29 \\
\hline
\end{tabular}

\section{Index Weight Analysis}

The index weight is used to describe the probability of each test-factor other than road curve condition. In M-FTLP Model, the index weight can be classified into four groups: weather, traffic, lengths of day-time and night-time, and percentages of workdays and weekends (Figure 38). The filed data for each weight group were obtained by using various ways, such as the weather data obtained by searching relative statistical reports online. After that, index weights for each group can be calculated based on the field data.

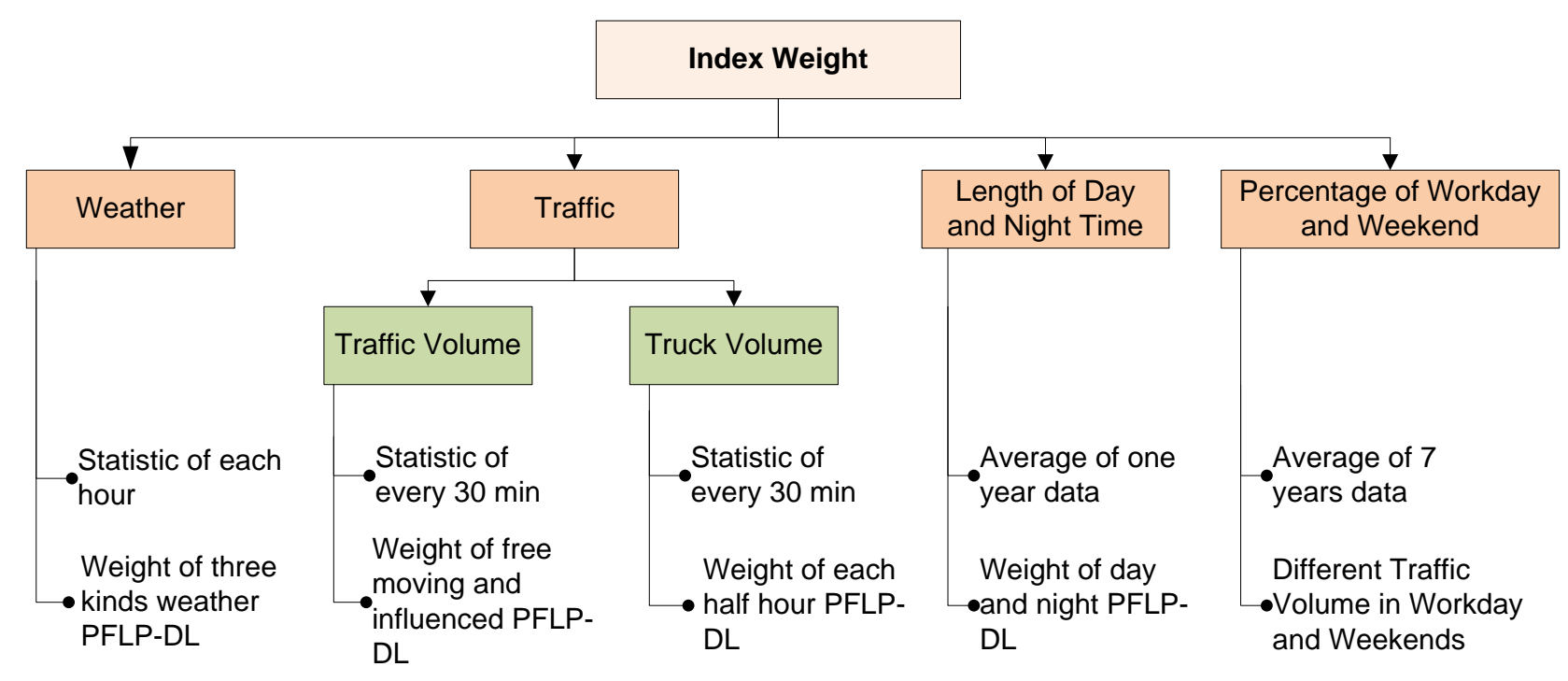

Figure 38 Diagram for Index Weight Classification 
In addition, the index weights in this study were discussed in three levels. For instance, the index weights of weather were based on the hourly distributions of three types of weather; the weights of lengths of daytime and nighttime were statistic by a day; the weights of percentage of workdays and weekends were examined in year, while the statistic of traffic or trucks volume were explored in half an hour. The detailed index weight for each group data can be illustrated in Figure 39.

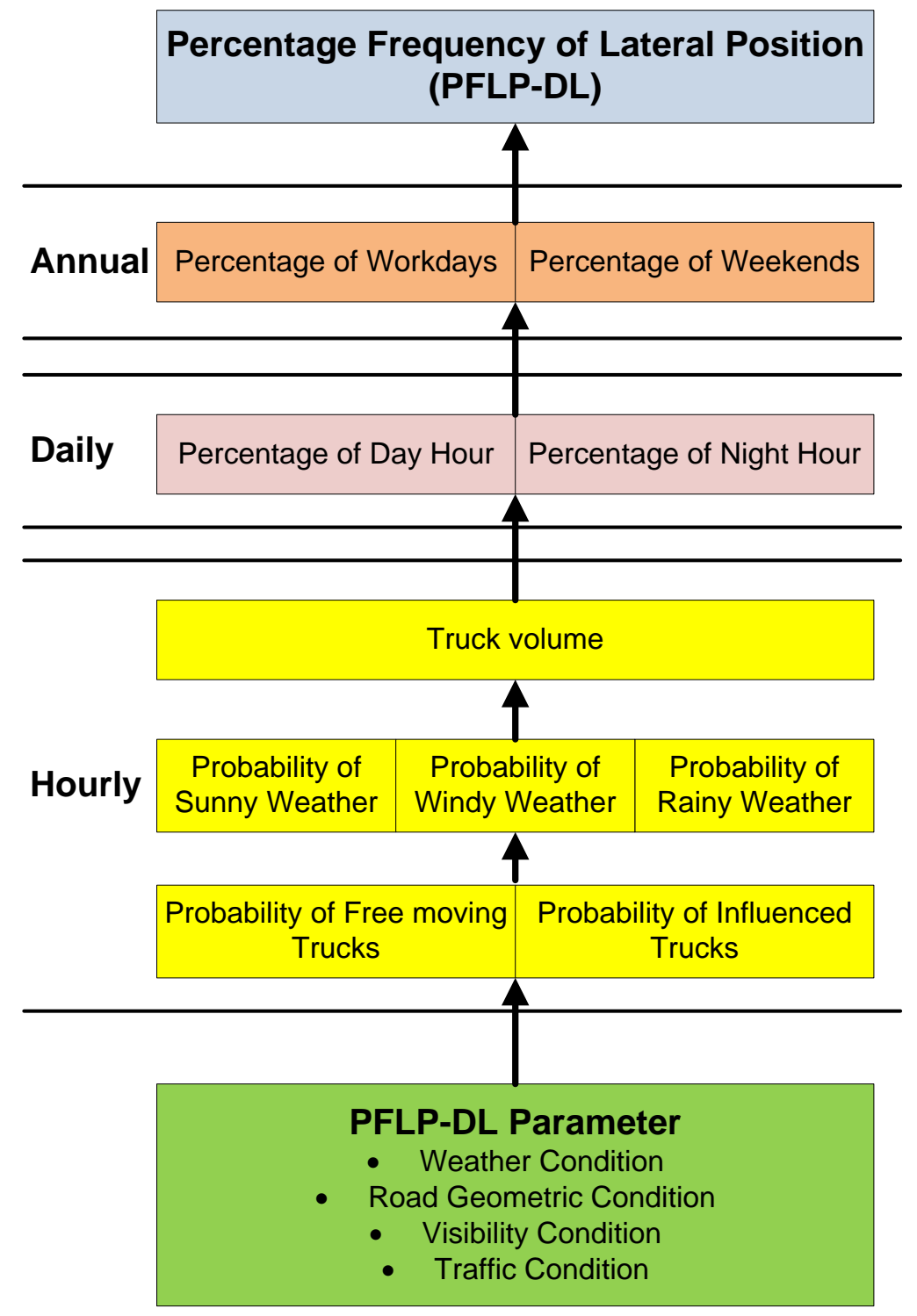

Figure 39 Schematic for Level Classification of Index Weights 
1) Index Weights of Weather Condition

The probabilities of three types of weather condition were described in test sites. These index weights derived from the statistic of the frequency of weather in each hour based on several years' weather data. The equations for weather probability calculation are given as follows:

$$
\begin{gathered}
\text { Weather }(w) \%_{n}=\frac{\sum_{i=2005}^{2011} Y(w)_{n i}}{\sum_{i=2005}^{2011} D(w)_{i}} \times 100 \% \\
Y(w)_{n i}=\sum_{j=1}^{12} M(w)_{n i j} \\
\text { Weather }(e) \%_{n}=\frac{\sum_{i=2005}^{2011} Y(e)_{n i}}{\sum_{i=2005}^{2011} D(e)_{i}} \times 100 \% \\
Y(e)_{n i}=\sum_{j=1}^{12} M(e)_{n i j}
\end{gathered}
$$

Where:

Weather $(w) \%_{n}$ : The percentage of windy/rainy/sunny weather at time " $n$ " (workdays);

Weather $(e) \%_{n}$ : The percentage of windy/rainy/sunny weather at time " $n$ " (weekends);

$Y(w)_{n i}$ : sum of hours of windy/rainy/sunny weather at time " $n$ " in year " $i$ " (workdays);

$Y(e)_{n i}$ : sum of hours of windy/rainy/sunny weather at time " $n$ " in year " $i$ " (weekends);

$D(w)_{i}:$ sum of workdays in year " $i$ ";

$D(e)_{i}$ : sum of weekends in year " $i$ ";

$M(w)_{n i j}:$ sum of hours of windy/rainy/sunny weather at time " $n$ " in one month " $j$ " (workdays); 
$M(e)_{n i j}:$ sum of hours of windy/rainy/sunny weather at time " $n$ " in one month " $j$ " (weekends);

$n$ : time from 0:00 to $24: 00(n=1,2, \ldots, 24)$;

$i:$ years $(i=2005,2006, \ldots, 2011)$;

$j:$ months $(j=1,2, \ldots, 12)$.

\section{2) Index Weights of Traffic Condition}

Index weight of traffic can be considered from the perspectives of traffic volume and truck volume. The traffic volume directly affects the frequency of influenced and free moving trucks. Generally, as traffic volume increase, the frequency of influenced trucks will increase, but the frequency of free moving trucks will decrease. The majority of axle load repetitions accumulating on pavement surface are primarily produced by trucks because studies indicated the effects of passenger cars on pavement surface and structure can be ignored relative to the trucks. Therefore, the wheel path definition in this thesis will be based on the truck traffic. The truck volume per half hour represents the weight of PFLP-DL in each $30 \mathrm{~min}$.

This research was conducted based on 100 hours traffic video data, and the traffic volume and the corresponding frequencies of free moving and influenced trucks were recorded every half an hour, thus the total sample size is up to 200 in this research. Based on the processed traffic data, this study attempts to investigate the relationship between the traffic volume and its corresponding probability of free moving trucks and influenced trucks. At first, the traffic volume in the 200 samples was sorted by descending as shown in Figure 40 (a). Secondly, the corresponding frequency for influenced and free moving trucks was calculated using Equations 17 and 18, and their resultants were shown in Figure 40 (b) and (c), respectively. 
Percentage frequency of free moving trucks $=\frac{\text { Number of free moving trucks }}{\text { Total number of trucks }} \times 100 \%$

Percentage frequency of influenced trucks $=\frac{\text { Number of influenced trucks }}{\text { Total number of trucks }} \times 100 \%$

Again in Figure 40, one finding can be drawn: the influenced trucks decrease with the decrease of the traffic volume, however, the free moving trucks increase with the decrease of the traffic volume.
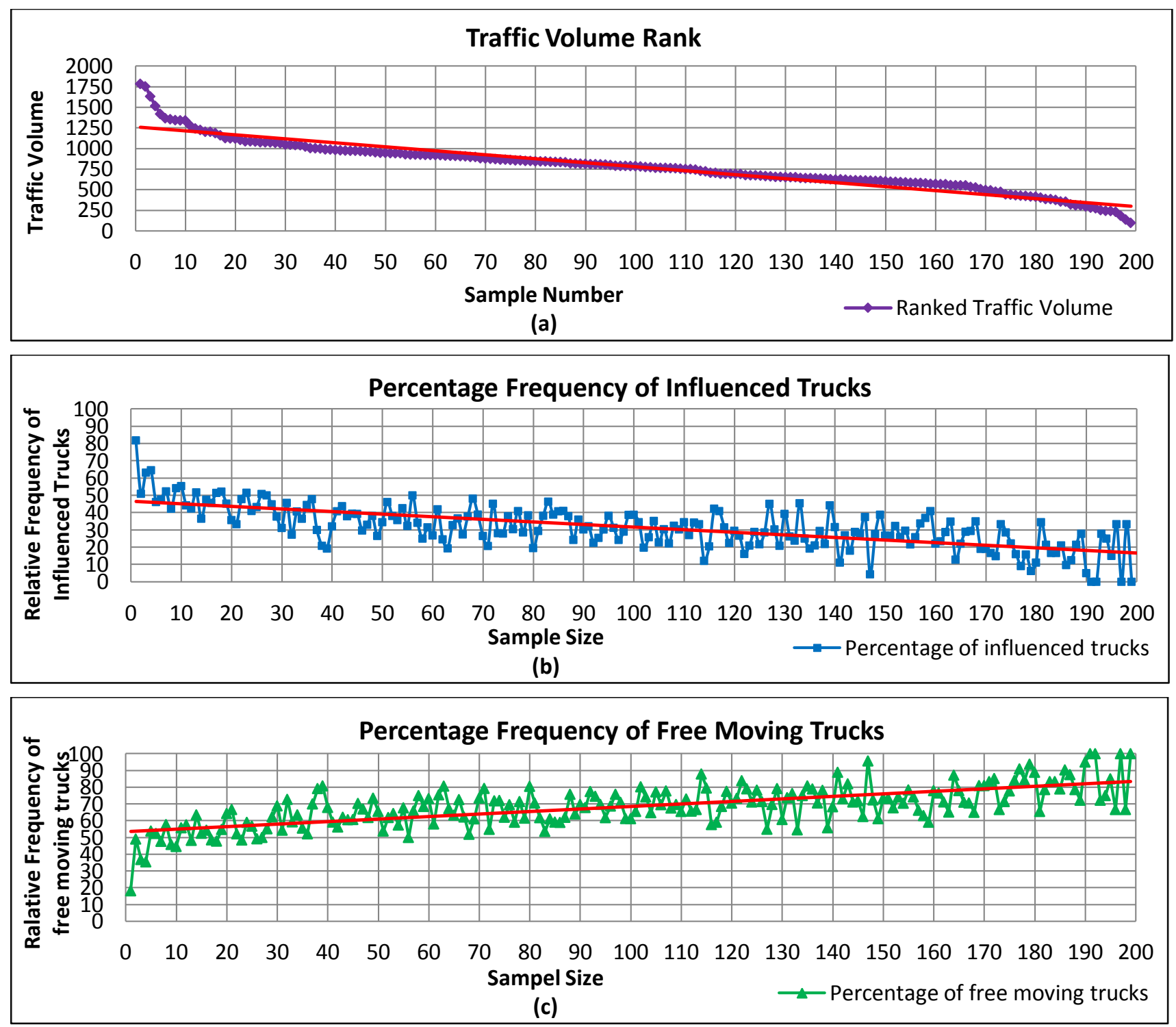

Figure 40 Traffic Volume Rank and its Corresponding Percentage Frequency for Free Moving and Influenced Trucks 
In order to intuitively describe the relationship between traffic volume and the percentage frequency of influenced trucks, the traffic volume with a known range value have been quantitatively designated to a specific percentage value, as shown in Table 21, based on the fluctuation of traffic volume and its corresponding percentage values of Influenced trucks in Figure 40.

Table 21 Influenced Truck Frequencies in Different Traffic Volume Levels

\begin{tabular}{cccc}
\hline Traffic volume & Influenced \% & Traffic volume & Influenced\% \\
\hline$>=1400$ & 61.05 & 750 & 29.56 \\
1300 & 49.84 & 700 & 29.02 \\
1200 & 44.09 & 600 & 28.25 \\
1100 & 45.69 & 500 & 27.45 \\
1000 & 43.15 & 400 & 20.07 \\
950 & 34.74 & 300 & 17.22 \\
900 & 32.69 & 200 & 11.9 \\
850 & 33.98 & $<200$ & 6.897 \\
800 & 33.48 & & \\
\hline
\end{tabular}

3) Index Weights of Day- and Night-time

The visibility was subjective to being influenced by the day-time and night-time. In addition, the duration of the day-time and night-time depends on the seasons and the latitude of the test sites. In this thesis, index weight of day-time and night-time is calculated based on the duration of daytime and night-time at test sites, and the average value was applied in the M-FTLP model.

4) Index Weights of Workdays and Weekends

Generally, the high traffic volume would be observed during the workdays, while the traffic volume would somewhat decrease in weekends. Since the traffic volume influenced the percentage frequency of lateral position data of free moving and influenced trucks, the percentage of workday and weekend in a year is considered as index weights for workdays and weekends. 


\section{M-FTLP Modeling}

\section{1) Primary Functions}

The function of M-FTLP Model is to incorporate the lateral position data under different testfactors to calculate the General Lateral Position (GLP) at each test site, and the calculated GLP can be employed to redefine the pavement wheel path. In this thesis, this proposed model is only suitable for GLP calculation at outside lane for the four-way divided highway.

\section{2) Application Framework}

The lateral position data and corresponding influenced factors should be combined before MFTLP model is applied, and this combination are based on the evaluations of four test factors' effect on lateral position. Herein, the effects of four factors on lateral position can be estimated based on the statistical results provided in Chapter 5 .

As Table 15 shows, the road curve is most significant factor on wheel shift for these four test-factors, which indicated that the large differences of traffic wandering might be existed at these five test sites. Accordingly, the large errors might be caused if the same lateral position distribution level was used at the five road sections in this research. Moreover, it is impractical to survey the mileages for each test section type and then combine the lateral position with the influenced factors at the five road sections to produce an input parameter for this model. Therefore, the M-FTLP Model covers five individual models corresponding to each road section, and each model possesses the same structure but different PFLP-DL parameters, as shown in Figure 41. 


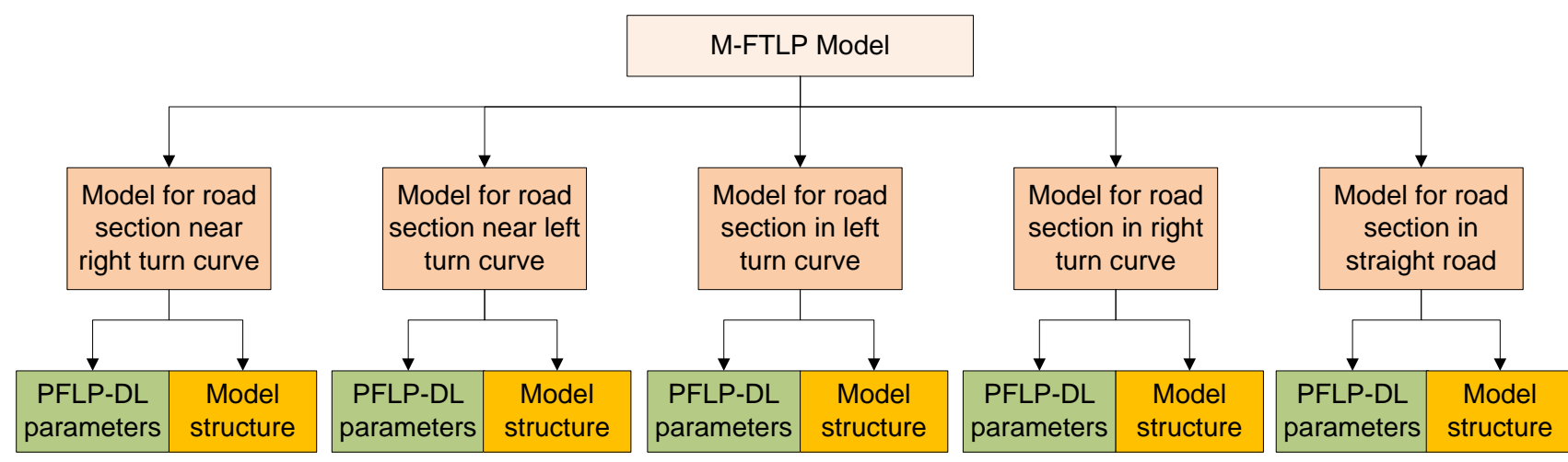

The same for each individual model

Different for each individual model

\section{Figure 41 Components for M-FTLP Model}

The traffic condition is considered the second significant factor on wheel shift and should be applied in M-FTLP model. Based on above statistical outcome, the lateral position under different traffic conditions can be combined by a comprehensive or general parameter called index weight of traffic, which can be regarded as the most fundamental index weight in M-FTLP Model.

The effect of weather on traffic wandering can be negligible when the weather and visibility simultaneously contribute to wheel shift, which are based on two reasons: firstly, the visibility and weather condition take smaller effect on wheel shift than road section types and traffic conditions, in addition, the effect of visibility on wheel shift is greater than weather condition; secondly, the low truck volume was observed during night time, which implied the small weight of lateral position during night time should be considered in GLP calculation.

Index weight is one of most principal components of this model, and the unit of index weight is converted to "yearly" or "annual" based on acquired data, so the M-FTLP Model was used to calculate the annual accumulative lateral positions. Figure 42 shows the framework of 
the M-FTLP model. Due to the differences of traffic volume and visibility condition, the lateral positions were computed during day time and night time, workday and weekend, respectively.

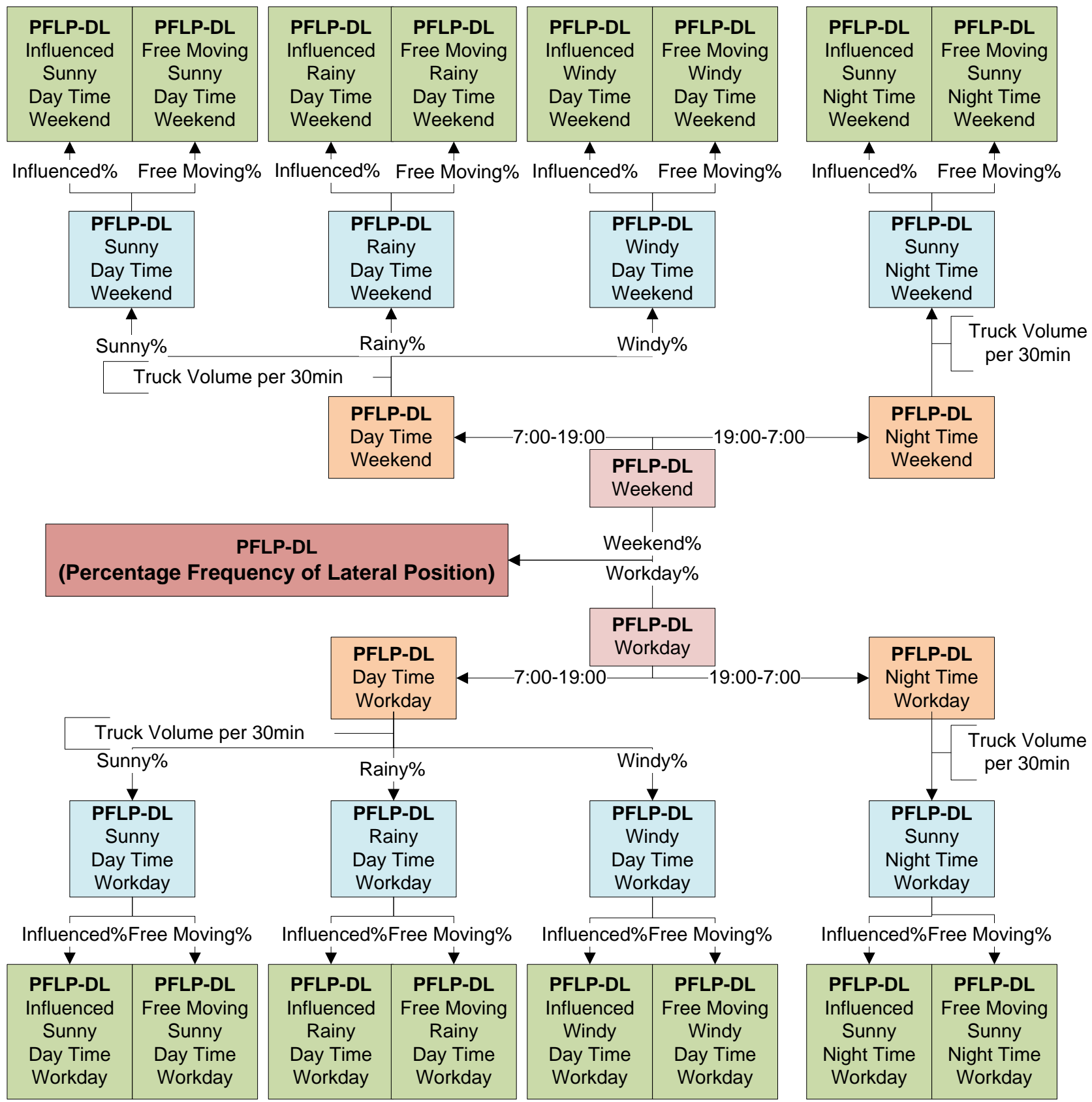

Figure 42 Framework of M-FTLP Model 
Based on the aforementioned analysis, the M-FTLP Model can be mathematically depicted as follows, which is suitable for the lateral position calculation of four-way divided highways.

$$
\begin{aligned}
R F L P=\left\langle\sum_{j=7}^{19}\{[\right. & \left.R F L P_{i s d} \times I_{o j}+R F L P_{f s d} \times F_{o j}\right) \times S_{o j} \\
& +\left(R F L P_{i r d} \times I_{o j}+R F L P_{f r d} \times F_{o j}\right) \times R_{o j} \\
& \left.\left.+\left(R F L P_{i w d} \times I_{o j}+R F L P_{f w d} \times F_{o j}\right) \times W_{o j}\right] \times T_{o j}\right\} \\
& \left.+\sum_{j=19}^{7}\left[\left(R F L P_{i s n} \times I_{o j}+R F L P_{f s n} \times F_{o j}\right) \times 100 \times T_{o j}\right]\right\rangle \times O \% \\
& +\left\langle\sum _ { j = 7 } ^ { 1 9 } \left\{\left[\left(R F L P_{i s d} \times I_{e j}+R F L P_{f s d} \times F_{e j}\right) \times S_{e j}\right.\right.\right. \\
& +\left(R F L P_{i r d} \times I_{e j}+R F L P_{f r d} \times F_{e j}\right) \times R_{e j} \\
& \left.\left.+\left(R F L P_{i w d} \times I_{e j}+R F L P_{f w d} \times F_{e j}\right) \times W_{e j}\right] \times T_{e j}\right\} \\
& \left.+\sum_{j=19}^{7}\left[\left(R F L P_{i s n} \times I_{e j}+R F L P_{f s n} \times F_{e j}\right) \times 100 \times T_{e j}\right]\right\rangle \times E \%
\end{aligned}
$$

Where:

$j$ : time $(\mathrm{j}=0,0.5,1,1.5,2, \ldots, 23.5,24)$;

PFLP-DL: Relative frequency percentage of lateral position;

$i$ : For influenced trucks;

$f$ : For free moving trucks;

$s:$ In sunny weather;

$r$ : In rainy weather; 
$w$ : In windy weather;

$d$ : At day time;

$n$ : At night time;

I: Frequency of influenced trucks in test;

$F$ : Frequency of free moving trucks in test;

$o$ : In work days

$e$ : In weekends

$S$ : Probability of sunny weather;

$R$ : Probability of rainy weather;

$W$ : Probability of windy weather;

$T$ : Truck volume;

$O$ : Percentage of workdays in a calendar year;

$E$ : Percentage of weekend in a calendar year.

\section{4) Implementation Procedures}

The procedures to use the M-FTLP Model can be described as follows: 1) Determine the type of test road section (near left turn curve; near right turn curve; in right turn curve; in left turn curve; in straight road); 2) Select the proper M-FTLP model based on road section type; 3) Calculate the index weight for each test-factor; 4) input the index weight into M-FTLP model; and 5) Output the accumulative annual lateral position. The specific procedures can be schematically represented in Figure 43. 


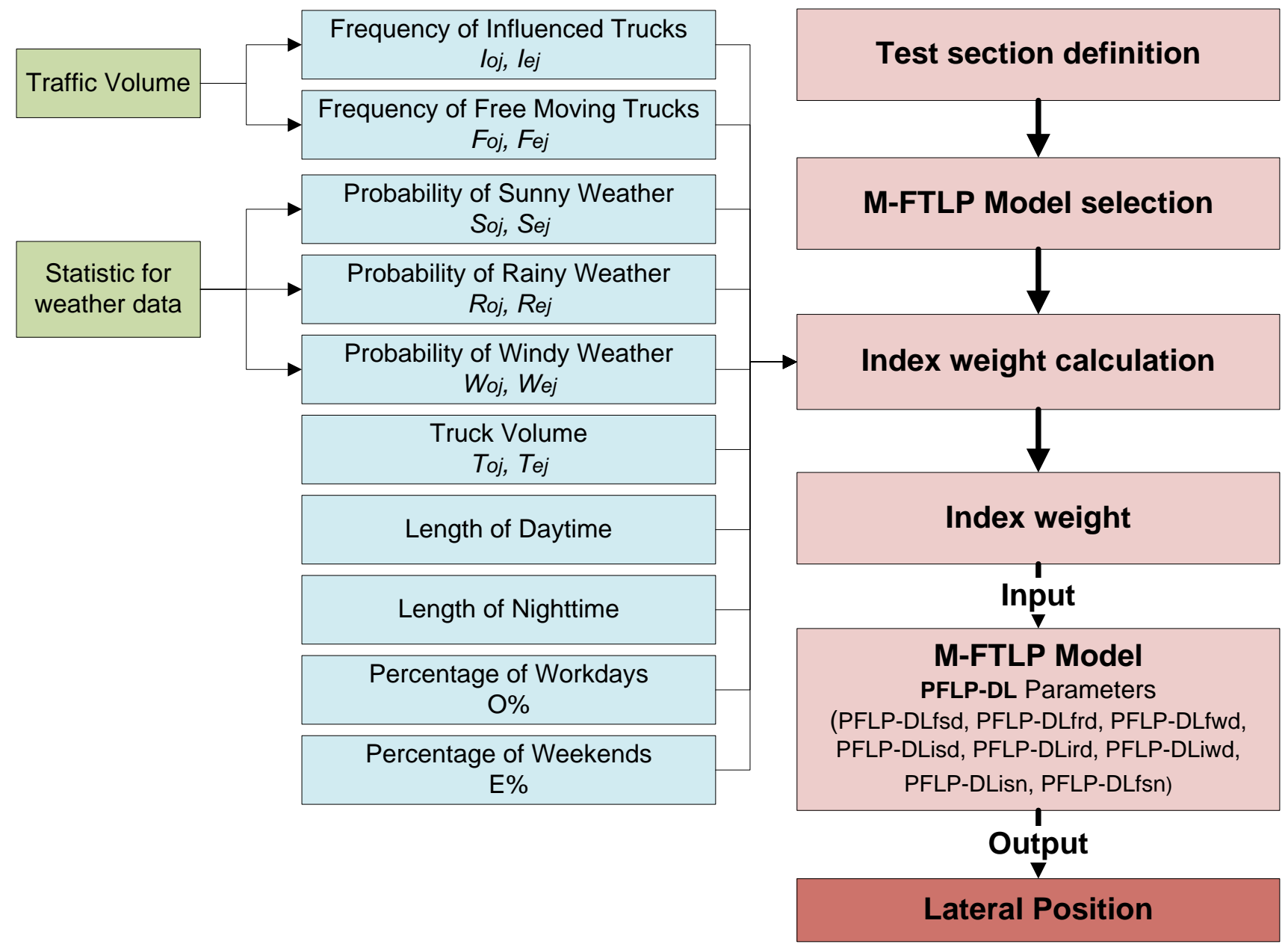

Figure 43 Schematic of Implementation Procedures of M-FTLP Model

\section{B. M-FTLP Model Application}

Five road segments located at I-540 Interstate highway of Fayetteville, AR were selected as test foundation for this research. On the basis of the collected lateral position data and the computed index weight for each test-factor, the M-FTLP Model was utilized to calculate the GLP at these five test sites. 


\section{Model Selection}

As introduced in Chapter 3, Figures 24 to 28 represent the test sites from Sites \#1 to \#5, respectively and the corresponding M-FTLP Model can be determined based on the distance between the road curve and test sites.

- test site \#1: M-FTLP Model for near left turn curve section

- test site \#2: M-FTLP Model for near right turn curve section

- test site \#3: M-FTLP Model for near right turn curve section

- test site \#4: M-FTLP Model for near left turn curve section

- test site \#5: M-FTLP Model for straight road section

Based on the type of road section, the PFLP-DL parameters given in Tables 16 to 20 can be used as the fundamental parameter to be loaded into the selected model.

\section{Index Weight Calculation}

1) Traffic and Truck Volumes

The number of the traffic and truck volumes in each half an hour during workdays and weekends were counted. In this research, the traffic and truck volumes at test sites \#1 (near the left turn curve) and \#2 (near the right turn curve) can be considered the "identical" since the statistical results of traffic and traffic volumes at both test sites are very close to each other. Likewise, the test sites \#3 (in the right turn curve) and \#4 (in the left turn curve) can also be assumed having the same traffic and truck volumes. Figure 44 shows the traffic and truck volumes during workday and weekend at three test sections of I-540 interstate highway. 


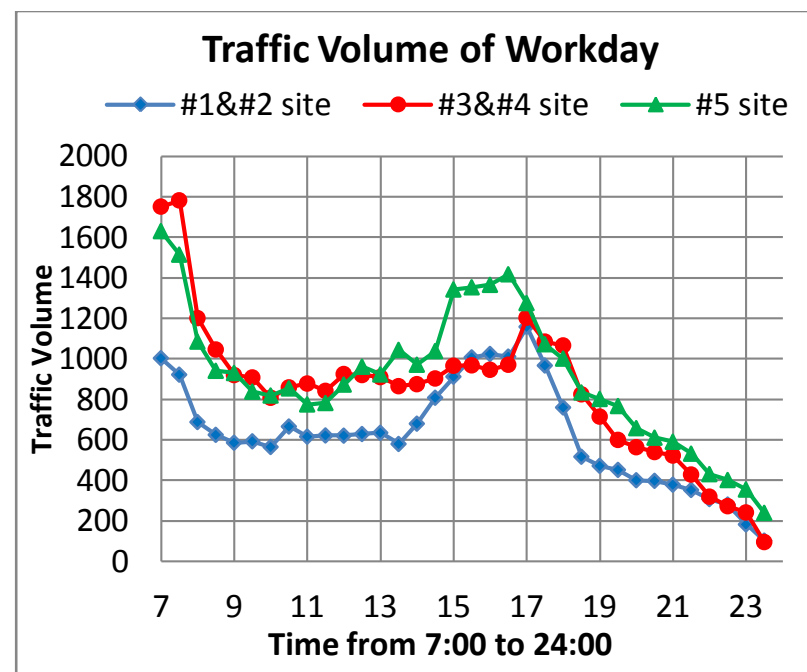

(a)

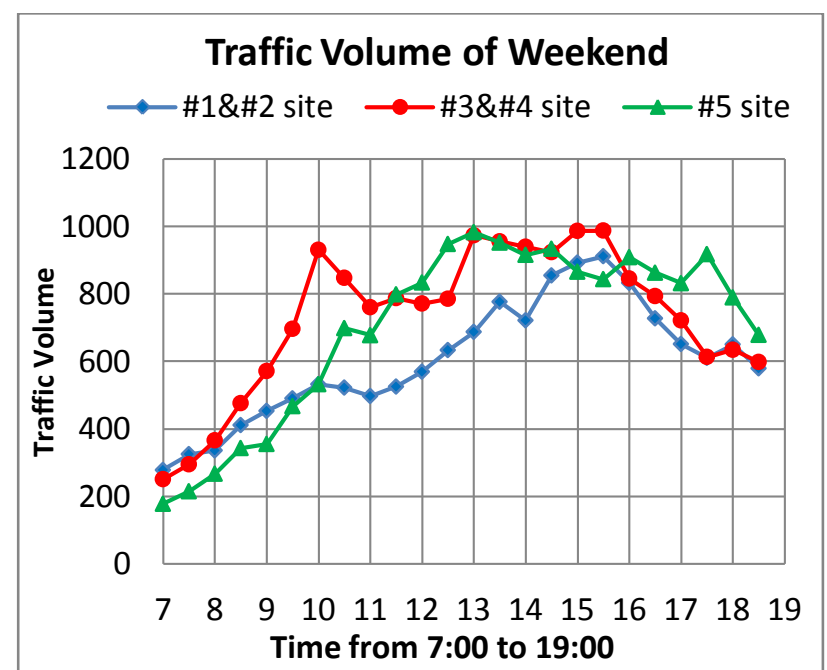

(c)
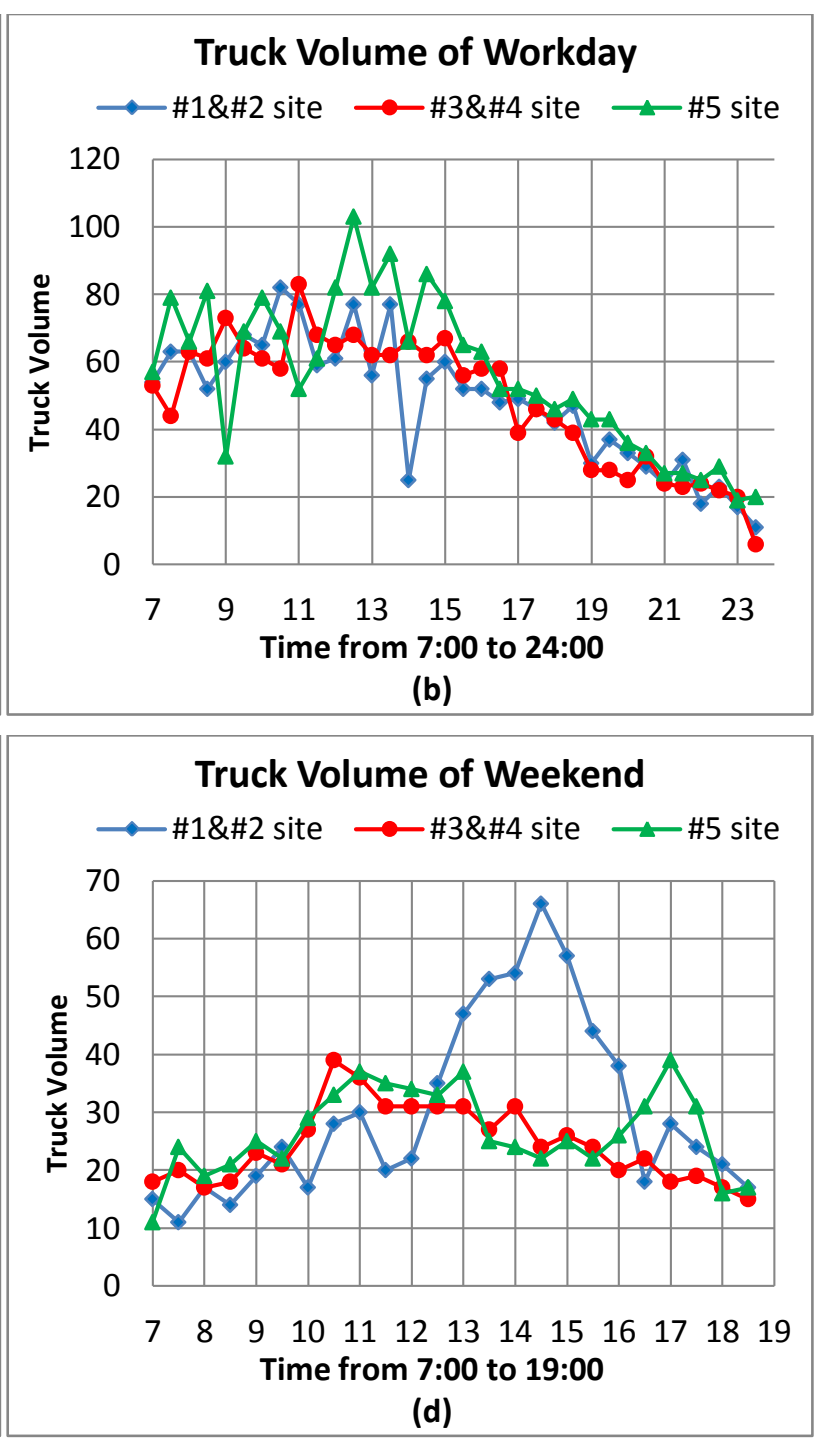

Figure 44 Traffic and truck volume at five test sites

As Figure 44 (a) shows, the traffic volume after 23:00 during workday is less than 200 vehicles per $30 \mathrm{~min}$, and the traffic volume after 18:00 appears downwards tendency. Since the low traffic volume is not as significant as high traffic volume for wheel path definition, only the traffic volume from 7:00 to 24:00 were measured in this thesis, and the traffic volume after 24:00 during workday is assumed having the same traffic volume as that at 24:00. Furthermore, the peak traffic hours at these sites mainly focus on 7:00-8:00 and 15:00-18:00. 
Comparison with the Figure 44 (a), Figure 44 (b) shows the truck volume per 30min from 7:00 to 24:00 during workdays, which emerges the same trend as the traffic volume distribution. As this Figure shows, the truck volume after 23:00 is also very low, even less than 20 trucks per 30min, and the truck volume after 16:00 appears downwards tendency. Similarly, the low truck volume also has very small effect on wheel path definition; subsequently, the truck volume after 24:00 during workdays at these test sites is assumed having the same as the traffic volume at 24:00.

The traffic and truck volumes during weekends were shown in Figure 44 (c) and (d), which indicated that the traffic or truck volume during weekends are less than these during workdays. Especially after 18:00, the truck volume was less than 20 trucks during that time unit. Therefore, the survey time would be spanned from 7:00 to 19:00 due to the low traffic and truck volume at weekend nights, and similarly, the traffic and truck volumes after 19:00 during weekends will be assumed have the same as these at 19:00.

According to the traffic and truck volume distribution during workdays and weekends at three sites, the findings can be drawn as follows:

- The traffic volume and truck volume during weekends is less than these during workdays;

- The traffic and truck volumes after 23:00 during workdays was less than 200 and 20 respectively, in each time unit (30 $\mathrm{min})$;

- the truck volume after 18:00 during weekends in three sites was less than 20 trucks per 30 $\min$;

- The traffic and truck peak hours are different. 
Based on the traffic volume distribution and the relationship between the traffic volume and frequency of influenced trucks shown in Table 21, the frequency of influenced trucks for each half an hour during workdays and weekends was obtained as shown in Tables 22 and 23, respectively. As for the relative frequency of influenced truck and the truck volume from 24:00 to 7:00 during workdays and from 19:00 to 7:00 during weekends, which were considered as the same frequency as them at 24:00 during workdays and 19:00 during weekends, respectively. Truck volume is also a significant index weight representing the weight of PFLP-DL, which recorded the majority of axle load repetitions accumulating on pavement surface. Therefore the truck volume per 30min for workdays and weekends was given in table 22 and 23. 
Table 22 Influenced Truck Frequencies and Truck Volume from 7:00 to 24:00 (Workdays)

\begin{tabular}{|c|c|c|c|c|c|c|}
\hline \multirow{2}{*}{$\begin{array}{c}\text { Workday } \\
\text { Time }\end{array}$} & \multicolumn{2}{|c|}{$\# 1 \& \# 2$ site } & \multicolumn{2}{|c|}{ \#3\&\#4 site } & \multicolumn{2}{|c|}{$\# 5$ site } \\
\hline & Influenced \% & Truck volume & Influenced \% & Truck volume & Influenced \% & Truck volume \\
\hline $7: 00$ & 43.15 & 54 & 61.05 & 53 & 61.05 & 57 \\
\hline $7: 30$ & 32.69 & 63 & 61.05 & 44 & 61.05 & 79 \\
\hline 8:00 & 28.25 & 63 & 44.09 & 63 & 43.15 & 66 \\
\hline $8: 30$ & 28.25 & 52 & 43.15 & 61 & 32.69 & 81 \\
\hline 9:00 & 27.45 & 60 & 32.69 & 73 & 32.69 & 32 \\
\hline $9: 30$ & 27.45 & 68 & 32.69 & 64 & 33.48 & 69 \\
\hline $10: 00$ & 27.45 & 65 & 33.48 & 61 & 33.48 & 79 \\
\hline $10: 30$ & 28.25 & 82 & 33.98 & 58 & 33.98 & 69 \\
\hline $11: 00$ & 28.25 & 77 & 33.98 & 83 & 29.56 & 52 \\
\hline $11: 30$ & 28.25 & 59 & 33.48 & 68 & 29.56 & 61 \\
\hline $12: 00$ & 28.25 & 61 & 32.69 & 65 & 33.98 & 82 \\
\hline $12: 30$ & 28.25 & 77 & 32.69 & 68 & 34.74 & 103 \\
\hline $13: 00$ & 28.25 & 56 & 32.69 & 62 & 32.69 & 82 \\
\hline $13: 30$ & 27.45 & 77 & 33.98 & 62 & 43.15 & 92 \\
\hline $14: 00$ & 28.25 & 25 & 33.98 & 66 & 34.74 & 66 \\
\hline $14: 30$ & 33.48 & 55 & 32.69 & 62 & 43.15 & 86 \\
\hline $15: 00$ & 32.69 & 60 & 34.74 & 67 & 49.84 & 78 \\
\hline $15: 30$ & 43.15 & 52 & 34.74 & 56 & 49.84 & 65 \\
\hline $16: 00$ & 43.15 & 52 & 32.69 & 58 & 49.84 & 63 \\
\hline $16: 30$ & 43.15 & 48 & 34.74 & 58 & 61.05 & 52 \\
\hline $17: 00$ & 45.69 & 49 & 44.09 & 39 & 44.09 & 52 \\
\hline $17: 30$ & 34.74 & 46 & 43.15 & 46 & 43.15 & 50 \\
\hline $18: 00$ & 29.56 & 42 & 43.15 & 43 & 43.15 & 46 \\
\hline $18: 30$ & 27.45 & 47 & 33.48 & 39 & 33.48 & 49 \\
\hline $19: 00$ & 20.07 & 30 & 29.02 & 28 & 33.48 & 43 \\
\hline $19: 30$ & 20.07 & 37 & 28.25 & 28 & 29.56 & 43 \\
\hline $20: 00$ & 20.07 & 33 & 27.45 & 25 & 28.25 & 36 \\
\hline $20: 30$ & 17.22 & 29 & 27.45 & 32 & 28.25 & 33 \\
\hline 21:00 & 17.22 & 24 & 27.45 & 24 & 27.45 & 27 \\
\hline $21: 30$ & 17.22 & 31 & 20.07 & 23 & 27.45 & 27 \\
\hline $22: 00$ & 17.22 & 18 & 17.22 & 24 & 20.07 & 25 \\
\hline $22: 30$ & 11.9 & 23 & 11.9 & 22 & 20.07 & 29 \\
\hline 23:00 & 6.897 & 17 & 11.9 & 20 & 17.22 & 19 \\
\hline $23: 30$ & 6.897 & 11 & 6.897 & 6 & 11.9 & 20 \\
\hline
\end{tabular}


Table 23 Influenced Truck Frequencies and Truck Volume from 7:00 to 19:00 (Weekends)

\begin{tabular}{ccccccc}
\hline Weekend & \multicolumn{2}{c}{ \#1\&\#2 site } & \multicolumn{2}{c}{ \#3\&\#4 site } & \multicolumn{3}{c}{ \#5 site } \\
Time & Influenced \% & Truck volume & Influenced \% & Truck volume & Influenced \% & Truck volume \\
\hline $7: 00$ & 11.9 & 15 & 11.9 & 18 & 6.897 & 11 \\
$7: 30$ & 17.22 & 11 & 11.9 & 20 & 11.9 & 24 \\
$8: 00$ & 17.22 & 17 & 17.22 & 17 & 11.9 & 19 \\
$8: 30$ & 20.07 & 14 & 20.07 & 18 & 17.22 & 21 \\
$9: 00$ & 20.07 & 19 & 27.45 & 23 & 17.22 & 25 \\
$9: 30$ & 20.07 & 24 & 28.25 & 21 & 20.07 & 22 \\
$10: 00$ & 27.45 & 17 & 32.69 & 27 & 27.45 & 29 \\
$10: 30$ & 27.45 & 28 & 33.48 & 39 & 28.25 & 33 \\
$11: 00$ & 20.07 & 30 & 29.56 & 36 & 28.25 & 37 \\
$11: 30$ & 27.45 & 20 & 29.56 & 31 & 29.56 & 35 \\
$12: 00$ & 27.45 & 22 & 29.56 & 31 & 33.48 & 34 \\
$12: 30$ & 28.25 & 35 & 29.56 & 31 & 32.69 & 33 \\
$13: 00$ & 28.25 & 47 & 34.74 & 31 & 34.74 & 37 \\
$13: 30$ & 29.56 & 53 & 34.74 & 27 & 34.74 & 25 \\
$14: 00$ & 29.02 & 54 & 32.69 & 31 & 32.69 & 24 \\
$14: 30$ & 33.98 & 66 & 32.69 & 24 & 32.69 & 22 \\
$15: 00$ & 33.98 & 57 & 34.74 & 26 & 33.98 & 25 \\
$15: 30$ & 32.69 & 44 & 34.74 & 24 & 33.48 & 22 \\
$16: 00$ & 33.48 & 38 & 33.48 & 20 & 32.69 & 26 \\
$16: 30$ & 29.02 & 18 & 29.56 & 22 & 33.98 & 31 \\
$17: 00$ & 28.25 & 28 & 29.02 & 18 & 33.48 & 39 \\
$17: 30$ & 28.25 & 24 & 28.25 & 19 & 32.69 & 31 \\
$18: 00$ & 28.25 & 21 & 28.25 & 17 & 29.56 & 16 \\
$18: 30$ & 27.45 & 17 & 27.45 & 15 & 28.25 & 17 \\
\hline
\end{tabular}

2) Weather Probability

The hourly weather from 2005 to 2011 were recorded in this research. The weather can be defined as rainy days if the precipitation is greater than zero and can be defined as windy days if the wind speed is over $15 \mathrm{mph}$. Figure 45 shows the percentages of sunny weather, rainy weather, and windy weather in Fayetteville AR from 2005 to 2011. According to the statistical outcome, the sunny weather is considered the most common weather in Fayetteville, occupying $79 \%$ of all surveyed days. In addition, the rainy and windy weather occupy $7 \%$ and $14 \%$, respectively. 


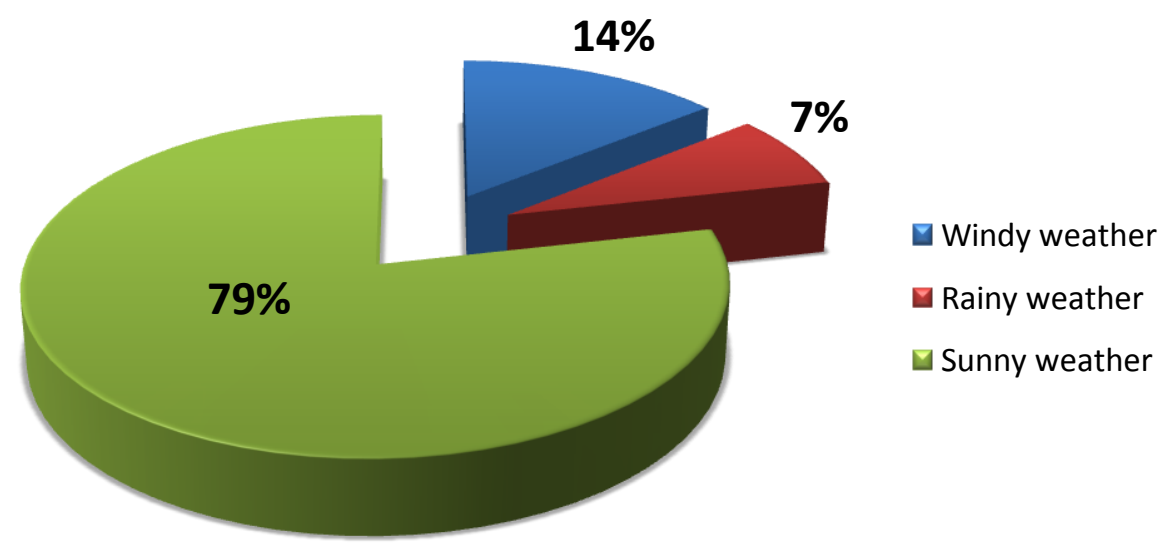

Figure 45 Weather Statistics from 2005 through 2011 in Fayetteville AR
a) Stationary Test

The weather probability calculation is based on the statistic of hourly weather in Fayetteville AR from 2005 to 2011. Before the test, it is necessary to check if the weather data is stationary or not. If the data is stationary, it means the weather will not be variable over time, and the past weather data can be used to describe the weather condition in the future.

In stationary test, if the mean, variance, and autocorrelation do not change by time, the time series is stationary. The Phillips-Perron procedure estimates autocorrelations in the error process, rather than assuming white noise errors, and for this reason the Phillps-Perron test is more generally applicable. (Perron, 1988)

Table 24 shows the statistical data of windy, rainy and sunny hours of each month in Fayetteville AR from 2005 to 2011. 
Table 24 Statistic of windy hours in every month from 2005 to 2011(Fayetteville AR)

\begin{tabular}{cccccccccccccc}
\hline Weather & Year/Month & $\mathbf{1}$ & $\mathbf{2}$ & $\mathbf{3}$ & $\mathbf{4}$ & $\mathbf{5}$ & $\mathbf{6}$ & $\mathbf{7}$ & $\mathbf{8}$ & $\mathbf{9}$ & $\mathbf{1 0}$ & $\mathbf{1 1}$ & $\mathbf{1 2}$ \\
\hline \multirow{6}{*}{ Windy } & 2005 & 86 & 123 & 186 & 145 & 163 & 25 & 27 & 33 & 25 & 36 & 84 & 82 \\
& 2006 & 232 & 113 & 203 & 192 & 107 & 50 & 75 & 33 & 55 & 82 & 77 & 103 \\
& 2007 & 81 & 146 & 162 & 131 & 96 & 54 & 5 & 79 & 31 & 110 & 89 & 99 \\
& 2008 & 182 & 103 & 179 & 213 & 144 & 185 & 17 & 3 & 13 & 70 & 108 & 242 \\
& 2009 & 92 & 163 & 195 & 194 & 39 & 113 & 39 & 53 & 28 & 104 & 56 & 102 \\
& 2010 & 89 & 59 & 138 & 219 & 110 & 58 & 23 & 85 & 79 & 83 & 181 & 118 \\
& 2011 & 51 & 111 & 119 & 232 & 233 & 131 & 37 & 49 & 46 & 117 & 227 & 57 \\
\hline \multirow{6}{*}{ Rainy } & 2005 & 51 & 36 & 89 & 51 & 45 & 27 & 27 & 28 & 11 & 72 & 26 & 64 \\
& 2006 & 43 & 44 & 80 & 65 & 69 & 43 & 27 & 43 & 49 & 52 & 88 & 72 \\
& 2007 & 116 & 70 & 27 & 70 & 70 & 53 & 41 & 18 & 68 & 42 & 33 & 104 \\
& 2008 & 49 & 68 & 100 & 63 & 63 & 76 & 56 & 70 & 80 & 38 & 42 & 43 \\
& 2009 & 29 & 32 & 82 & 61 & 111 & 48 & 51 & 37 & 99 & 133 & 34 & 68 \\
& 2010 & 69 & 48 & 69 & 47 & 44 & 24 & 57 & 1 & 54 & 21 & 33 & 22 \\
\multirow{6}{*}{ Sunny } & 2011 & 23 & 87 & 37 & 81 & 62 & 18 & 8 & 44 & 45 & 38 & 74 & 50 \\
\hline & 2002 & 607 & 513 & 469 & 524 & 536 & 668 & 690 & 683 & 684 & 636 & 610 & 598 \\
& 2006 & 469 & 515 & 461 & 463 & 568 & 627 & 642 & 668 & 616 & 610 & 555 & 569 \\
& 2007 & 547 & 456 & 555 & 519 & 578 & 613 & 698 & 647 & 621 & 592 & 598 & 541 \\
& 2008 & 513 & 525 & 465 & 444 & 537 & 459 & 671 & 671 & 627 & 636 & 570 & 459 \\
& 2009 & 623 & 477 & 467 & 465 & 594 & 559 & 654 & 654 & 593 & 507 & 630 & 574 \\
& 2010 & 586 & 565 & 537 & 454 & 590 & 638 & 664 & 658 & 587 & 640 & 506 & 604 \\
& 2011 & 670 & 474 & 588 & 407 & 449 & 571 & 699 & 651 & 629 & 589 & 419 & 637 \\
\hline \multirow{6}{*}{} & 2007 & & & & & & & & & & & &
\end{tabular}

Figure 46 shows the scatter plot of the statistical data. As figure 46 shows, the distribution of windy, rainy and sunny weather data seems like stationary. In order to further validate the data is stationary or not, using PP.test, R project was selected to achieve that goal and the test results are given in Table 25. Based on the PP.test result, the P-Value equals to 0.01, which indicated that the weather data, namely windy, rainy, and sunny weather can be regarded as stationary.

b) Probability of sunny, windy, or rainy weather in 24 hours

Based on the equations and weather data (in Fayetteville AR from 2005 to 2011), the probability of three types of weather in each hour during workdays and weekends in Fayetteville AR can be calculated and shown in Table 26. 
Monthly windy hours in Fay etteville AR from 2005 to 2011

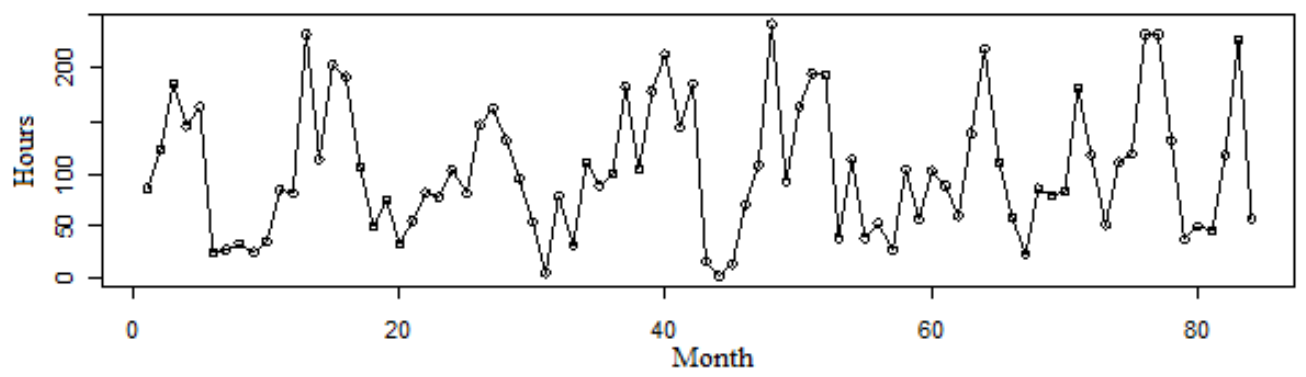

(a)

Monthly rainy hours in Fayetteville AR from 2005 to 2011

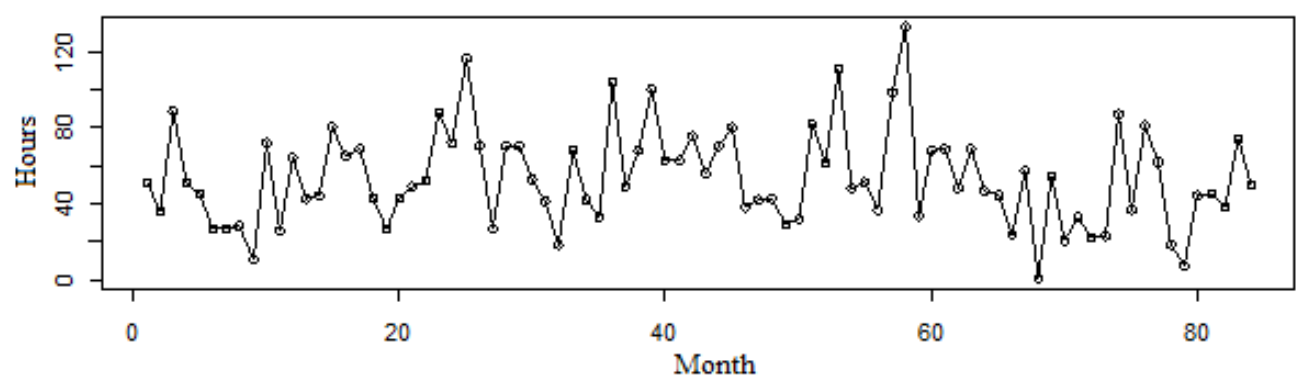

(b)

Monthly sunny hours in Fayetteville AR from 2005 to 2011

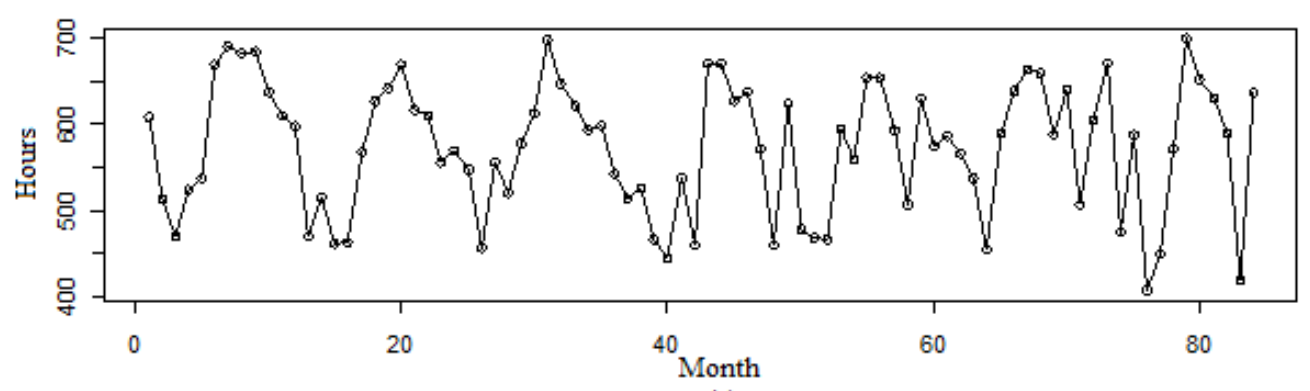

(c)

Figure 46 Scatter plot of windy hours in every month from 2005 to 2011 (Fayetteville AR)

Table 25 the pp.test Result for windy, rainy and sunny weather condition

\begin{tabular}{ccccc}
\hline \multirow{2}{*}{ Weather } & \multicolumn{2}{c}{ Phillips-Perron Unit Root Test } & & alternative hypothesis \\
& Dickey-Fuller Z(alpha) & Truncation lag parameter & p-value & \\
\hline Windy & -51.908 & 3 & 0.01 & stationary \\
Rainy & -77.7081 & 3 & 0.01 & stationary \\
Sunny & -52.8102 & 3 & 0.01 & stationary \\
\hline
\end{tabular}


Table 26 Possibility of windy/rainy/sunny weather

\begin{tabular}{|c|c|c|c|c|c|c|}
\hline \multirow{2}{*}{ Time } & \multicolumn{3}{|c|}{ Workday } & \multicolumn{3}{|c|}{ Weekend } \\
\hline & Wind \% & Rain \% & Sun\% & Wind \% & Rain \% & Sun \% \\
\hline $1: 00$ & 6.728665 & 5.743982 & 87.52735 & 6.730769 & 5.769231 & 87.5 \\
\hline $2: 00$ & 7.275711 & 6.728665 & 85.99562 & 7.82967 & 6.043956 & 86.12637 \\
\hline 3:00 & 7.822757 & 6.947484 & 85.22976 & 8.653846 & 6.456044 & 84.89011 \\
\hline 4:00 & 7.439825 & 7.166302 & 85.39387 & 9.203297 & 5.906593 & 84.89011 \\
\hline $5: 00$ & 7.768053 & 7.49453 & 84.73742 & 8.928571 & 6.456044 & 84.61538 \\
\hline $6: 00$ & 7.49453 & 7.603939 & 84.90153 & 9.752747 & 6.730769 & 83.51648 \\
\hline 7:00 & 7.877462 & 7.822757 & 84.29978 & 9.478022 & 6.456044 & 84.06593 \\
\hline $8: 00$ & 9.463895 & 7.932166 & 82.60394 & 10.57692 & 7.142857 & 82.28022 \\
\hline 9:00 & 11.81619 & 7.658643 & 80.52516 & 13.04945 & 8.241758 & 78.70879 \\
\hline 10:00 & 17.56018 & 7.658643 & 74.78118 & 18.54396 & 7.967033 & 73.48901 \\
\hline 11:00 & 21.99125 & 7.877462 & 70.13129 & 22.66484 & 8.379121 & 68.95604 \\
\hline $12: 00$ & 26.42232 & 8.588621 & 64.98906 & 26.64835 & 8.516484 & 64.83516 \\
\hline 13:00 & 28.22757 & 7.658643 & 64.11379 & 29.80769 & 8.516484 & 61.67582 \\
\hline $14: 00$ & 29.04814 & 7.932166 & 63.01969 & 30.08242 & 8.104396 & 61.81319 \\
\hline $15: 00$ & 28.33698 & 8.479212 & 63.18381 & 30.76923 & 8.104396 & 61.12637 \\
\hline $16: 00$ & 24.56236 & 8.315098 & 67.12254 & 27.06044 & 7.554945 & 65.38462 \\
\hline $17: 00$ & 19.85777 & 7.877462 & 72.26477 & 22.52747 & 7.554945 & 69.91758 \\
\hline 18:00 & 14.49672 & 7.877462 & 77.62582 & 15.52198 & 7.417582 & 77.06044 \\
\hline 19:00 & 10.39387 & 7.603939 & 82.00219 & 11.4011 & 7.554945 & 81.04396 \\
\hline 20:00 & 8.971554 & 7.275711 & 83.75274 & 8.379121 & 7.554945 & 84.06593 \\
\hline 21:00 & 8.588621 & 7.056893 & 84.35449 & 8.516484 & 7.82967 & 83.65385 \\
\hline 22:00 & 7.932166 & 6.400438 & 85.6674 & 8.516484 & 7.142857 & 84.34066 \\
\hline 23:00 & 7.056893 & 5.798687 & 87.14442 & 8.241758 & 6.181319 & 85.57692 \\
\hline 24:00 & 5.743982 & 5.743982 & 88.51204 & 7.554945 & 5.906593 & 86.53846 \\
\hline
\end{tabular}

3) Day and Night Distribution

Taking Fayetteville AR as an example, the daytime and nighttime in spring and fall are 12 hours, that is, from 7:00 to 19:00. However, the daytime in summer and in winter has 14 hours from 5:00 to 20:00, and 10 hours from 8:00 to 18:00, respectively. Table 27 shows the daytime and nighttime distribution in Fayetteville, AR. The averaged alternating time of day and night is considered 12 hours, which is applied in the M-FTLP model. 
Table 27 Daytime and Nighttime Distribution in Fayetteville AR

\begin{tabular}{ccccc}
\hline & Spring (Mar to May) & Summer $($ June to Aug) & Fall (Sep to Nov) & Winter (Dec to Feb) \\
\hline Day Time & $7: 00-19: 00(12 \mathrm{hr})$ & $5: 00-20: 00(14 \mathrm{hr})$ & $7: 00-19: 00(12 \mathrm{hr})$ & $8: 00-18: 00(10 \mathrm{hr})$ \\
Night Time & $19: 00-7: 00(12 \mathrm{hr})$ & $20: 00-5: 00(10 \mathrm{hr})$ & $19: 00-7: 00(12 \mathrm{hr})$ & $18: 00-8: 00(14 \mathrm{hr})$ \\
\hline
\end{tabular}

4) Workday and Weekend Distribution

The distributions of workdays and weekends are also considered as index weight in M-FTLP model in that the traffic and truck volumes are different during workdays and weekends. Table 28 shows the number of workdays and weekends from 2005 through 2011. Based on the data shown in Table 28, an average value, 104 days' weekends and 261 days' workdays in a calendar year, was used in this thesis.

Table 28 Distributions of Workdays and Weekends in a Calendar year

\begin{tabular}{cccccccc}
\hline Year & $\mathbf{2 0 0 5}$ & $\mathbf{2 0 0 6}$ & $\mathbf{2 0 0 7}$ & $\mathbf{2 0 0 8}$ & $\mathbf{2 0 0 9}$ & $\mathbf{2 0 1 0}$ & $\mathbf{2 0 1 1}$ \\
\hline Workdays & 263 & 260 & 261 & 262 & 261 & 261 & 260 \\
Weekends & 102 & 105 & 104 & 104 & 104 & 104 & 105 \\
\hline
\end{tabular}

\section{GLP Calculation}

Once the appropriate model is determined and index weight for each test-factor is calculated, these parameters can be fitted into the M-FTLP Model; afterwards, the GLP can be calculated at each test section, as Table 29 shows. In addition, the computation results of index weight for each test -factor can refer to the following tables:

- The relative frequency of influenced trucks $\left(I_{o j}, I_{e j}\right)$ and the relative frequency of free moving trucks $\left(F_{o j}, F_{e j}\right)$ can be referred to Tables 22 and 23;

- $\quad$ The truck volume $\left(T_{o j}, T_{e j}\right)$ is available from Tables 22 and 23;

- The probability of weather $\left(S_{o j}, S_{e j}, R_{o j}, R_{e j}, W_{o j}, W_{e j}\right)$ can be found in Table 26;

- The percentage of workday and weekend $(O \%, E \%)$ can be obtained in Table 28. 
As Table 29 shows, at test site\#1, most trucks were traveling towards the edge of pavement and the lateral position of trucks were mainly distributed from $0.5 \mathrm{ft}$ right deviation to the edge of pavement. At test sites \#2, \#3 and \#5, the lateral position of trucks were primarily located from lane center to the edge of pavement. Apparently, the lateral position of test sites \#1, \#2, \#3, and \#5 are towards to the right side when the trucks travel on the outside lane. However, the lateral position of trucks at test site \#4 is distributed from $1 \mathrm{ft}$ left deviation to $0.5 \mathrm{ft}$ right deviation.

Table 29 Results of lateral position in five test sites by M-FTLP Model

\begin{tabular}{cccccccccccc}
\hline Deviation (ft) & $\mathbf{- 1 . 7 5}$ & $\mathbf{- 1}$ & $\mathbf{- 0 . 7 5}$ & $\mathbf{- 0 . 5}$ & $\mathbf{- 0 . 3}$ & $\mathbf{0}$ & $\mathbf{0 . 2 5}$ & $\mathbf{0 . 5}$ & $\mathbf{0 . 7 5}$ & $\mathbf{1}$ & $\mathbf{1 . 7 5}$ \\
\hline$\# 1$ & 0.73 & 0.52 & 0.20 & 1.36 & 1.19 & 6.60 & 4.93 & 12.93 & 9.20 & 17.70 & 44.63 \\
$\# 2$ & 1.51 & 1.67 & 1.63 & 5.87 & 4.50 & 16.53 & 9.37 & 17.59 & 12.77 & 16.15 & 12.40 \\
$\# 3$ & 0.63 & 1.77 & 2.49 & 6.35 & 4.63 & 15.11 & 9.50 & 20.78 & 11.31 & 15.08 & 12.36 \\
$\# 4$ & 5.79 & 10.31 & 8.95 & 14.73 & 8.68 & 18.53 & 8.86 & 10.41 & 5.24 & 3.90 & 4.59 \\
$\# 5$ & 1.02 & 1.54 & 1.39 & 4.03 & 2.74 & 13.93 & 9.40 & 24.79 & 13.81 & 15.42 & 11.93 \\
\hline
\end{tabular}

Table 30 shows the raw data from field work. Comparing the data from table 29 and 30, due to the M-FTLP Model, there is some difference between these two data.

Table 30 Raw data from field work

\begin{tabular}{cccccccccccc}
\hline Deviation (ft) & $\mathbf{- 1 . 7 5}$ & $\mathbf{- 1}$ & $\mathbf{- 0 . 7 5}$ & $\mathbf{- 0 . 5}$ & $\mathbf{- 0 . 3}$ & $\mathbf{0}$ & $\mathbf{0 . 2 5}$ & $\mathbf{0 . 5}$ & $\mathbf{0 . 7 5}$ & $\mathbf{1}$ & $\mathbf{1 . 7 5}$ \\
\hline$\# 1$ & 0.35 & 0.69 & 0.26 & 1.77 & 1.51 & 7.70 & 6.19 & 15.45 & 10.64 & 18.69 & 36.82 \\
$\# 2$ & 0.71 & 2.50 & 2.20 & 6.48 & 5.12 & 18.14 & 9.70 & 15.59 & 11.90 & 16.06 & 11.60 \\
$\# 3$ & 0.68 & 1.88 & 2.66 & 6.72 & 5.05 & 15.79 & 9.85 & 21.05 & 10.89 & 14.54 & 10.89 \\
$\# 4$ & 5.26 & 9.22 & 8.09 & 14.48 & 8.98 & 18.28 & 9.71 & 11.73 & 5.259 & 4.61 & 4.37 \\
$\# 5$ & 0.66 & 1.08 & 0.90 & 4.48 & 3.11 & 16.08 & 9.62 & 26.12 & 12.92 & 14.95 & 10.09 \\
\hline
\end{tabular}




\section{WHELL PATH DEFINITION}

Wheel path geometric definition can be used for pavement design and pavement distress survey. The dimension and lateral position of trucks is the foundation of the wheel path definition. Different from the wheel path definition of LTPP, the wheel paths proposed in this thesis were defined at different road sections.

\section{A. Lateral Position and Dimension of Trucks}

Wheel path is the portion of the pavement surface where the majority of vehicle wheel passages are concentrated. (FHS, 2008) According to the definition of wheel path, a close association exists between the lateral position distribution of trucks and wheel path.

Typically, majority of the traffic load was from heavy vehicles (class 4 to class 13) in that their track and dimension are highly related with the wheel path geometric definition. In the field, the trucks are not exactly travel along the centerline of lane, but may take a little left or right deviation. Based on the truck dimensions (the width of dual-tire is $2 \mathrm{ft}$, the length of axle is $4.5 \mathrm{ft}$ and the width of the vehicle is $8.5 \mathrm{ft}$ ) and the wheel shift, the width of wheel path must be more than $2 \mathrm{ft}$ and the space between two wheel path must be less than 4 feet, as Figure 47 shows.

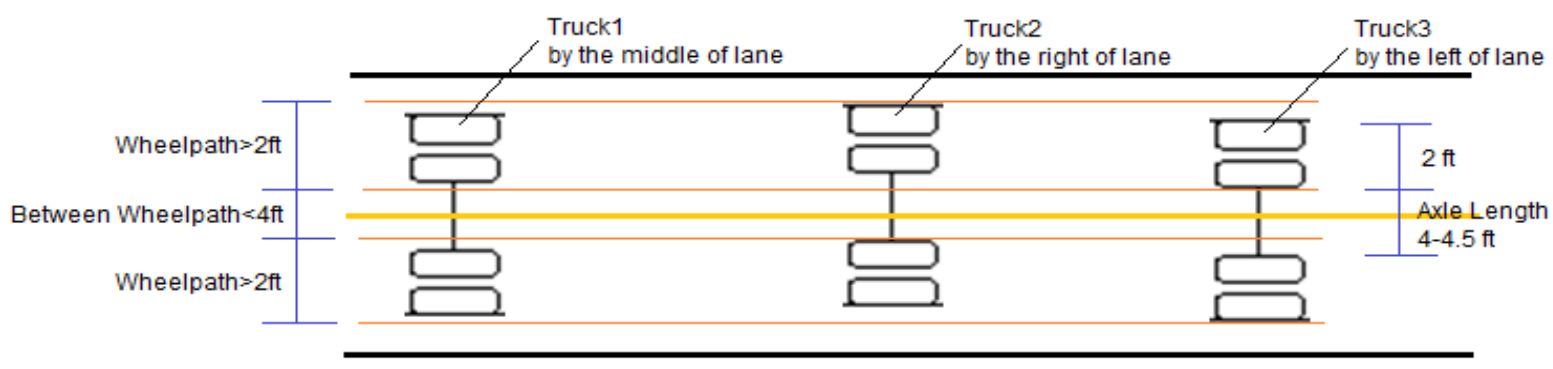

Figure 47 Geometrical definition of wheel path based on traffic wandering 


\section{B. Wheel Path Description}

Table 29 shows the lateral position of trucks, derived from the M-FTLP models, at five road segments of I-540 Interstate highway of Fayetteville AR. The effect of traffic loading on the lateral position will be ignored if the percentage frequency of lateral position is less than 10 percent. Since the results shown in table 29 were based on the local index weight (e.g. the weather condition, traffic volume, length of day and night time). Therefore, the wheel path definitions might have somewhat difference at other locations (e.g. other states or cities). Herein, the wheel path definition was suitable for I-540 interstate highway in Fayetteville, AR.

On the basis of the results shown in Table 29, the majority of lateral position was concentrated from $0.5 \mathrm{ft}$ right deviation to the edge of pavement at test site \#1 (near left turn curve), thus the wheel path geometric design at this road section can be defined as Figure 48 . In this figure, the inside and outside wheel paths are parallel to the centerline of the lane with 3.25 $\mathrm{ft}$ wide, and the inner edge of inside wheel path is $0.5 \mathrm{ft}$ away from the lane centerline, and the inner edge of outside wheel path is $2.75 \mathrm{ft}$ away from the lane centerline. For a typical $12 \mathrm{ft}$ wide lane, the distance between the outer edge of the inside wheel path and the left edge of lane is $2.25 \mathrm{ft}$, while the outer edge of the outside wheel path is right located at the right edge of the lane.

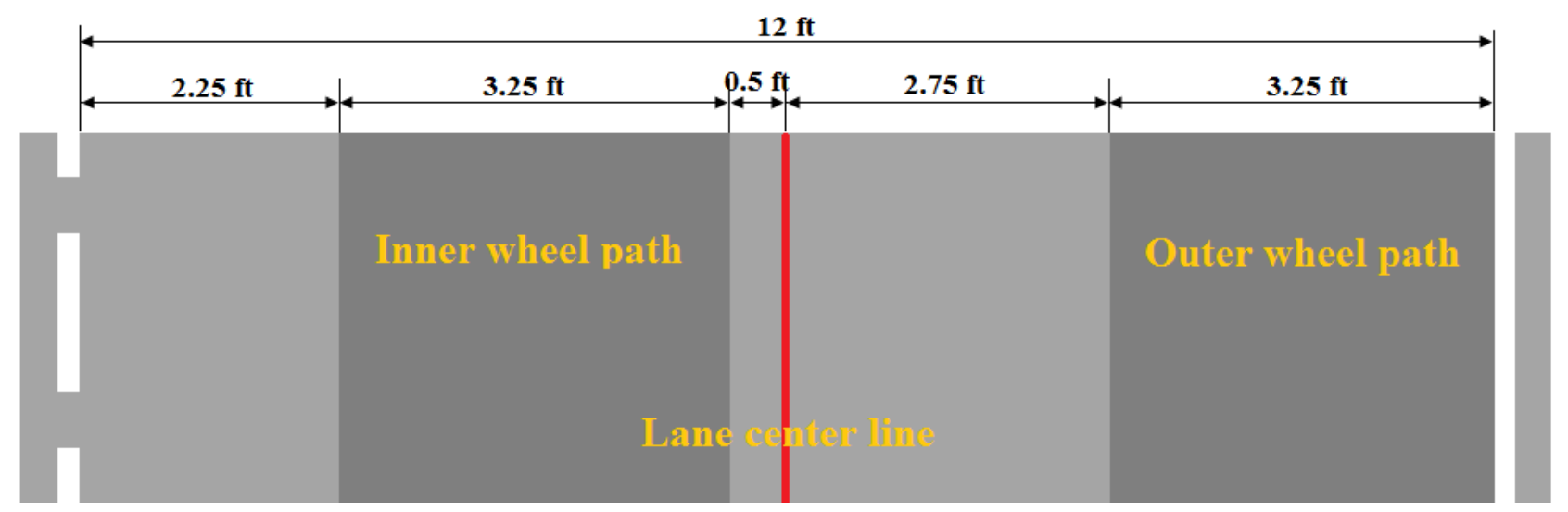

Figure 48 Wheel Path Geometric Definition at Test Site \#1 
As Table 29 shows, at test sites \#2 (near right turn curve), \#3 (in right turn curve), and \#5 (in straight road), the majority of lateral position are distributed from lane centerline to the edge of pavement, so the wheel path geometric design of these three road sections can be defined as Figure 49. Unlike with the definition of test site \#1, the inside and outside wheel paths have 3.75 $\mathrm{ft}$ wide, and the inner edge of outside wheel path is $2.25 \mathrm{ft}$ away from the lane centerline. In addition, the distance between the outer edge of the inside wheel path and the left edge of the lane is $1.75 \mathrm{ft}$, which is less than $0.5 \mathrm{ft}$ than that at test site \#1.

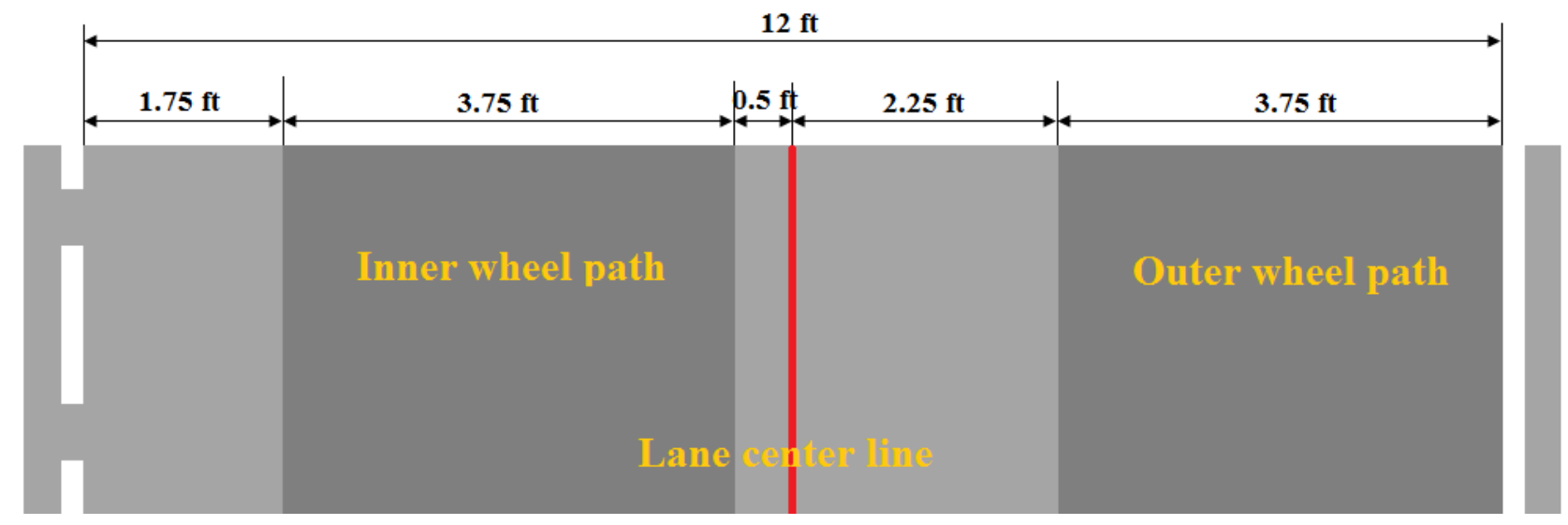

Figure 49 Wheel Path Geometric Definition at Test Sites \#2, \#3, and \#5

Based on the computed lateral position distribution shown in Table 29, the majority of lateral position was concentrated from $1 \mathrm{ft}$ left deviation to the $0.5 \mathrm{ft}$ right deviation from lane centerline test site \#4 (in left turn curve), thus the wheel path geometric definition of this road section can be designed as Figure 50. Unlike with the above four test sites, the inside and outside wheel paths possess $3.5 \mathrm{ft}$ wide. The inner edges of inside and outside wheel path are $1.75 \mathrm{ft}$, and $1.25 \mathrm{ft}$ away from the lane centerline, respectively. The distance between the outer edges of the inner wheel path and the left edge of lane is $0.75 \mathrm{ft}$, whereas the distance between the outer edge of the outside wheel path and the right edge of lane is $1.25 \mathrm{ft}$. 


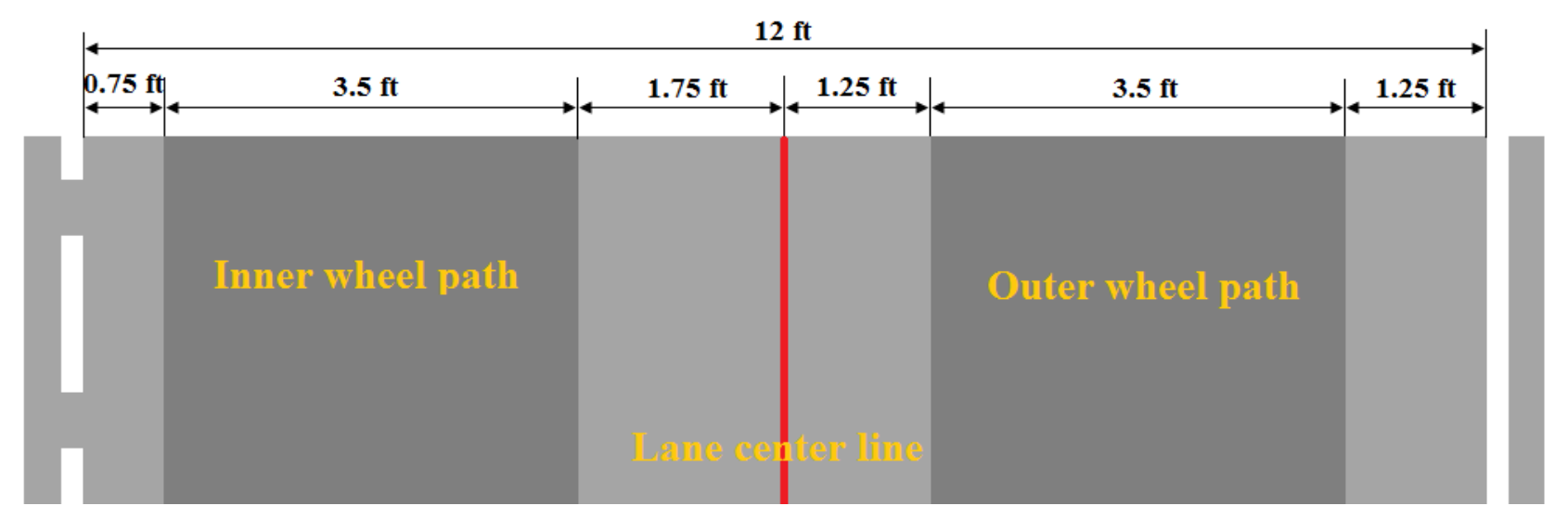

Figure 50 Wheel Path Geometric Definition for \#4 Test Sites

As illustrated in Figures 48 to 50, these newly proposed wheel path geometric definitions are different from the wheel path definition of LTPP as shown in Figure 9, and some remarkable features can be summarized as follows:

- These two wheel paths are not equidistant in each side of the lane center line, and these two wheel paths might have a right or left deviation away from lane center line based on the actual lateral position of trucks at different road sections.

- The LTPP only provide one wheel path geometric definition regardless of effects of road curves on wheel path definition. Accordingly, three wheel path geometric definitions were proposed in this research based on five test sites, which cover different road curves;

- The width and position of wheel path are defined based on the lateral position data from filed test which covers 100 hour video data and more than 9000 trucks. Moreover, the index weights for each test-factor were also incorporated into the M-TLP Model to compute the GLP. 


\section{CONCLUSION}

The factors influencing wheel shift can be classified into seven categories based on literature review: 1) weather, 2) driver habits, 3) traffic condition, 4) visibility, 5) road characteristics, 6) environment, and 7) vehicle characteristics. However, only four factors were considered to be the most important in this thesis, namely weather, road curve, visibility, and traffic condition, which were studied to estimate their influence on wheel shift. Five test sites were selected on I-540 interstate highway, a four-lane divided highway in Fayetteville AR, including on straight section, near left/right turn curve sections, and in left/right turn curve sections.

With an aim to acquire the lateral position data under different conditions, a HD video camera was mounted on the overpass, and the reference line was marked on the pavement to record the lateral position of trucks before testing. To collect the lateral distribution data with different influencing factors, the data collection was conducted during daytime and nighttime, during weekdays and weekends, in sunny, rainy, and windy weather, and at five different locations on the interstate highway.

An ideal condition was considered as the reference for the four factors on lateral position displacement: sunny weather, with day time visibility, on straight road section and in free moving condition. Under this ideal condition, the four factors have no or minor influence on wheel shift. Based on the reference wheel position and Equal Quantity ANOVA statistical test, the test-factors can be ranked by the levels of their influence on wheel shift: road curve, traffic condition, visibility condition, and weather condition. Road curve carried the most significant effect on lateral position: The trucks travelling near the road curve deviate to the right side of the lane; while the trucks travelling in the road curve tend to shift to the left side of the lane. As for 
the traffic condition, the influenced trucks were more inclined to approximate to the outer edge of the pavement than free moving trucks. Darkness also made the trucks shift to the outer edge of the lane. However, weather carried small influence on wheel shift. Consequently, the shift tendency was subjective to the road sections and traffic condition.

The M-FTLP model consisting of two components: PFLP-DL parameters and index weight was developed to incorporate the lateral position data with different index weights of test-factors to calculate the comprehensive lateral position. The PFLP-DL parameter represents the percentage frequency of lateral position at each deviation level. The index weight represents the weight of the PFLP-DL parameters, including traffic, weather, and length of day and night time, and percentage of workdays and weekends of a calendar year. This thesis took the road sections of I-540 interstate highway in Fayetteville AR as an example to redefine wheel path, and the results in regard to lateral distribution of trucks was computed based on M-FTLP model.

New wheel path definitions were proposed based on the computed results using the M-FTLP model. Different from the LTPP definition, the two wheel paths are not equidistant from the lane center line, and have the distinct widths at different road sections. Based on the lateral position distribution of trucks at five road sections, three wheel path definitions are proposed in this thesis: 1) Near left turn curve: Both wheel paths are $3.25 \mathrm{ft}$ wide. The inner edges of inside and outside wheel paths are $0.5 \mathrm{ft}$ and $2.75 \mathrm{ft}$ away from the lane centerline, respectively; 2) Near right turn curve, in right turn curve, and in straight road: Both wheel paths are $3.75 \mathrm{ft}$ wide. The inner edges of inside and outside wheel paths are $0.5 \mathrm{ft}$ and $2.25 \mathrm{ft}$ away from the lane centerline, respectively; 3) In left turn curve: Both wheel paths are $3.5 \mathrm{ft}$ wide. The inner edges of inside and outside wheel paths are $1.75 \mathrm{ft}$ and $1.25 \mathrm{ft}$ away from the lane centerline, respectively. 
The new wheel path definition can be applied on Pavement Management System (PMS) and Pavement design. It accurately described the location of traffic load, since the definition was based on lateral position survey only for heavy vehicles. Traffic load is the direct factor contributing pavement damage, so the engineers always make reinforcement on the parts of pavement with repeated traffic load. Based on the new wheel path definition, the Engineers can give special pavement structure design. Another application of this new wheel path definition is longitudinal cracking and fatigue cracking identification. Although these two types cracking have similar shape, the causes of these two types cracking are different: fatigue cracking was contributed by traffic load, and longitudinal cracking was caused by pavement structure damage. Current research, such as MEPDG, uses the wheel path to identify fatigue cracking and longitudinal cracking. Therefore the accurate wheel path definition based on traffic load is the key to solve this problem. 


\section{REFERENCE}

A policy of geometric design of highway and street, AASHTO, 5 Edition, 2004

ARA Inc. (2004). Guide. Retrieved 9 12, 2009, from NCHRP 1-37A Design Guide: http://onlinepubs.trb.org/onlinepubs/archive/mepdg/guide.htm

ARA Inc., ERES Division. (2004). MEPDG Guide. Retrieved 10 12, 2009, from NCHRP 1-37A Design Guide: http://onlinepubs.trb.org/onlinepubs/archive/mepdg/Part2_Chapter5_Evaluation.pdf

ARA inc., ERES Division. (2004). MEPDG Guide. Retrieved 10 12, 2009, from NCHRP 1-37A Design Guide: http://onlinepubs.trb.org/onlinepubs/archive/mepdg/Part2_Chapter4_Traffic.pdf

A. Taragin. "Driver Behavior Related to Types and Widths of Shoulders on Four-way Highways" Public Roads, Vol. 29, No. 9, 1957, pp. 197-205.

A. Taragin. "Effect of Roadway Width on Vehicle Operation" Public Roads, Vol. 24, No. 6, 1945, pp. 143-160.

A. Taragin. "Lateral Placements of Trucks on Four-way Highways and Four-Lane Highways" Public Roads, Vol. 30, No. 3, 1958, pp. 197-205.

Andrew J. Wimsatt, Carlos M. Chang-Albitres, Paul E. Krugler, Tom Scullion, Tom J. Freeman, and Maria B.Valdovinos. "CONSIDERATIONS FOR RIGID VS. FLEXIBLE PAVEMENT DESIGNS WHEN ALLOWED AS ALTERNATE BIDS: TECHNICAL REPORT” FHWA Report, August 2009, pp. 17-30.

Benekohal, R.F., Hall, K.T. and Miller, H.W.: Effect of Lane Widening on Lateral Distribution of Truck Wheels. Transportation Research Record 1286, Washington D.C. USA, 1990.

Blab, R. and J. Litzka, "Measurements of the Lateral Distribution of Heavy Vehicles and its Effects on the Design of Road Pavements," Proceedings of the International Symposium on Heavy Vehicle Weights and Dimensions, Road Transport Technology, University of Michigan, 1995, pp. 389-395.

Buiter, R., W.H.M. Cortenraad, A.C. Van Eck and H. Van Rij, "Effects of Transverse Distribution of Heavy Vehicles on Thickness Design of Full-Depth Asphalt Pavements," Transportation Research Record No. 1227, Transportation Research Board, Washington D.C., 1989, pp. 66-74.

Bunker, Jonathan and Parajuli, Ashis, "Examining Lateral Positions of Cars and Heavy Vehicles on a Two Lane, Two Way Motorway", Transport Engineering in Australia, 10(2), 2006, pp. 129-139. 
Cohen, Jacob. 1988. Statistical Power Analysis for the Behavioral Sciences, 2nd ed. Hillsdale, NJ: L. Erlbaum Associates.

Cottrell, B., T. Schinkel, T. Clark. A traffic data plan for mechanistic-empirical pavement designs (2002 pavement design guide), VCTIR Report. 2003, pp15-16.

David H. Timm, Angela L. Priest, "Wheel Wander at the NCAT Test Track", National Center for Asphalt Technology, NCAT Report 05-02, Apr, 2005.

Djurovic Z., Kovacevic B., Barroso V., "Statistical Signal and Array Processing", 10th IEEE WorkShop, Pocono Manor, PA, USA, 2000, pp. 243-247.

E.J. Miller and G.N. Stuart. Vehicle Lateral Placement on Urban Roads. Journal of the Transpotation Engineering Division, ASCE, vol. 108, Sept. 1982.

Fu P., Harvey J.T., Lee J.N., Vacura P., "New Method for Classifying and Quantifying Cracking of Flexible Pavements in Automated Pavement Condition Survey", Transportation Research Record 2225, Washington D.C., USA, 2011, pp. 99-108.

Global Insight, Inc. "The U.S. Truck Driver Shortage: Analysis and Forecast" U.S. General Services Administration. May, 2005, pp. 34-36.

Guany, B., "Modelling lane discipline on multilane uninterrupted traffic flow", Traffic Engineering and Control 40(9), 1999, pp 440-447

High Friction Roads, 2008: http://www.highfrictionroads.com/index.php?q=node/7

Julian J. Faraway, "Practical Regression and ANOVA using R", Linear Models with R, August 2004, pp: $168-170$

Lennie, Sandra C and Bunker, Jonathan M, "Evaluation of Lateral Position for MultiCombination Vehicles", In Mathams, John, Eds. Proceedings of the Queensland Main Roads Road System and Engineering Technology Forum, Bardon, Brisbane, 2003.

Lennie, Sandra C and Bunker, Jonathan M, "Using Lateral Position Information as a Measure of Driver Behavior around MCVs", Road \& Transport Research, 14(3), 2005, pp. 62-77.

Miller, John S. and William Y. Bellinger. Distress Identification Manual for the Long-Term Pavement Performance Program. U.S. Department of Transportation. 2003, pp. 90-91.

Nishizawat., Kajikawa Y., and Fukuda T., "Effects of Lateral Distribution of Heavy Vehicles on Fatigue Cracks of Concrete Pavements", 5th International Conference on Concrete Pavement Design and Rehabilitation, Apr, 1993, pp. 245-253.

Puals, J.T., "Transverse Distributions of Motor Vehicle Traffic on Paved Highways. Public Roads, vol. 6, No. 1, 1925,pp. 243-257. 
Phillips, P.C.B and P. Perron, "Testing for a Unit Root in Time Series Regression", Biometrika, 75, 1988, pp: 335-346.

Shankar, P.R. and Lee, C.E.: Lateral Placement of Truck Wheels within Highway Lanes. Transportation Research Record 1043, Washington D.C. USA, 1985.

Smith, G. "Pavement Edge Marking: Purpose, effects and Warrant Requirements (Report No. AIR 1013-1). Vermont, VIC: Australian Road Research Board, 1976.

Soliday, S.M., "Lane Position Maintenance by Automobile Drivers on Two Types of Highway", Ergonomics, Vol. 18, No. 2, 1975, pp. 175-183.

Special Report 211: Twin Trailer Trucks. TRB, National Research Council, Washongton, D.C., 1986.

Stempihar, J.J., R.C. Williams and T.D. Drummer, "Quantifying the Lateral Displacement of Trucks for use in Pavement Design," Transportation Research Board Preprint, Washington, D.C., 2005.

Triggs, T.J., "Pavement Marking and the Delineation of the Roadway Ahead." In R.S. Easterby \& H. Zwaga (Eds.), Visual presentation of information. Chichester, UK: Wiley. 1983

Triggs, T.J., \& Wisdom, P.H., "Observations of Vehicle Lateral Position-Keeping and the effects of Pavement Delineation Marking" Proceedings of the Nine Australian Road Research Board Conference, 1978, 9(5), pp. 38-48.

Triggs, T.J., "The Effect of Approaching Vehicles on the Lateral Position of Cars Travelling on a Four-way Rural Road", Australian Psychologist, Vol. 32, Issue 3, Nov, 1997, pp. 159163.

Tolman, H.L., "Effects of observation errors in linear regression and bin-average analyses", Q.J.R. Meterol. Soc. (1998), 124, pp. 897-917.

Top speed, 2006, Speed limits on the USA highway: http://www.topspeed.com/cars/speedlimits-on-the-usa-highway-ar9977.html 